\title{
The impacts of camera placement on species detectability in an Indonesian terrestrial community
}

by

\section{Eric W. Van Dam}

A thesis submitted to the Victoria University of Wellington in fulfilment of the requirements for the degree of Master of Science in Conservation Biology

School of Biological Sciences

Faculty of Science

Victoria University of Wellington

January 2021 


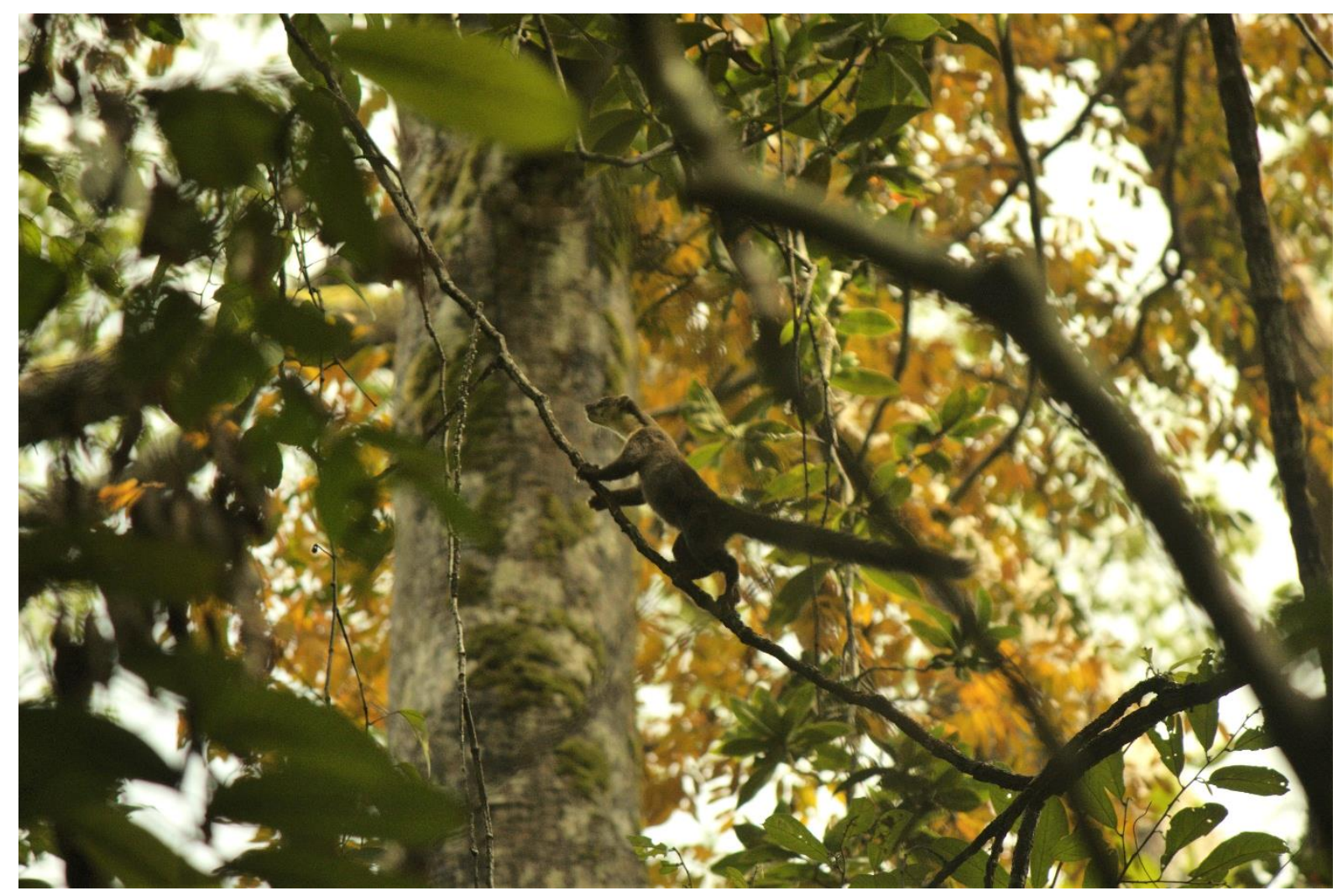

Yellow-throated marten (Martes flavigula), climbing a liana in Gunung Palung National Park (Eric Van Dam). 


\section{Abstract}

Ecologists have increasingly favoured the use of camera traps in studies of animal populations and their behaviour. Because camera trap study design commonly implements nonrandom selective placement, we must consider how this placement strategy affects the integrity of our data collection. Selective placement of camera traps have the benefits of 1) maximizing the probability of encounter events by sampling habitats or microhabitats of known significance to a focus or closely-related species and 2) reducing data collection and maintenance effort in the field by situating cameras along more easily-accessible landscape features. Introducing a non-random survey method, such as selective placement, into a project studying a species or community that also expresses non-random habitat use may lead to unintentionally biased data and inaccurate results. By using a paired on-trail/off-trail camera-trap study design, my aim is to investigate potential differences in popular ecological indices, species detection probability $(p)$ using multimethod occupancy models, and intraspecific temporal activity for a terrestrial community in Gunung Palung National Park in Indonesian Borneo. Differences in detection probability between on and offtrail cameras were compared against species characteristics (including body size, diet, and taxonomic group) to find potential correlations. While several species exhibited a significant difference in detection probability between cameras placed on foot trails and those placed randomly off-trail, there was no measured community trend. This stresses my conclusion further that a nonrandom study design leaves results open to bias from unknown patterns in detection due to underlying variation in behaviour and microhabitat use. Selective placement may be effective for increasing detection probability for some species but can also lead to substantial bias if the features selected for are not explicitly taken into account within the analysis or balanced with a control in the study design. In addition, a positive interactive effect was found between on trail species detection and body size for the terrestrial omnivore guild, and three species presented significant variation in temporal activity between camera placement types. This provides evidence that camera placement not only affects species state parameters and indices but has a noticeable impact on behavioural observations that require accountability as well. 


\section{Acknowledgements}

I am very appreciative to my advisor, Heiko Wittmer, who provided his insight and comments through the many twists and turns of my thesis. I'm equally grateful to my secondary advisor, Andrew Marshall, who provided his support from afar even after change in enrolment took place. My fellow lab mates: Frowin, Johannes, Grace, and Rachel, have been there from the start to bounce ideas off of and simply be good friends in and out of the office. I would also like to thank Patricia Stein and Gillian Turner for their administrative support and immense understanding during my Masters conversion. You really helped me navigate a very turbulent several months.

Thank you to Živa Justinek and Beth Barrow for showing me the ropes both in Ketapang and in the field in Gunung Palung. To Agus Trianto, thank you for your continued effort in processing the years of camera trap footage obtained at Gunung Palung, and for showing me your process back in Jakarta. The same gratitude goes out to all of the staff at Cabang Panti Research Station, and especially to the many field technicians who have hiked up and down Mount Palung to maintain the cameras that this thesis' results have relied upon. Thank you very much for teaching me the ins and outs of the camera grid protocol at CPRS (and going easy on me in the post-work ping pong games).

I'd like to thank my friends and family back home in the US for your support and encouragement that began long before I started my studies at Victoria University of Wellington. To my mom, dad, and brother, Brian, your many phone and video calls have helped ground me more than you know. Most importantly, I want to thank my girlfriend, Shelby, for being my rock through all my time in this program. Despite being 7,000 miles and many many time zones away, you've always been there to listen in the challenging times and celebrate the little victories with me. I couldn't have asked for better partner and friend through this. 


\section{Table of Contents}

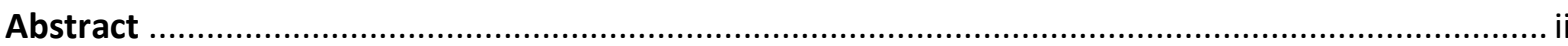

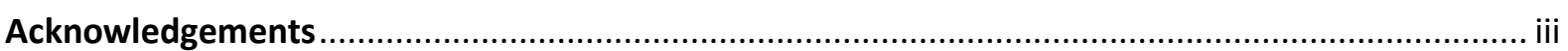

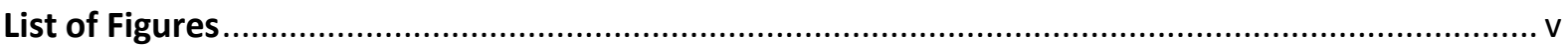

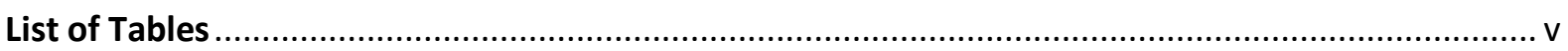

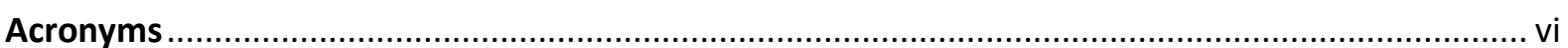

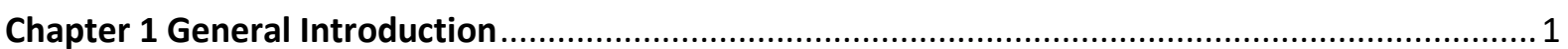

1.1 A brief summary of remote sensing in ecological monitoring ................................... 1

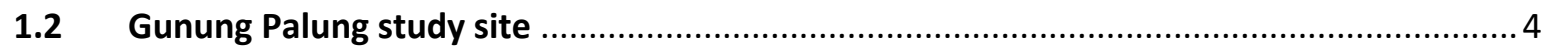

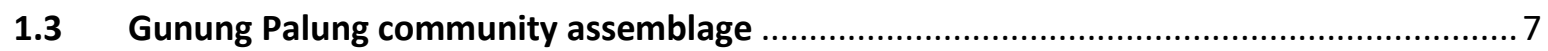

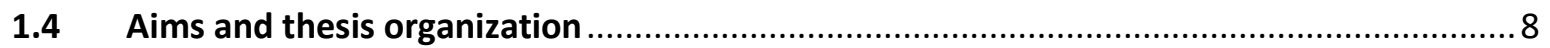

Chapter 2 The impact of masting events on wildlife trophic levels ........................................ 11

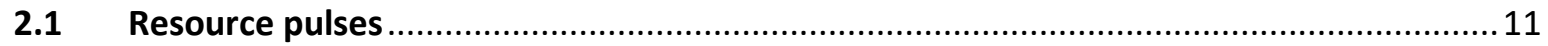

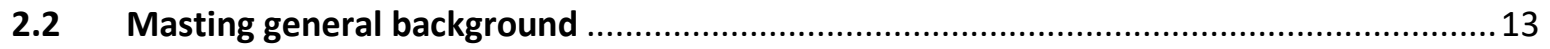

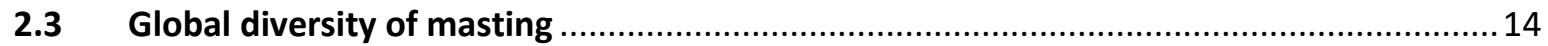

$2.4 \quad$ Natural history of masting in Borneo ................................................................ 16

$2.5 \quad$ Terrestrial species of Borneo and their diet .................................................... 18

2.6 How food availability and plant structure affect species distribution and abundance..... 19

2.7 How plant-frugivore relationships informs future conservation and management ........ 21

2.8 Camera trapping: a method of choice for illustrating terrestrial faunal dynamics ..........21

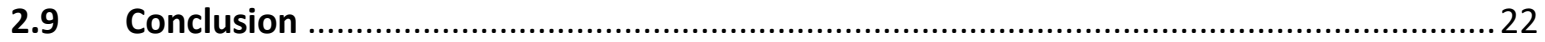

Chapter 3 An investigation of camera placement strategies on state parameters and behaviour for

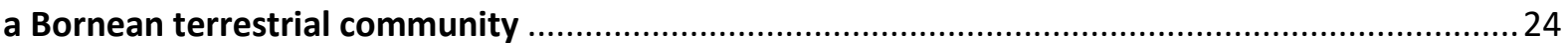

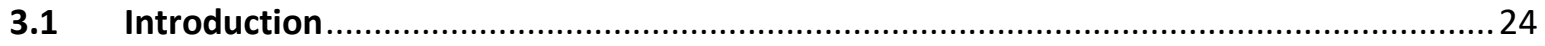

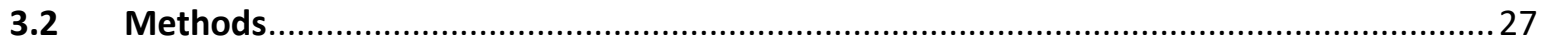

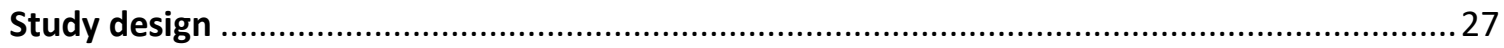

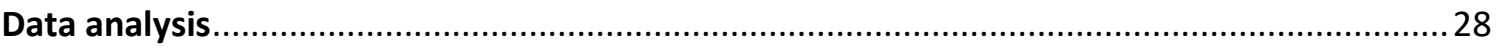

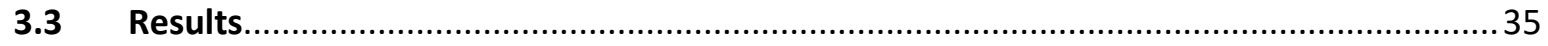

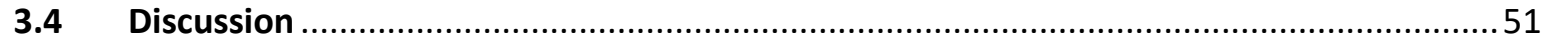

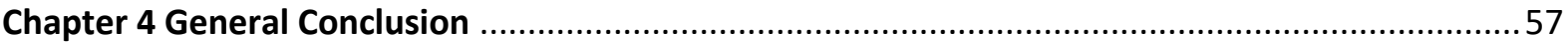

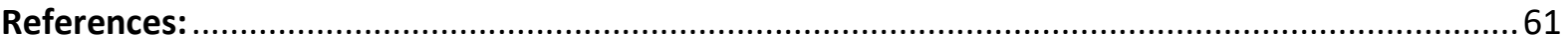

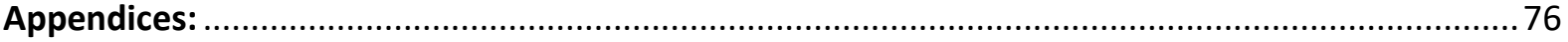




\section{List of Figures}

Figure 1.1: The research study site at Gunung Palung National Park in West Kalimantan, Indonesian Borneo (90000 ha; 1잉, 110이르).

Figure 3.1: Species richness accumulation curve for cameras placed selectively on trails and randomly

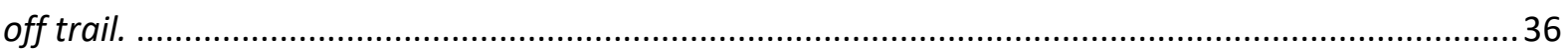

Figure 3.2: Species capture events with a 60 minute independence buffer..................................... 41

Figure 3.3: Species detection probability curves based on top model detection probability estimates and minimum necessary trap nights for $95 \%$ detection .46

Figure 3.4: On-trail beta estimates for detection probability grouped and colour coordinated by diet and taxonomic group.

Figure 3.5: Body weight vs. camera placement detection probability $\beta$ estimates for the entire modelled community.

Figure 3.6: Body weight vs. camera placement detection probability $\beta$ estimates by diet and by taxa with associated Spearman's correlation coefficients and p-values.

Figure 3.7: Activity patterns over a 24 hour cycle for all species with temporal behaviour deemed significantly different by the Watson's two-sample test. ....

\section{List of Tables}

Table 3.1: Covariates used in the modelling framework for single-species site occupancy $(\psi)$, local occupancy $(\theta)$, and detection probability $(p)$.

Table 3.2: Mean relative abundance indices (RAIs), RAI standard deviations in parentheses, and independent captures for all terrestrial species captured within the study site.

Table 3.3: All modelled species, their associated top models with all covariates for $p$ (global), the number of parameters for each model $(\mathrm{K})$, the $\triangle \mathrm{AICC}$ for top models including and excluding camera placement as a function for $p$, and AICc weights for each $p$ covariate.

Table 3.4: Percent change ( + or - ) in detection probability for on vs off trail cameras by species...... 44

Table 3.5: Camera placement sample sizes, overlap coefficient for activity on and off trail $(\Delta)$, lower and upper 95\% confidence intervals $(\mathrm{Cl})$ and Watson's two-sample test $\mathrm{p}$-values and respective test statistic $\left(U^{2}\right)$ 50 


\section{Acronyms}

AICc - Akaike Information Criterion, corrected for small sample sizes

CPRS - Cabang Panti Research Station

GPNP - Gunung Palung National Park

RAI - Relative Abundance Index

R/E - Rarefaction/Extrapolation 


\section{Chapter 1 General Introduction \\ 1.1 A brief summary of remote sensing in ecological monitoring}

Population monitoring is one of the primary strategies that ecological research uses to obtain information on species abundance, composition, and distribution, as well as their reaction to natural and human-caused changes in their environment (Pereira et al., 2013). Whether it is for the expansion of ecological knowledge or applied management of a species, monitoring is usually a critical step. At its inception, data collected for the purpose of ecological monitoring was collected manually; through point counts, distance samples along transects, and other human-based methods of observation. Logistical obstacles such as limited funding, time, available technology, and research technicians have always constrained the scope of monitoring programs though, and efforts began early on to develop remote data collection techniques that maximized the impact of limited research resources. Not long after the invention of cameras themselves, "trap photography" using wiretriggered stations were introduced into the field of conservation to remotely record elusive species (Hamel et al., 2013; A.F. O'Connell et al., 2010). Cameras programmed to trigger independently, hereby referred to as camera traps, have made it easier than ever for biologists to visually monitor species at incredibly fine spatial and temporal resolutions. Today, camera traps are usually motionactivated, and the first recorded use of camera traps for the statistical analysis of a wildlife population was conducted with Panther tigris at Nagarahole National Park in 1991 (Karanth, 1995).

Equally as important, remote monitoring methods provide a less invasive means of collecting wildlife observations that before may have been influenced by human presence (Nowak et al., 2014). Such instances include avian nest predation (Cutler \& Swann, 1999), pollination ecology of a rare orchid (Houlihan et al., 2019) and subnivean behavioural studies of small mammals (Soininen et al., 2015). It is worth noting that camera trap presence has still been found to affect species behaviour, as observed in some common Australian predators (Meek et al., 2016), and cameras are not completely invisible within the landscape. Other forms of remote sensing have also been adapted or invented that further add to biologists' toolkits. Besides localized photographic data collection, the entire field of bioacoustics has also arisen as an alternative means of remotely collecting data at a species level. Bioacoustic studies have proven especially useful for avian species, whose volant nature are often not well-suited for terrestrial camera study designs. LIDAR, thermal imaging, and even small satellite constellations have all also been used to measure important population and environmental parameters that are not realistic for camera traps (Wang et al., 2010). 
Although just a small branch of remote sensing, camera traps have been widely adopted by the biological research community, and the scope of their application has grown massively for studies in behaviour, ecology, and management. Advancements in camera trap hardware, grid study design, and statistical analyses have allowed for more sophisticated research and a wider array of subjects to be explored (Newey et al., 2015; Swann et al., 2011). Since the late 1990s, the mark recapture framework has been widely implemented using camera traps to estimate abundance for species identifiable on an individual level (Karanth \& Nichols, 1998). Predator-prey dynamics, habitat preference, species fecundity, food web interactions, home range extent, and fragmentation effects are just a few subjects that have been explored using camera traps as the core method of data collection (Barrueto et al., 2014; Brodie et al., 2014; McShea et al., 2016; Meek et al., 2014; Steenweg et al., 2017).

Most commonly, camera traps are laid out en masse across a research site in a design tailored to a specific study question. Steenweg et al. (2017) have outlined the potential of standardizing camera trap data to larger scales. As they are already incredibly popular tools within the research community, creating a standardized camera trap methodological framework that can be adapted and applied to a variety of study sites carries the potential to monitor populations and estimate system states on scales that were previously unreachable (Steenweg et al., 2017). The Tropical Ecology Assessment and Monitoring (TEAM) network is one such program where a standardized camera trap methodology has been employed to estimate species diversity, distribution, and abundance across 19 different forest sites in Asia, Latin America, and Africa (Rovero \& Ahumada, 2017). Although this chapter focuses on just Gunung Palung, local study sites could be further combined to gauge landscape connectivity on regional scales. When combining camera grids across a regional or even global scale, broader questions, such as the effect of climate change on certain ecosystems, endangered species territorial ranges, and net biodiversity estimates can also be examined (Steenweg et al., 2017).

Although camera traps continue to be used in increasingly sophisticated studies and analyses, many conservation and management projects still rely on simple metrics to inform their decisions. Indices based on the photo or video capture rate of a species are often used in conjunction with detection/non-detection data to estimate species abundance, diversity, and occupancy within their study sites (Rovero et al., 2013). From video capture data, the number of animal sightings per camera trap night (usually presented as the number of capture events per 100 camera trap days) can be derived into capture frequencies. These frequencies are often presented as relative abundance indices, or RAls, and act as a proxy for true animal abundance when said estimates are logistically or financially challenging to attain (Palmer et al., 2018). From a 
management perspective, relative abundance has been used in the past and currently as an indicator for carrying capacities, colonization rates, reproductive success, and ultimately habitat quality (Hobbs \& Hanley, 1990; Pearce \& Ferrier, 2001; Vögeli et al., 2010). Clearly, some danger exists in making broad management assumptions based on RAls which are themselves not without their limitations. RAls have been rightfully challenged for not taking into account imperfect detection (i.e. through a detection probability parameter) and being overly sensitive to inflation as a result of variation in species home range size (Sollmann et al., 2013). When these issues are taken into account, RAls have continued to prove a useful and relatively straightforward measure of species relative abundance (Jenks et al., 2011; Palmer et al., 2018; Pearce \& Ferrier, 2001).

Especially when species cannot be identified to the individual level, detection/non-detection data is often the best asset available for biologists to model species occupancy and distribution. Similar to RAls, occupancy estimates have been used within ecological research as a surrogate for true abundance and a broad indicator parameter for habitat assessment. One of the most popular ways to estimate species patch occupancy with presence/absence data is through occupancy modelling, where the proportion of patches in a landscape are definitively calculated (MacKenzie et al., 2017). At their core, all versions of occupancy models set out to estimate two parameters: site occupancy $(\psi)$ and detection probability $(p)$. Detection probability, or the probability that an individual may be detected in a survey unit given that it is present, is one area where occupancy models separate themselves from RAls in that they account for imperfect detection (MacKenzie \& Kendall, 2002). Detection probability is sometimes considered a nuisance parameter that simply informs estimates of the more sought-after occupancy parameter. Accurately modelling detection probability is, in fact, an imperative step when calculating any number of population metrics, yet the factors that go into accounting for and controlling variation in detection probability are still being explored.

Occupancy modelling is becoming increasingly popular as an analysis for camera trap study designs because of its compatibility and flexibility with their datasets. Supplying covariates to an occupancy modelling framework allows researchers to measure the influence of a suite of environmental factors to both occupancy and detection parameters (MacKenzie et al., 2017). Such examples include habitat type, canopy coverage, slope, time of day, and temperature for the occupancy parameter; and sampling intensity, visibility, and vegetative ground cover for detection probability. The ability to adjust the occasion length, or expressed length of a camera survey session, of models ad hoc also allows for temporal replication and greater model fit. Applying model selection methods such as Akaike's Information Criterion (AIC) to a list of candidate occupancy 
models enables ecologists to tease out covariates most important for model fit, and consequently, most influential towards species occupancy and detection (Burnham \& Anderson, 2002).

\subsection{Gunung Palung study site}

At an estimated age of 140 million years old, the rainforests of Borneo are among the oldest in the world (Mackinnon et al., 1996). LANDSAT imagery dating as far back as 1973, when Brunei, Malaysia, and Indonesia first began to document industrialized deforestation practices in Borneo, estimated that forest covered 75.7\% of the island (Gaveau et al., 2014). Between 1973 and 2010, Borneo lost $30.2 \%$ of its forest cover primarily to industrial oil palm plantations, followed by agriculture, timber harvesting, and wildfires (Gaveau et al., 2013; Gaveau et al., 2014). With forest habitat decreasing at such an alarming rate in Borneo, efforts to document and understand its ecology have become all the more important. Although much of Borneo's remaining forest is unprotected, a handful of parks on the island; such as Gunung Palung National Park (GPNP) in Southwestern Indonesian Borneo, provide relative safe havens for the island's biodiversity. GPNP was established as a national park in 1989 (Curran \& Leighton, 2000) and has been used as a field site to study intact, old growth rainforest systems in Borneo for decades. My supervisor, Heiko U. Wittmer, alongside his collaborator and director of the One Forest Project operating within the park, Andrew J. Marshall; have been gathering data at GPNP since 2007, and camera trap data since 2015. Their combined dataset comprises terrestrial species camera trap records, terrestrial and arboreal faunal distance samples, weather and rainfall data, and phenology of more than 6,000 marked woody plants from plots occurring throughout the park's eight forest types (Cannon et al., 2007; Marshall, 2009; Marshall et al., 2014). These records produced in GPNP provide a rare opportunity to study community dynamics over long time scales with a variety of environmental data: a rare occurrence in tropical biomes, especially in southeast Asia.

Within Gunung Palung National Park (90,000 ha West Kalimantan, Indonesia: 115'S, $110=10^{\prime} \mathrm{E}$ ), variation in soil, local climate, and elevation has resulted in 8 distinct forest types that support a diverse community of species (Marshall et al. 2014). The Air Putih (White Water) River weaves throughout the research area as part of the Gunung Palung watershed and acts as a natural divide between the two nearby peaks, Mount Palung and Mount Panti (Curran \& Leighton, 2000). The Cabang Panti Research Station (CPRS), situated at the base of Mt. Palung and on the bank of the Air Putih River, provides a unique and convenient location for researching the park's wildlife community in this forest type gradient. Only a small collection of footpaths provide access to Cabang 
Panti from the closest town, Tanjung Gunung: about a five hour hike away. An alternative eight hour canoe trip also provides access. Comprised of a grid network of footpaths, the field site straddles two ridgelines and encompasses the following eight forest types: 1) peat swamp on nutrient-poor, bleached white soils (5-10 $\mathrm{m}$ asl); 2) freshwater swamp on nutrient-rich, seasonally flooded, poorly drained gleyic soils (5-10 $\mathrm{m}$ asl); 3) alluvial bench on rich sandstone-derived soils recently deposited from upstream sandstone and granite parent material (5-50 m asl); 4) kerangas heath forest on acidic, sandy soils (20-60 $\mathrm{m}$ asl): 5) lowland sandstone on sandstone-derived soils (20-200 m asl); 6) lowland granite on granite-derived soils (200-400 m asl); 7) upland granite on granite-derived soils (350-800 $\mathrm{m}$ asl); and 8) montane on mostly granite-derived soils (750-1100 $\mathrm{m}$ asl) ((Cannon et al., 2007; Marshall, 2004; Marshall, 2009; Paoli et al., 2006). Because of its protected status and limited access, relatively little human traffic exists in the park. Camera traps have captured occasional hunters and poachers likely from surrounding communities, but the majority of human presence are from researchers based in CPRS. Indeed, the park does also experience very small scale hand-logging specifically in its riparian forest patches where timber can be carried out by raft (Hiller et al., 2004). A general layout of the field site can be seen in Figure 1.1. 

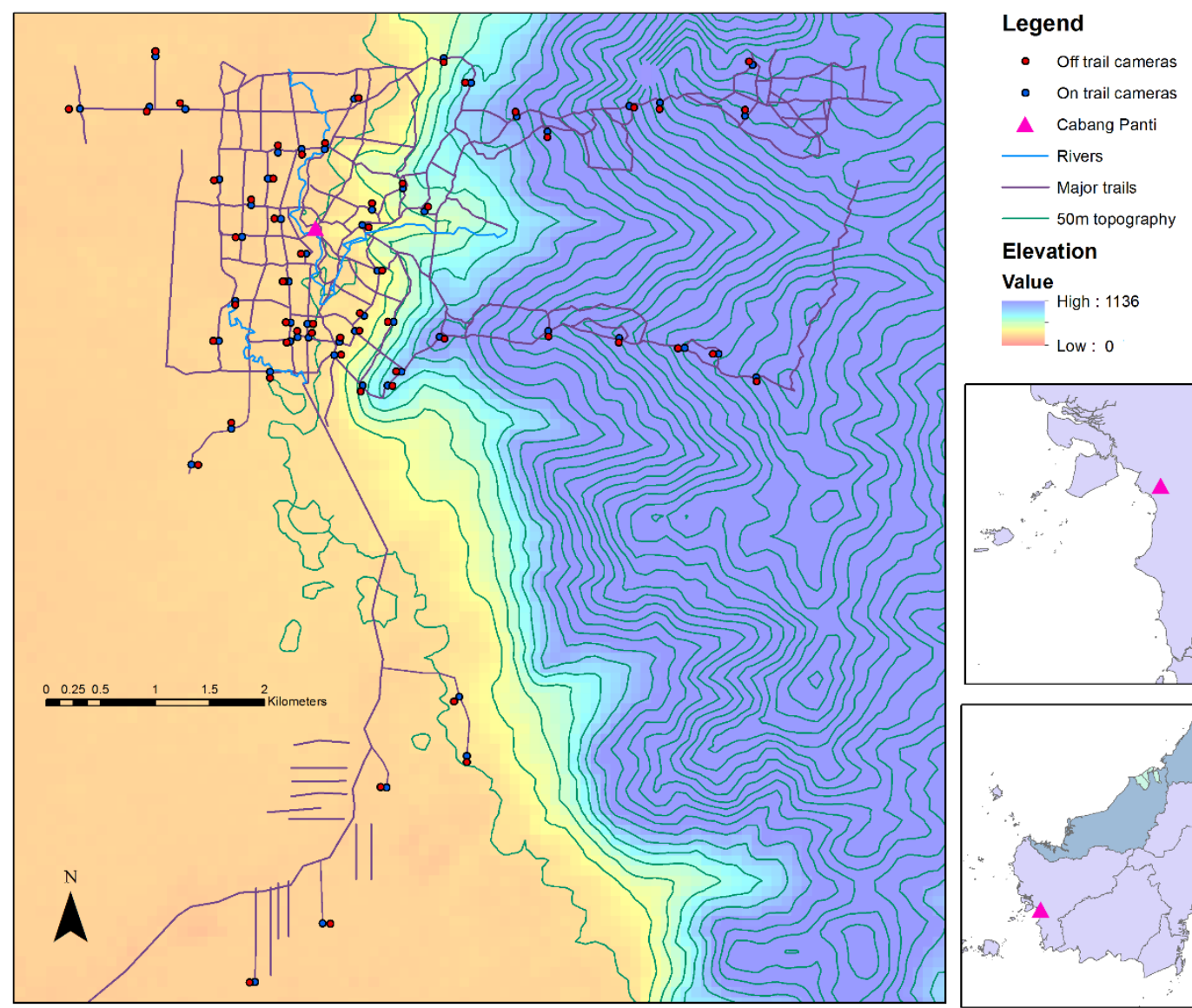

Elevation

Value

Value : 1136

Low : 0
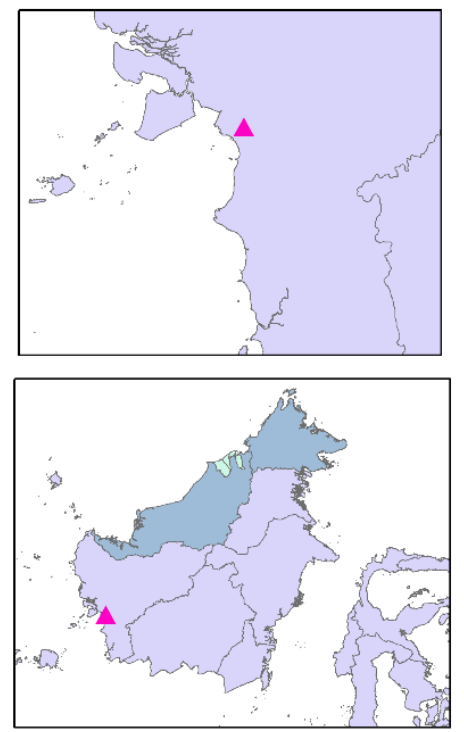

Figure 1.1: The research study site at Gunung Palung National Park in West Kalimantan, Indonesian Borneo (90000 ha; 1015'S, 11010'E). Blue and red points indicate on and off trail camera locations, which were placed around the central Cabang Panti field station (pink triangle). Green lines denote a $50 m$ elevation gain, blue lines are small rivers and tributaries, and purple lines indicate trails.

Gunung Palung, like much of Borneo, experiences an extreme tropical climate defined by two "wet" and "dry" monsoon seasons. Average temperatures in Borneo remain relatively steady between $25^{\circ} \mathrm{C}$ and $35^{\circ} \mathrm{C}$ year round, with the majority of seasonal differences pertaining to rainfall. The dry monsoon period usually spans the months of May through October, and the wet period: the months of November through April. Gunung Palung and West Kalimantan in general experience higher than average annual rainfall compared to the rest of the island as south-easterly winds from low-pressure zones in mainland Asia and north-westerly winds from low-pressure zones above Australia are redirected by the central mountain area and focused around the western and northern sides of the island (Mackinnon et al., 1996). Borneo also experiences intense periods of wildland and forest fires, particularly during the "dry" monsoon season. Fires are almost entirely human-induced due to economic incentives to develop land for agricultural use (Edwards \& Heiduk, 2015). These fires result in enormous loss of habitat across Borneo, especially in low peatland habitats (Miettinen 
et al., 2017). Little is yet known about how the indirect results of fire, such as decreased air quality and heightened displacement of wildlife, may affect the ecology of Borneo's protected area. The intensity of Borneo's wildfires are likely to increase in intensity in the future, and recent studies have warned of the potential compounding effects that El Niño events and burned forest areas have on each other (Chapman et al., 2020; McAlpine et al., 2018).

\subsection{Gunung Palung community assemblage}

Gunung Palung is home to the Dipterocarpaceae plant family: comprising 16 genera and 695 recorded species that occur throughout the tropics (Christenhusz \& Byng, 2016). Also known as "dipterocarps", this family of trees, as well as some members of the Burseraceae, Fagaceae, Myristicaceae, Polygalaceae, and Sapotaceae families are mostly responsible for the large-scale mast fruiting that Borneo as well as other areas of Southeast Asia experience supra-annually (MauryLechon \& Curtet, 1998). Despite the large-scale deforestation that Borneo has experienced in the past several decades, the largest expanse of intact forest stands in the IndoMalay ecoregion outside of Papua New Guinea is found within Borneo (Kier et al., 2005). This community of highly productive and diverse plants also supports a similarly diverse animal community.

Although perhaps known primarily for its charismatic arboreal species, Borneo also contains a rich terrestrial community. As a protected area recognized by the Indonesian government, Gunung Palung contains a wildlife assemblage believed to be representative of typical pre-disturbance Bornean ecosystems (Marshall et al., 2009). Consequently, the park is an invaluable resource for biologists aiming to better understand species ecology and behaviour with minimal signs of human disturbance. Almost three hundred mammal species, nearly a third of which are bats, inhabit Borneo (Phillipps \& Phillipps, 2016). All five Bornean species of wild cats: the Sunda clouded leopard (Neofelis diardi), flat-headed cat (Prionailurus planiceps), Bornean bay cat (Pardofelis badia), marbled cat (Pardofelis marmorata), and the leopard cat (Prionailurus bengalensis), have been recorded within Gunung Palung by the camera traps placed within the Cabang Panti field site. Besides this diverse array of felids, GPNP boasts a whole suite of other species that make up the terrestrial carnivore guilds. Some of the members include: the Malay weasel (Mustela nudipes), the yellow-throated marten (Martes flavigula), the Asian small-clawed otter (Amblonyx cinereus), three species of mongooses (Herpestes spp.), the banded linsang (Prionodon linsang), and the Asian water monitor (Varanus salvator) (Phillipps \& Phillipps, 2016). 
GPNP contains an even more diverse array of omnivorous and herbivorous species. Several large species, such as southern red muntjac (Muntiacus muntjak), Bornean yellow muntjac (Muntiacus atherodes), bearded pig (Sus barbatus) and sun bear (Helarctos malayanus) occur throughout the park. Other mammalian terrestrial species of moderate size include the lesser mouse deer (Tragulus kanchil), greater mouse deer (Tragulus napu), common porcupine (Hystrix brachyura), and long-tailed porcupine (Trichys fasciculata). Civets, such as the Malay civet (Viverra tangalunga) and binturong (Arctictis binturong) are also relatively common mid-sized mammals found in GPNP. A diverse collection of small rodents includes several species of ground and arboreal squirrels (Exilisciurus spp., Rheithrosciurus macrotis, Callosciurus spp., etc.), rats (Rattus spp., Maxomys spp., Niviventer spp., etc.), several species of shrew (Suncus murinus and Crocidura spp.) and the rodent-like treeshrews (Tupaia spp.) (Phillipps \& Phillipps, 2016). Several small to mediumsized members of the Phasianidae family, like the green wood partridge (Rollulus rouloul), crested fireback (Lophura ignita) and crestless fireback (Lophura erythrophthalma), make up the terrestrial birds of GPNP, with the addition of the larger argus pheasant (Argusuanus argus). Some extremely rare species found in the park, such as the Sunda pangolin (Manis javanica), otter civet (Cynogale bennettii), P. planiceps, and P. badia are listed as endangered or worse on the IUCN Red List (IUCN, 2020). Other animals, like Horsfield's tarsier (Cephalopachus bancanuswere), H. malayanus, A. binturong, $A$. cinereus, and $N$. diardi are listed as vulnerable (IUCN, 2020). Most of the wildlife studies that have come out of GPNP are targeted around arboreal species (Johnson et al., 2005; Marshall, 2004; Marshall et al., 2014; Marshall et al., 2009), and its bank of terrestrial camera trap data has gone comparatively untouched. Many of the terrestrial species' general ecology is understudied, let alone more sublte differences in detection between microhabitats.

\subsection{Aims and thesis organization}

As this Masters thesis is a converted work from an original PhD project, its chapters are somewhat unorthodox. The original aims for my original PhD thesis were to explore how plant productivity (specifically masting resource pulses) influenced different trophic levels of the terrestrial community in Gunung Palung and take advantage of the robust camera system to shed light on the ecology of the 5 rare felid species within GPNP. My thesis was broken into 5 prospective chapters, whereby 1) the concepts behind masting and its known effects on wildlife ecology were collected as a literature review 2 ) fluctuations in plant productivity was examined as a bottom-up process through trophic levels, 3 ) top-down pressures in response to potential increases in prey 
abundance was measured, and 4) absolute abundance and distributions of rare felid species was calculated using spatially explicit capture recapture models. Lastly, a fifth methodological chapter was planned to explore the effects of camera placement on species detection and better inform the results of the three aforementioned data chapters. After consulting my advisors, I decided that a conversion to a Masters degree was in my best interest. My literature review and methodological chapters were selected by myself to constitute my new Masters thesis as they were the two most attainable chapters given the new limited timeframe to complete this thesis. Although my literature review is not directly related to the subject of my primary methodological chapter, I am submitting it as evidence of previous research conducted before my thesis conversion occurred.

\section{Chapter 2. The impact of masting events on wildlife trophic levels}

This chapter explores through a literature review the concepts of masting events as a resource pulse, global examples of masting, and the body of knowledge surrounding faunal responses to masting events in Borneo.

Chapter 3. An investigation of camera placement strategies on state parameters for a Bornean terrestrial community

Selective camera placement strategies are often employed in ecological camera trap studies, yet their effects on research findings go largely unaccounted for. Using a paired camera design, I calculate the influence of camera placement on popular state parameters: species richness, relative abundance, and detection probability. Further effects of camera placement on species behaviour (through temporal activity curves) and a potential interaction between camera placement and body size are also explored.

\section{Chapter 4. General discussion, implications, and future research}

I provide a synthesis and collation of the main findings of my study as well as the broader implications and future paths of study for camera trap placement strategies and Bornean terrestrial species conservation. 
This thesis is structured as two manuscripts in publication format, with my data chapter having its own specific introduction, methods, results, and discussion. As a result, some necessary repetition exists between my general intro and discussion and my chapter-specific intro and discussion. A general abstract is provided at the start of the thesis, and a combined reference list at the end. 


\section{Chapter 2 The impact of masting events on wildlife trophic levels}

This literature review sets out to outline the current body of knowledge describing resource pulses (specifically masting events) and how the wildlife community responds to this pulse. While there is a large collection of literature describing mast fruiting in plants and their possible ecological or evolutionary mechanisms, there remains a paucity of information that quantifies how animals of different trophic levels respond to masting events. Furthermore, I highlight the potential importance of masting events on community dynamics within Bornean forest systems, with the ecology of tropical terrestrial mammals standing as a topic in particular that can gain from exploring this relationship. The further study of the connection between masting events and Bornean terrestrial faunal populations may offer a unique opportunity towards learning their life histories, behaviour, and the management strategies necessary for their continued conservation.

\subsection{Resource pulses}

Resource pulses are described as periods of increased resource availability that are infrequent, of short duration, and of large magnitude (Yang et al., 2008). These pulses can manifest as abiotic or biotic resources and occur in a diverse array of ecosystems across the globe. On the beaches of southern Brazil, winter cold fronts lead to higher concentrations in the deposition and accumulation of the diatom, A. glacialis, onshore (Netto \& Meneghel, 2014). The meiofaunal communities residing in each tidal zone are quick to respond to this temporary increase in organic matter with increased densities and biodiversity (Netto \& Meneghel, 2014). In deep ocean environments, whale carcasses create extremely ephemeral, energy-rich resource deposits that are capitalized by a diverse array of sharks, seabirds, and smaller scavenging fish alike (Clua et al., 2013; Dudley et al., 2000). Tropical forests floors in Puerto Rico experience pronounced shifts in invertebrate community composition directly after hurricanes as a result of changes in leaf litter biomass, light levels, and soil moisture (Ostertag et al., 2003; Richardson et al., 2010). Northern Californian wildflower populations experienced increased nectar concentrations and longer flowering durations after fires as a result of changes in soil chemistry and hydrology (Mola \& Williams, 2018). These temporary patches of highly-productive grasslands provided more efficient feeding grounds for bumblebees and encouraged greater colony fitness overall (Mola \& Williams, 2018). 
Not only do resource pulses occur in a diverse range of ecosystems, but they affect organisms at every trophic level. Pulses can radiate up the food chain, beginning with direct bottomup effects and ending with potential indirect top-down effects as these resources reach higher trophic levels (Yang et al., 2008). In Australia, increases in rodent populations after flooding rains in 2010 resulted in a boom in the mesopredator populations of feral cats (Felis catus) and red fox (Vulpes vulpes) (Greenville et al., 2014). Populations of dingos (Canis dingo), which prey on all three prey species, experienced a surge long after the initial increase in rodent populations had subsided (Greenville et al., 2014). Between 2010 and 2012, this terrestrial mammal community experienced a shift from a bottom-up driven boom in plant productivity cascading up the trophic levels to a topdown driven increase in predation rippling back down the food web. This example also brings into light the issue of overgeneralization in studying the effects of resource pulses on communities. Simple food-chain models tend to ignore whether all herbivore species are impacted by a resource pulse equally and whether the same herbivores experience similar top-down pressures from carnivores (Hopcraft et al., 2010). More complex food webs may incorporate omnivory as well as ontogenetic and environmentally-driven changes in diet that blur the lines between trophic levels in more traditional models (Polis \& Strong, 1996). Ecosystems with high connectivity within the food web, such as those in the tropics, may be more well described by a "trophic spectrum" which does not group organisms into heterogeneous levels (Darnell, 1961). Hunter and Price (1992) argue that environmental heterogeneity in abiotic and biotic factors through space and time create an everchanging trophic cascade of top-down and bottom-up forces. A duality of top-down and bottom-up interactions along a "trophic spectra" may be less straight forward than using one overarching force to describe community interactions along a linear trophic scale or pyramid, but it may better describe the structural complexities of hyper-diverse ecosystems (Darnell, 1961; Power, 1992). Fortunately, resource pulses provide a natural experimental design to address questions involving community responses to resource fluctuations. Schwinning \& Sale (2004) suggest that there are tiered responses to resource pulses, where pulses of high intensities are met with a wider faunal response in behaviour, and more ephemeral pulses incur a weaker reaction. As a result, some physiological processes in organisms may only be triggered by a pulse event of a certain magnitude, and pulses that do not exceed a certain threshold are ignored (Schwinning \& Sala, 2004). Masting events are a classic example of resource pulsing in terrestrial systems that typically trigger bottomup community interactions and also exhibit significant variance in their magnitudes. 


\subsection{Masting general background}

Mast fruiting, or the temporary increase in production of fruit or seed crops followed by a comparatively low period of productivity, is a natural phenomenon that spans numerous plant families (Herrera et al., 1998). Mast fruiting characteristically plays out over a supra-annual timeline, with high-fruiting periods occurring on a semi-consistent basis; such as every 2-3 or 4-6 years. Mast fruiting, or masting events, describe the peaks in cyclical productivity that any masting plant undergoes. Literature focusing on masting events are usually referring to synchronous masting, where a population of one or more species of plants produces high comparative volumes of fruit or seeds simultaneously. Synchronous masting scales a resource pulse that would otherwise be contained within the seed shadow of an individual plant to a community level and can greatly amplify its effects. Similarly, asynchronous masting describes a plant species that displays mast fruiting, but without simultaneous expression within a whole community. To say that mast fruiting occurs supra-annually is not to say that the species or individuals in question do not produce any fruit in the intermediate period, but that the mast produced by many floral species is almost exclusively on a supra-annual, synchronous basis.

One of the most widely accepted explanations for masting is predator satiation, where an explosion in herbivore food availability overwhelms seed predator populations such that it is not possible for them to process all of the crop produced, which then allows for higher probability of successful seed propagation (Crawley \& Long, 1995; Janzen, 1971). In subsequent years following a mast, and before the next large masting event (referenced hereafter as an intermast period), seed predator population are predicted to decline due to the comparative decrease in fruit productivity (Kelly \& Sullivan, 1997). This drop in seed predator numbers then allows more seeds to escape predation in the following mast. Similarly, mast years encourage greater concentrations of seed dispersers (through both immigration and reproductive recruitment), improving chances of seed propagation later on (Givnish, 1980). The pollination efficiency hypothesis postulates that synchronous flowering provides greater incentives for pollinators to visit plant populations, and is consequently more efficient than more modest fruiting year-round (Maycock et al., 2005; Pearse et al., 2016). Predator satiation and pollination efficiency both are pillars of the "economy of scale" hypothesis first proposed by Norton and Kelly (1988). In this hypothesis, floral reproductive output increases at a quicker pace than reproductive effort, suggesting that larger, less frequent reproductive episodes are more efficient than more frequent, weaker pulses (Norton \& Kelly, 1988).

One of the factors that makes masting such a compelling example of a resource pulse is the phenomenon of interspecific synchrony described earlier. Synchronous, interspecific masting could 
be a remnant trait of a common ancestral plant that has persisted in descendants (LaFrankie \& Chan, 1991). A core group of tree species that mast synchronously would provide an evolutionary cue for other species to follow suit, consequently broadening the scope of masting across a region (Ashton et al., 1988). Herrera et al. (1998) argue that current ecological literature on masting puts too much emphasis on the 'extreme cases' of masting such as interspecific synchrony, and that all reproductive variability in plants is of value for research. All species that mast have inherent variability in seed or fruit output between masts and intermast periods, and this variability may have just as important of an effect on other trophic groups as massive masting events. Indeed, the physiological reasons and ecological significance behind masting events are still widely debated especially between biomes (Pearse et al., 2014).

\subsection{Global diversity of masting}

Masting occurs in many vegetated ecosystems, and the diversity of the world's environments are reflected in the different characteristics of their mast fruiting. In the late 1990s, an assessment on the current literature associated with masting in woody plants noted clear ecosystem biases. Boreal and temperate biomes had been sampled far more than their tropical or subtropical cousins (Carlos M. Herrera et al., 1998). Nearly $41 \%$ of the data sets used in this review described Fagaceae and Pinaceae species, despite these two families only comprising $1.6 \%$ of the diversity highlighted in the review (Carlos M. Herrera et al., 1998). Recently, however, interorganizational projects such as the MASTIF (Mast Inference and Forecasting) network headed by Duke University are compiling seed trap and crop count data collected from a wide array of plant communities throughout the United States to explain how climate, habitat, and individual characteristics influences plant fecundity (Clark et al., 2019). By integrating data from sites across the continent, MASTIF stands to paint a more representative picture of masting diversity in the United States as well as shed light on floral and faunal interactions that occur during mast events on individual, local, regional, and even continental scales (Clark et al., 2019). In the future, MASTIF aims to go further still by expanding their study framework to tropical field sites outside of the US. Not only are the plant species directly involved in masting incredibly different, but the reverberating effects that they have on their ecosystems are also unique to their location.

In New Zealand, many taxa express masting synchrony, in some rare cases even across genera. Species of tussock grasses, herbaceous monocots, and both dicot and gymnosperm trees were all found to exhibit interspecific synchronous masting over hundreds of kilometres (Schauber et al., 2002). Such a diverse range of taxa fruiting in synchrony could be a characteristic of New 
Zealand's natural history. The islands' unique absence of mammalian herbivores and humans for much of its existence may have allowed its plant species the circumstances necessary to evolve the long life spans that make masting a practical reproductive strategy (Schauber et al., 2002). Despite a lack of terrestrial mammals for much of New Zealand's history, many of its plants may have evolved synchronized masting as a response to seed predation. Roughly a dozen species of native tussock grasses (Chionochloa spp.) seemed to have adapted synchronized masting to avoid seed predation by specialized chloropid fly larvae, who were found to damage as much as $94 \%$ of grass florets in a year (Kelly et al., 1992). Nothofagus beech nut viability has been found to improve with increased total seedfall, suggesting that heavy seed years maximized pollination success (Allen \& Platt, 1990; Burrows \& Allen, 1991). These beech mast years increased predator densities of non-native mice (Mus musculus) and stoats (Mustela erminea), which then switch their feeding focus to native mohua (Mohoua ochrocephala) after seed availability dwindled (O'Donnell \& Phillipson, 1996).

In the north-eastern United States, ecologists and epidemiologists were able to reliably predict high-risk years for exposure to Lyme Disease based on the masting history of their native oak (Quercus spp.) forests (Jones et al., 1998). White-footed mice (Peromyscus leucopus) and whitetailed deer (Odocoileus virginianus) abundance in a stand is positively correlated with acorn crops, which is observed to undergo periods of intense productivity every 2-5 years (Wolff, 1996). Whitefooted mice are the main host for the bacteria (Borrelia burgdorferi), that causes Lyme Disease. White-tailed deer are also the main host for the black-legged tick (Ixodes scapularis): the primary culprit for interspecies transmission of Lyme Disease (LoGiudice et al., 2003). Oak masting provides an increase in resource availability that ripples through the food web: directly and indirectly raising the populations of all four of the species described above. Masting attracts large populations of all four species in a concentrated area, which raises the chances of ticks becoming infected with Borrelia burgdorferi and consequently infect humans two years after masting occurs (Jones et al., 1998).

In the Carson Range of western Nevada, Jeffrey, ponderosa, and sugar pine seeds experience increased animal-mediated seed dispersal in masting years (Vander Wall, 2002). In years of high pine productivity, scatter-hoarding rodents cached seeds in multiple caches, some almost $30 \%$ further from source trees than in non-mast years (Vander Wall, 2002). This is significantly different in comparison to rodent behaviour in intermast years, where seeds are often cached in one location relatively close to the tree-of-origin. The higher number of caches in masting years led to a higher frequency of forgotten caches and increased seed propagation.

The frequency of each masting event is irregular across their respective ecosystems, and the primers for these events are also a topic of debate. It is a general consensus, however, that the 
catalyst for synchronized masting lies in plants' responses to weather (Janzen, 1971; Kelly et al., 2013). A study on valley oak (Quercus lobata) in California found correlations between microclimate and acorn production, suggesting that warm April temperatures triggered synchronized masting (Koenig et al., 2015). High average temperatures resulted in a cascade of phenological and climatic effects, including: homogenizing of oak microclimates, more temporally concentrated flowering, higher available pollen in the atmosphere, and consequent larger acorn crops (Fernández-Martínez et al., 2012; Koenig et al., 2015). Koenig et al. (2015) hypothesize that a warming climate may lead to less microclimate variability in the future and less intense differences in acorn crop sizes as a result. Other researchers argue that seasonal temperatures are not what cue high masting years but differences in temperature between the two previous growing seasons (Kelly et al., 2013). This "weather as a cue" hypothesis concludes that while there may be gradual increases in mean annual temperatures, differences between consecutive years will likely be very subtle, and synchronous mast fruiting will be relatively insensitive to climate change in this regard (Kelly et al., 2013). The base of knowledge trying to understand whether climate change has an effect on El Nino - Southern Oscillation is still in formative stages, however any variation in ENSO frequency or intensity that results from climate change may have deep consequences on global masting cues (Gergis \& Fowler, 2009). Yet regardless of their ecological cues, the spatial scale and community involvement of masting events vary greatly between systems, with Indonesian Borneo providing an extreme example.

\subsection{Natural history of masting in Borneo}

With more than 3,000 tree species existing in Indonesian Borneo alone, the island provides a highly diverse resource base for its faunal communities (Christenhusz \& Byng, 2016). One of the island's many plant families has gained notoriety for its widespread, supra-annual mast fruiting events. Dipterocarpaceae is a family of trees comprising 16 genera and 695 recorded species that occur throughout the tropics (Christenhusz \& Byng, 2016). Also known as "dipterocarps", this family of tree, as well as some members of the Burseraceae, Fagaceae, Myristicaceae, Polygalaceae, and Sapotaceae families are mostly responsible for the large-scale mast fruiting that Borneo as well as other areas of Southeast Asia experience supra-annually. Leading theories suggest that dipterterocarpaceae originated in seasonal tropical environments due to their strong floral trigger at the beginning of the dry season (Ashton et al., 1988). Once they migrated to the aseasonal tropics, they speciated into the diverse family that we know today, but still largely retained their synchronous fruiting characteristics. 
More than $95 \%$ of dipterocarp pollination is performed by three species of thrip insects (Thysanoptera). Thrips are well suited as pollinators for synchronized flowering species as their generations experience quick turnovers with high average fecundity: allowing quick population responses to sudden fluctuations in dipterocarp productivity (Ashton et al., 1988). In turn, dipterocarps have developed their own adaptations to ensure high pollinator efficiency when they do flower en masse. Specifically within the Shorea genus of dipterocarps, flowering times during a mast year have been observed to stagger between stands; lowering competition for pollinators (Ashton et al., 1988). Unlike many of their temperate cousins, dipterocarp seeds are dispersed solely by wind (Curran \& Leighton, 2000). The Greek origin of their name, translated to "two-winged fruit", is a telling description of the morphological adaptation for several members of this family that slows the seed's fall from the tree and allows it more time to be carried by the wind further away from its parent (Ashton, 1988). Although wind is their sole seed distributor and animal herbivory has no direct benefit for dipterocarps through endozoochory, predator satiation may allow for increased survivorship of seedlings following a mast fruiting event (Williamson \& Ickes, 2002). The role of environmental cues for supra-annual masting is also still under debate, although there are a few leading theories.

Some environmental explanations of dipterocarp mast fruiting are based on meteorological observations. In peninsular Malaysia, Shorea and Mutica species experienced mass flowering 8-9 weeks after short but significant drops in the usually narrow, high nightly temperatures ranges (Ashton et al., 1988). In addition to this, 4 periods of high dipterocarp productivity between 1987 and 1998 were also found to be highly associated with El Niño-Southern Oscillation (ENSO) events (Curran et al., 1999). Curran et al. (1999) suggests that ENSO years provide the climate conditions that cue mast fruiting of dipterocarps in Borneo, and any fluctuations in these conditions (whether natural or human-induced) will likely have significant consequences on these plants' future seeding and recruitment. Throughout Indonesian Borneo, the lower average annual rainfall that is also strongly linked to ENSO years has been shown to exacerbate the annual dry-season fires initiated primarily by the logging and agricultural industry (Salafsky, 1994). Increasing wildfires are not only a symptom of climate change, but also a contributor to change in their own right. In a study focused mainly on North American wildfire events, smoke particles lead to a reduction in surface temperatures and rainfall, effectively extending drought periods that may have facilitated the fire in the first place (Liu et al., 2014). How wildfire-induced changes in climate affect Borneo and the environmental cues that trigger masting is unknown but may be a crucial element in projecting forest productivity into the future. 
To understand the importance of temporal fluctuations in fruit productivity in Borneo, a description of the main fruit contributors within the intermast period is necessary as well. The 750 species that comprise the Ficus genus play a huge role in this respect, and the 150 species of native and non-native figs that occur in Borneo provide fruit for the island year-round (Shanahan, 2000). Figs occur in a variety of forms, such as trees, shrubs, vines, epiphytes, and hemiepiphytes (including the well-known strangler figs) (Mackinnon et al., 1996). Such high variation amongst the genus allows figs to thrive in pioneer, secondary, and primary forests across elevational gradients (Harrison, 2001). Figs, unlike dipterocarps, fruit asynchronously even within populations of the same species, yet create short-lasting, intense crops of ripe fruit in their respective locations (Lambert \& Marshall, 1991). Fig fruits have already been shown to be attractive in Bornean mammals. Faecal samples taken from 13 Bornean species of squirrels, rats, and treeshrews over a 2 year period displayed fig seeds $11 \%$ of the time (Wells et al., 2009). Other genera of native plants provide fruit in the intermast period by fruiting often (Girroniera) or by fruiting with high asynchrony between individuals (Artabotrys, Syzygium, and Diospyros) (Dillis et al., 2015). For the Bornean endemic, the white-bearded gibbon, asynchronous fruiting is the best predictor of how commonly they include a plant genus in their diet (Dillis et al., 2015). Whether this is a product of the exclusively-arboreal gibbon's specialized feeding ecology has yet to be seen, and further calls into question how closely terrestrial frugivores share this inclination towards asynchronous species. Understanding terrestrial frugivore and seed predator involvement in asynchronous and synchronous masting not only sheds light on their feeding ecology, but may inform conservationists as to the resiliency of Borneo's forest community in the face of continued anthropogenic disturbance. Concern is growing over the invasive pioneer tree, Bellucia pentamera, in Borneo's forest due to its hyper-productive and highfrequency fruiting (Dillis et al., 2018). If high frequency, asynchronous fruiting does prove to be an attractive trait for terrestrial frugivores, $B$. pentamera may find no shortage of seed-dispersers willing to encourage its spread through Borneo, perhaps even to the detriment of other endozoochorous species.

\subsection{Terrestrial species of Borneo and their diet}

Borneo is home to a diverse collection of terrestrial vertebrates, many of whose diet is described but largely unquantified. For many of these herbivore species, descriptions of their feeding behaviour extend only as far as to "fruits, seeds, new growth, etc." without specifying species, dietary staples, or seasonal variations. For some of the more charismatic predator species, such as N. diardi, F. bengalensis, and P. marmorata; their diet is largely anecdotal or recorded in 
one-time observations, and further elaborations on their feeding behaviour is lacking (Borries et al., 2014; Rabinowitz et al., 1987). Some well described diets do exist, however, such as with $V$. tangalunga and S. barbutus. These reports shed light on the importance of fall-back fruits in intermasting cycles as well as which floral groups provide these resources (Colón, 2002; Hancock et al., 2005). In addition to the dietary composition of each mammal largely being unknown, their interspecific interactions in response to food availability are mostly a mystery below the forest canopy as well. For a more detailed description of the terrestrial community of Gunung Palung, please see section 1.3 in my General Introduction.

\subsection{How food availability and plant structure affect species distribution and abundance}

Study sites in systems outside of Borneo have touched upon faunal responses to changes in fruit diversity and abundance. A study in Puerto Rico compared native bird feeding behaviour in two coffee plantations that incorporate fruiting shade-trees into their design, one with a nearmonoculture of the shade tree Inga vera, and another with a diverse community of more than ten shade-tree and shrub species (Carlo et al., 2004). Overall, bird activity had a positive relationship with shade-species fruit abundance, but the more diverse polyculture had high and more prolonged bird feeding activity (Carlo et al., 2004). A similar study in Pennsylvania drew a more direct link between fruit and frugivore abundance: showing that invasive Asian honeysuckle (Lonicera spp.) fruit abundance had the most significant correlation with avian frugivore abundances by far when compared to other native masting plants and overall fruit diversity (Gleditsch \& Carlo, 2011). Lonicerra spp., with its high fruit volume, has been a pioneer species competitor with native plants and a vital food source for frugivores since its introduction into the Northeastern United States in the early 1900s (Luken \& Thieret, 1996). The relationship that Lonicerra spp. has with native avian frugivores is so intertwined that native fruit consumption was $30 \%$ higher in areas also containing high Lonicerra densities, and removal of this invasive in areas where it is well established could cause alarming drops in bird populations (Gleditsch \& Carlo, 2011).

A study in the Western Ghats in India also examined fruit abundance's relationship with frugivore abundance. Here, the field study lasted for three years, and consequently excluded any frugivore's relationship with some supra-annual masting trees (Ganesh \& Davidar, 1999). Plants producing seeds with hard outer shells had a slight majority within the masting community assemblage compared to those with soft-pulped fruits, which were also produced more stochastically (Ganesh \& Davidar, 1999). Ganesh and Davidar (1999) hypothesized that mast type 
(seeds with hard shells vs seeds with soft fruit) had the most significant relationship with faunal abundance, and larger abundances of mammalian seed predators existed in the study site compared to avian fruit-eaters who were ill-equipped to eat the more consistently available hard seeds. In a similar study, scientists in the Neotropics used multiple regression analyses to detect correlations between primate species richness and relative abundance, fruit trap estimates, climate records, and latitudinal variables (Stevenson, 2008). Stevenson (2008), found that endozoochorous (reliant on dispersal via faunal ingestion) fruit biomass estimates served as the best predictor for both frugivorous primate biomass and species richness. As expected, neither seed predator abundance nor folivorous primate abundance showed any correlations with fruit biomass (Stevenson, 2008). Latitudinal gradient and plant species richness were seen as the best predictor for overall primate species richness possibly due to higher plant reproduction for fruiting and seeding species (Stevenson, 2008). Another study, this time in the Chihuahuan Desert of Northern Mexico, analysed the strength of black jackrabbits' response to variation in predator abundance and plant productivity (measured in percent cover quadrants) (Hernández et al., 2011). Plant productivity and jackrabbit abundance shared a strong positive relationship as opposed to a limited numerical response of coyotes to jackrabbit abundance (Hernández et al., 2011). As these studies show, plant productivity, abundance, and composition can be strong predictors for faunal abundance, distribution, and behaviour within their respective ecosystems. While literature on this relationship in Borneo does exist, not all of the faunal community has been addressed.

Previous work in Gunung Palung with 10 arboreal frugivorous vertebrates suggests little habitat specialization due to food availability or competitor co-occurrence, although this behaviour cannot be assumed to be true for species feeding on the forest floor (Marshall et al., 2014). Other studies in Borneo have highlighted the strong reactions of a select few nomadic bird species and $S$. barbutus to synchronized masting in Dipterocarps, but with a focus on quantifying seedling success in Dipterocarps rather than recording terrestrial faunal responses (Curran \& Leighton, 2000). Studies also have yet to highlight how non-Dipterocarp mast production influences terrestrial species abundance and distribution in intermast periods (Curran \& Leighton, 2000). These current gaps in knowledge regarding how food availability shapes terrestrial herbivore groups in the tropics is perhaps a symptom of the structure of the ecosystem itself, where feeding observations in dense jungles are comparatively easier to make with arboreal species as opposed to more elusive terrestrial individuals. 


\subsection{How plant-frugivore relationships informs future conservation and management}

Gunung Palung is one of the only protected study sites in Borneo that provides terrestrial vertebrate population data for lowland and upland forest types spanning more than $1000 \mathrm{~m}$ in elevation. Such a wide elevational scope may give insight into faunal population responses to climate change-induced shifts along forest gradients. While many tree species are well adapted to the natural intrannual variation in rainfall, daily temperature ranges, humidity, and solar radiation that Borneo experiences, all of these variables are expected to fluctuate to extreme levels with climate change (Corlett \& Lafrankie, 1998). Future projections of these variables with respect to climate change may put existing plant species in "climates that may be outside the range that occurred during the evolutionary history of the present flora" and push against plants' physiological boundaries (Corlett \& Lafrankie, 1998; Mackinnon et al., 1996). Drought intensified by Borneo's widespread wildfires have already been found to elevate fruit tree mortality for sun bears in a study by Fredriksson, Danielsen, \& Swenson (2007). Tracking faunal species' response to masting resource pulses allows us to tease out fruit and seed-producing plant groups (possibly even to the species level where applicable) that are important in animal life histories. This knowledge can aid in predicting animal distribution in response to altitudinal habitat gradient shifts or other forest composition changes due to anthropogenic influences. Better understanding plant-animal bottomup interactions can impact conservation directly, as seen with the invasive plant, Bellucia pentamera, mentioned above. Like many invasive pioneer species, B. pentamera flourishes in disturbed area such as burned agricultural land, illegally-logged forest stands, and monoculture plantations (Dillis et al., 2017). All of these disturbed habitats abound in Borneo. Understanding how different faunal species utilize asynchronous, endozoochorous soft-mast crops could help inform efforts to halt the spread of $B$. pentamera and other invasives like it. Other factors such as nitrogen deposition and atmospheric $\mathrm{CO}_{2}$ change remain too poorly understood to rule out future implications in the community dynamics of Borneo (Sodhi et al., 2004).

\subsection{Camera trapping: a method of choice for illustrating terrestrial faunal dynamics}

Unlike field technicians, camera traps have the ability to take an impartial, holistic view of terrestrial community activity immediately upon installation. Field technicians, regardless of training, are bound to err occasionally and to vary in their probability of successfully detecting target species. Human presence itself may act as a deterrent to reclusive species that would otherwise be captured 
on camera traps (Sutherland, 2006). Some methods of population monitoring, such as distance sampling, require a combination of visibility and a large enough distance from the subject so as not to scare it away before identification can be made. In dense rainforests, this translates into a bias towards arboreal species. Due to their passive nature and usual set-up on ground-level, camera traps are used extensively for terrestrial animal monitoring (Peres \& Palacios, 2007; Tobler et al., 2015). At Gunung Palung already, the current camera array has been used to study the previously unknown behaviour of scent marking by $N$. diardi (M. L. Allen et al., 2016). Camera traps also aide in facilitating data standardization. The program Wild.ID, started by the Tropical Ecology Assessment Monitoring (TEAM), is currently being used to collate camera trap data from sites across the world (Bolger et al., 2012). Through software like Wild.ID, camera trap data can be cross-examined by multiple observers for accuracy and standardized into formats that can be applied to broader fields of study (Bolger et al., 2012). This idea is especially important for reclusive and relatively understudied species such as the endemic felids of Borneo. The ability to combine standardized camera trap data from multiple studies across Borneo could turn several weak datasets into one robust enough to tackle more complex ecological concepts such as predation rates, food refugia habitat, species fecundity, and fragmentation effects (Barrueto et al., 2014; Brodie et al., 2014; McShea et al., 2016; Steenweg et al., 2017). Although the dataset at Gunung Palung is already promising as an independent entity, using camera traps in a more rigorous standardized study design is an investment in a data collection medium that can only grow to be more useful for tropical ecologists with time.

\subsection{Conclusion}

Resource pulses are both a common feature and an important driver for wildlife communities within ecosystems across the globe. Yet the potential relationship between one of the world's most impressive masting events and an incredibly diverse terrestrial community has largely remained unexplored. Not only this, but masting provides a rare, natural variation in resource availability that permits a unique opportunity to understand how energy moves through the terrestrial mammalian community. Identifying whether the Bornean mammal community is bottomup driven, top-down driven, or a mix of the two can help cement the roles that each member of the community plays in each other's life stages. Tracking how each of these species react to changes in food availability (as seen in large masting years) may also provide useful insights into their feeding ecology just as the studies listed above have done to their respective focal species. Identifying important resources and periods of resource availability also informs conservation and wildlife 
management on an island that has experienced severe anthropogenic disturbances in the past half century. 


\section{Chapter 3 An investigation of camera placement strategies on state parameters and behaviour for a Bornean terrestrial community}

\subsection{Introduction}

In the past several decades, camera traps have been used increasingly by the biological research community for applications in the fields of animal behaviour, ecology, and conservation management (Burton et al., 2015). For the latter two fields, camera trap data (in the form of photo or video records) is used to generate estimates of species state parameters, such as species richness, abundance and occupancy. Population modelling of individually-identifiable species is prevalent within the current literature (Karanth, 1995), and allows for the estimation of all three parameters. For the majority of cases where species cannot be identified to an individual level, presence/absence data can still be used to estimate species richness and occupancy from a wide array of occupancy models to best match the research question (MacKenzie et al., 2017). The rate of photo or video record capture has also been used as a proxy for actual abundance estimates to create relative abundance indices (RAls) (Meek et al., 2014). No matter the parameter of interest, they are all only as accurate as the camera's ability to detect the target species, which is itself dependant on the study design.

It has become common practice for researchers searching to better understand species' ecology through remote camera trapping methods to adopt a quasi-random experimental design in lieu of truly random selection (Cusack et al., 2015; Oberosler et al., 2017). Selective placement of study units can be used to maximize the probability of encounter events by sampling habitats or habitat features of known significance to the focus species (Hamel et al., 2013; MacKenzie et al., 2017). This can be seen time and time again with trails (Weckel et al., 2006), roads (Di Bitetti et al., 2014), logs (Brooks \& Cheyne, 2018), bait stations (Mccoy et al., 2011), animal sign (Colyn et al., 2018), and mineral licks (Tobler et al., 2009). Often times, camera placement is determined at random on a grid design, and camera stations are then allowed a small spatial buffer to be placed selectively in the vicinity of landscape features to improve detection probability. This selective placement strategy also acts to reduce data collection effort in the field by situating cameras along more easily-accessible trails, roads, or clearings (Cusack et al., 2015). However, selecting microhabitats or placing attractants near cameras may create a bias towards these features that 
negatively affects detection probabilities of some species while also positively impacting the chances of detecting others.

Possibly the simplest solution to the issue of selective camera placement would be to place cameras only in random locations. Within a random study design, mineral licks, roads, trails, and clearings would be selected for camera station placement in proportion to their prevalence within the study area, so they would not be entirely excluded in theory. Especially for studies focusing on specialist and/or rare individuals, the prospect of a random camera placement study design may equate to considerably lower detections than placing cameras in locations that are tried and true attractants for their target species. This reason alone has undoubtedly made many researchers hesitate to adopt truly random placement strategies. Some studies have attempted hybrid designs, such as that used within the methods of this paper, where cameras are placed in pairs on and off trail so that differences in detection probability may be controlled for (Kays et al., 2009; Kolowski \& Forrester, 2017; Mann et al., 2015). Occupancy models are especially suited for this. In addition to estimating occupancy $(\Psi)$, occupancy models also estimate detection probability $(p)$ as its own state parameter. This allows ecologists to explicitly account for differences in detection probability, such as camera placement, with covariates that can easily be entered into the model framework. Estimates of species richness and relative abundance however, are not able to analytically account for imperfect detection like occupancy, and generally must rely on a study design featuring nonselective camera placement for unbiased results (Sollmann et al., 2013). Despite their relative simplicity and shortcomings, these estimates are still commonly used today to inform conservation literature and make management decisions. As an example of their prevalence, a literature review by O'Brien \& Kinnaird (2011) calculated that 71\% of camera trap mammal surveys in Indonesia did not correct for differences in detectability in their analyses.

Besides measurements of ecological system states, relatively little is known in terms of how selective placement affects species behaviour. Behavioural biologists also use camera trap record observations as well as capture metadata to better understand a vast range of species behaviour, such as feeding habits, anthropogenic impacts, and activity patterns (Caravaggi et al., 2017). Their utilization of camera traps as the principal means of data collection makes behavioural studies just as susceptible to bias through study design as those focusing on occupancy or measures of diversity. Although limited, some prior research exists specifically with how camera placement affects temporal activity. A recent study by Geyle et al. (2020) on red fox (Vulpes vulpes) and feral cats (Felis catus) in south-eastern Australia attempted to examine activity overlaps seasonally between the two species both on and off trails. While significant differences were found in peak activity times on-trail, the analysis could not be continued off trail due to limited detections. Another study by Gerber et al. 
(2012) explored how selective camera placement (in their case with baited and non-baited cameras) influenced intraspecific temporal activity for the Malagasy civet (Fossa fossana). Although their analysis resulted in no significant difference in activity patterns between baited and non-baited cameras, the authors raised a valid point in that placement strategies have the potential to introduce bias into almost any kind of ecological data, selective placement demands to be measured and accounted for. Differences in intraspecific temporal activity as a result of camera positioning in different microhabitat features clearly requires future research, and no information on this topic exists within Borneo as of the time of this thesis submission.

Camera placement also has equal precedence to influence species behaviour in other aspects. In many cases, other papers seeking to understand the differences in detectability for cameras selectively and non-selectively placed recognized significant differences on the levels of functional groups, and sometimes even entire community assemblages. The most common trend was found within the carnivore guild, which often displayed much higher detectability on road and trail systems (Mann et al., 2015; Trolle \& Kéry, 2005). Some studies have similarly noted that herbivore detection was significantly lower off trails (Srbek-Araujo \& Chiarello, 2013; Weckel et al., 2006). All of these findings occurred in the new-world tropics, leaving a paucity of knowledge regarding how communities and functional or dietary group detectability is influenced by selective camera placement in South-east Asia. In addition to taxonomic or dietary patterns, other research has documented the positive relationship that body size shares with camera detectability (Anile \& Devillard, 2016; Bukombe et al., 2016; Kays et al., 2010; Tobler et al., 2008). Two studies have even suggested that body size may also interact with camera placement location in how it affects detectability (Di Bitetti et al., 2014; Harmsen et al., 2010). These authors discussed that trails may improve camera visibly and act as a mechanical path of least resistance for larger-bodied animals, resulting in increased detection on tail systems for animals of increasing size (Di Bitetti et al., 2014; Harmsen et al., 2010). My camera dataset provides an excellent opportunity to further information as to whether this interaction is real, and to what extent.

The objective of this chapter was to determine the influence of camera placement on common biodiversity indices such as relative abundance and species richness as well as detection probability due to its great significance in occupancy estimates. Additional covariates were also included in occupancy models to determine other potential variation in detection probability and local occupancy. The effects of differences in detectability for cameras on versus off trail was explored on a community, taxonomic, dietary, and species level. Based on previous studies targeting predator behaviour on trail systems (Weckel et al., 2006), I predicted that carnivorous species would have higher detection on trails due to their utility as travel and hunting corridors. I predicted that 
prey species (mostly composed of the herbivore guild) would largely avoid trail systems to reduce contact with predators in accordance with the "landscape of fear" ecological hypothesis (Laundré, Hernández, \& Ripple, 2010; Severud, Belant, Bruggink, \& Windels, 2011). These effects were further examined in species behaviour through a potential interaction between body size and camera placement as well as differences in intraspecific temporal activity. On a community level and for each diet and taxonomic class, I predicted that increasing body size would improve the probability of detecting a species on trails based on the observations from Di Bitettie et al. (2014) and Harmsen et al. (2010) and the general relationship of cameras detection and body size that were found by Anile \& Devillard (2016) and Bukombe et al. (2016). To achieve these objectives, a paired camera design was employed across the study site both on small human-used footpaths and in close proximity offtrail in order to limit spatial bias between camera placement types. For maximum results, the entire terrestrial community at Gunung Palung National Park was included in this analysis.

\subsection{Methods}

\section{Study design}

Motion-triggered camera traps (Bushnell TrophyCam, Overland Park, KS) were deployed at the Cabang Panti research site between August 2017 and April 2020. All cameras were set approximately half a meter above the ground facing the most naturally clear orientation in their designated positions. Individual cameras were programmed to record a 20 second video for every motion trigger with a 10 second refractory period between videos. All camera traps performed automatic captures (listed as field scans in the dataset) at 12:00 each day to ensure camera activity could be gauged at least on a daily timescale in case of malfunctions. Stations were serviced monthly to ensure batteries were charged, SD cards were swapped if necessary, and broken or dislodged cameras could be exchanged and repaired. Cameras were dispersed throughout the field site in pairs with 4 cameras per forest type at any given time ( 2 cameras placed off trail and 2 cameras placed on) with the exception of the smaller Kerangas habitat where only one pair was placed at a time. On trail cameras were placed evenly across their designated forest type, with their focus trained on clear footpaths or trail junctions. Although game trails do exist in the field site, human footpaths were targeted due to their popularity in other camera trap study designs (Allan F O'Connell et al., 2010). Camera stations placed off trail were placed randomly with a separation from their partnered 
on-trail camera between $20-50 \mathrm{~m}$. Care was taken to ensure that no trail was visible from the off trail cameras. Pairing cameras within close proximity to each other was done in an effort to limit spatial bias so that site occupancy could be assumed to be consistent between cameras. Paired camera stations were maintained in position for roughly 90 day intervals, at which point they were either cycled to another of the pre-existing positions within their forest type at random (Fig 1.1), or allowed to stay in place for another 90 day duration. The decision to move the camera at the end of each 90 day period was made at random to withhold the introduction of a spatiotemporal placement pattern into the study. Supplemental data collected at the time of initial camera installation was also used for other model covariates. The local habitat type surrounding the camera station was assigned according to known elevational guidelines, soil composition, and plant composition. Camera longitude, latitude, and elevation were also collected by GPS waypoints taken at each camera site.

Videos collected from all camera traps were watched both by One Forest Project (OFP) field assistants on-site at Cabang Panti, and then by the project's dedicated camera trap manager, Mr. Agus Trianto. Video data was tagged with the captured species ID, capture date and time, camera number, and location metadata using a custom-made software enabling it to be stored in a remote MySQL database. For the field portion of my project, I assisted with camera trap maintenance, repair, and data processing both in Gunung Palung and Jakarta with Mr. Trianto between August and November of 2019. My presence in Gunung Palung and involvement in data collection were approved by Victoria University of Wellington, the Indonesian Ministry of Research and Technology (RISTEKDIKTI), and the Indonesian National Park Bureau. Wildlife data used in this study were collected exclusively through camera traps, with no physical interaction between myself or other field technicians and the wildlife observed. Animal ethics was consequently satisfied.

\section{Data analysis}

\section{Species richness and indices}

Species richness was calculated for all paired on and off trail camera placements and pooled into matrices by placement type. Species richness averages for both camera placement strategies were then tested for significant differences by comparing their matched richness matrices against each other using the Wilcoxon signed-rank test, which is used to compare two related, nonparametric sample means (Wilcoxon et al., 1970). Additionally, measurements of species diversity and evenness were calculated for the entire site and by camera placements using the ShannonWeiner Diversity and J' evenness indices respectively. Sample-based rarefaction/extrapolation (R/E) 
curves were calculated to determine whether species richness was accumulated at significantly different rates between camera placement strategies at any time during the entirety of the study period (indicated by non-overlapping 95\% confidence intervals) (Gotelli \& Colwell, 2011). R/E curves were constructed from 500 randomizations with replacement (Colwell et al., 2004) using the iNext package in Program R (Hsieh et al., 2016; Team, 2020). Relative abundance indices, or RAls, were collected for all terrestrial species by calculating the number of video captures per 100 camera trap nights (also referenced as 'capture rate' (O'Brien et al., 2003; Sollmann et al., 2013). RAls were determined per species in the same method as species richness, where relative abundance estimates were collated per camera into on and off trail matrices. Species-specific on and off trail RAI matrices were then compared for significant differences also using the Wilcoxon signed-rank test.

\section{Occupancy modelling}

Presence/absence data was deemed independent if consecutively captured videos from the same camera exhibited different individuals or were timestamped apart from one another at a 1hour time interval. Using 1 hour as an independence time interval is common practice for similar camera-trap studies, especially when dealing with larger, highly mobile species (Scotson et al., 2017; White \& Garrott, 2012). Detection histories were created for each species using the camtrapr package in Program R, with each survey site representing one camera station (Niedballa et al., 2016; Team, 2020). Detection history occasion length was held constant for all species to ensure proper comparison between species after models were fit. An occasion length of 5 days was selected as it effectively reduced zero inflation for species with low capture rates and facilitated acceptable model goodness of fit.

Single-species, single-season site occupancy models with a 'stacked' multi-season approach were used to model both detection probability $(p)$ and occupancy $(\psi)$ of Gunung Palung's terrestrial community (Fuller et al., 2016; Kery \& Royle, 2020). This modelling framework also accounts for imperfect detection and allows me to fit various environmental and methodological covariates that may influence $\psi$ and $p$ (MacKenzie et al., 2017). By fitting single-season models with seasonal effects (site $x$ season), one site becomes 'stacked' by the number of seasons (hereby referred to as survey periods) that it is active into multiple independent sites, allowing for a pseudo-multi-season modelling framework. While this type of multi-season model does not account for estimations of colonization or extinction, the interest of this study lies more with how species detection probability changes across microhabitat. A 'stacked' multi-season modelling approach also creates more unique 
'sites', allowing for a larger suit of explanatory variables to be reliably run with lower sample sizes. 'Stacked' models effectively compliment datasets such as mine that features species with particularly zero-inflated detection matrixes. Survey periods themselves were stacked into 30 day durations (6 occasions per survey period) from August of 2017 to April of 2020 to conform to the assumption of closure, whereby populations are assumed to be closed to changes in occupancy (immigration, emigration, birth, and death) during the survey period. Stacked survey periods were included in my models as a time covariate and categorized as "wet" or "dry" based on what month the majority of a survey period occurred in to reflect the general climatic seasons observed in Borneo (Mackinnon et al., 1996) (Table 1).

Logit-linear, multi-method models were used to model the linear combinations of covariates for both occupancy and detection probability state parameters. Multi-method (also known as multiscale) models are especially useful for methodological analyses of occupancy and detection probability as they calculate not only $p$ and $\psi$, but a third state parameter, $\theta$. While $\psi$ estimates the probability of broader site occupancy, $\Theta$ represents local occupancy; in this case a paired camera station. By also estimating local occupancy, multi-method models account for the lack of independence between cameras within a paired station. In this way, the probability that a species is locally available for detection is taken into account, and method-specific detection probabilities can be delineated within the model. This is perhaps clearer when constructing a multi-method model design matrix in practice. Camera surveys are broken into sub-surveys that are used to test multiple method covariates on different state parameters (in this case detection), effectively factoring them into different levels or scales. The lack of site independence for the method being tested is taken into account within this modelling framework by grouping each method (on and off trail cameras) as a single sample site with the number of sub surveys equivalent to the number of surveys multiplied by the number of methods being tested. Covariates taking advantage of this multi-method framework are often referred to as survey-specific or sample-specific covariates (Mackenzie et al., 2017).

A small collection of site and survey-specific covariates were used in my occupancy models (Table 3.1). Human presence was modelled for $\theta$ on a survey-specific level. Detection probability was modelled as a function of camera placement, seasonality, habitat type, and search (or sampling) effort for each camera pair. Camera placement, as the target covariate of this study, was modelled as a binary, survey-specific covariate. Seasonality was modelled as a site-specific binary covariate. Search effort was also employed as a survey-specific covariate. As continuous covariates, human presence and search effort were standardized using z-score normalization to streamline model convergence and allow model coefficients to be interpreted as the change in the log-odds ratio of 
occupancy relative to a 1-standard deviation change in the covariate from its mean (Cooch \& White, 2005). Because habitat type represents a combination of biotic and abiotic factors that may influence occupancy or detection probability, it was allowed in candidate models as covariates for $\Psi$ and $p$. This flexibility in model fitting reduces the confounding effects that may occur when a covariate that affects occupancy is forced into modelling detection probability or vice versa (MacKenzie et al., 2017). Habitat type, which originally consisted of a factored categorical covariate with 8 levels for each distinct forest type, was simplified into "Upland" and "Lowland" habitats. This reduction in habitat classification was done to facilitate model convergence but still retain the two most distinct upland and lowland habitat types that are seen throughout Borneo. An additional elevational covariate was not included in model construction due to its inclusion purely as a function of site occupancy, which was not the primary focus of this study, and its moderate collinearity with habitat type (Pearson's $r=0.65, p<0.05$ ) (Burnham \& Anderson, 2002). The following model framework was adapted from the paper by Kolowski \& Forrester (2017). 
Table 3.1: Covariates used in the modelling framework for single-species site occupancy $(\psi)$, local occupancy $(\theta)$, and detection probability $(p)$.

\begin{tabular}{|c|c|c|}
\hline Covariate & $\begin{array}{l}\text { Model } \\
\text { parameter }\end{array}$ & Model explanation \\
\hline Camera placement & $p$ & $\begin{array}{l}\text { Binary covariate delineating camera placement per paired } \\
\text { station as on (1) or off (0) the study site trails. }\end{array}$ \\
\hline Search effort & $p$ & $\begin{array}{l}\text { Standardized survey-specific covariate of the camera activity } \\
\text { matrix to measure sampling intensity per survey for each } \\
\text { sample site. }\end{array}$ \\
\hline Habitat type & $P, \Psi$ & $\begin{array}{l}\text { Binary covariate for habitat type that does and does not } \\
\text { experience seasonal flooding ("Lowland" vs "Upland"). } \\
\text { Lowland habitat is pooled from peat swamp, alluvial bench, } \\
\text { freshwater swamp, and kerangas habitats. Upland habitat is } \\
\text { pooled from lowland sandstone, lowland granite, upland } \\
\text { granite, and montane habitats. }\end{array}$ \\
\hline Seasonality & $P$ & $\begin{array}{l}\text { "Wet" and "Dry" seasons delineated by the time of video } \\
\text { capture. Videos between May } 1^{\text {st }} \text { and November } 1^{\text {st }} \text { were } \\
\text { marked as the "Dry" season and all else marked as "Wet". }\end{array}$ \\
\hline Human presence & $\theta$ & $\begin{array}{l}\text { Survey-specific counts of every human capture event per } \\
\text { camera. Counts were standardized using the z-score } \\
\text { normalization. Used as a rough proxy for human presence in } \\
\text { the field site. }\end{array}$ \\
\hline
\end{tabular}

All combinations of covariates for $\psi$ and $\theta$ were run with a global model set for $p$. The best model, found through Akaike's Information Criterion for small sample sizes (AICC), for the occupancy state parameters were then ran with a global model for $p$ (including camera placement) and the same model for $p$ where camera placement was omitted. By comparing the two models that include and exclude camera placement, the effect of on and off trail placement strategies on detection probability could be definitively measured through their respective AICC weights. The $\triangle \mathrm{AICc}$ between the top models featuring and not featuring camera placement were provided as a supplemental measurement of the influence of camera placement on detection probability through model fit. The effects of the other covariates for detection probability were also measured by running all covariate combinations for $p$ using their top model for $\psi$ and $\theta$ and calculating each covariates' cumulative AICC weights. In the case of this study, an AICC weight $>=0.70$ was used to indicate strong covariate influence on the target parameter, although the 'significance' of covariates based on their model 
weight should be set on a case by case basis (Kolowski \& Forrester, 2017). The importance of human presence on local occupancy was also found using the same method for camera placement. This template assemblage of models was fit by hand without the use of step-wise methods and run consistently for all species included in this study.

Models and model assessments were run using Program Presence. AICc and AICc weights were calculated for each species model assemblage (Mazerolle \& Mazerolle, 2017). Global model fit was tested using a parametric bootstrap test $(n=1,000)$. Model fit was also assessed by calculating the Pearson chi-square goodness of fit statistic $\left(x^{2}\right)$ and overdispersion was measured and accounted for with the chi-squared overdispersion parameter (ĉ) (MacKenzie \& Bailey, 2004).

\section{Detection percent changes and detectability curves}

Detection probability estimates calculated from species' top models were compared to find the percent changes between camera placement strategies. The same detection probabilities for species where camera placement strongly influenced detection were plotted on detectability curves to gauge the minimum survey effort necessary to detect a target species with any given level of confidence both on and off trail within the study site. Given that a species is present, the probability that a species will be detected at least once after $n$ camera trap nights was adapted from (Wintle et al., 2005), where $p$ is the estimated detection probability (Eq.1):

$$
\begin{gathered}
\sum_{x=1}^{n}\left(\begin{array}{l}
n \\
x
\end{array}\right) p^{S}(1-p)^{n-x} \\
=1-(1-p)^{n}
\end{gathered}
$$

Entering estimated detection probabilities for each species by camera placement and plotting over a range of $n$ allowed me to visualize the degree of variation in search effort required to detect at least one individual between camera placement strategies. Finding the value of $n$ when $p=0.95$, for instance, determines the search effort (in camera trap nights) necessary to gauge whether a species is present or absent with $95 \%$ confidence. 


\section{Taxonomic and dietary trends}

Beta estimates and standard errors for the camera placement covariate were calculated using each species' top global model for $p$ (Burnham \& Anderson, 2002). Covariate effect sizes and direction were grouped and compared by taxonomic group and by diet to highlight potential ecological patterns. All species were categorized into 7 taxonomic groups; felids, civets, terrestrial birds, treeshrews, rodents, carnivora, and ungulates. Lastly, the diet was ordered into 3 groups: carnivores, herbivores, and omnivores.

\section{Detection probability and body size}

Average body weight for each species were defined in kilograms from field guides and online databases to compare against detection probability on and off trails ("Birds of the World," 2020; Phillipps \& Phillipps, 2016). Top model $\beta$ estimates for the camera placement covariate calculated in the previous occupancy models were compared against average body weight for each species using simple linear regression models. Beta estimates were compared against body weight as a community, by taxonomic group, and by diet. The strength and direction of association for all three of these analyses were measured using the Spearman rank-order correlation coefficient for nonnormal distributions (Gibbons \& Chakraborti, 2014). The entirety of these analyses were run using base functions in Program R (Team, 2020).

\section{Temporal variation by camera placement}

In addition to modelling explanatory variables for species detection spatially between camera placement strategies, differences in detection was explored in terms of species' temporal activity. Using the R package, overlap, timestamp metadata from camera video recordings were manipulated into kernel densities across a 24 hour period (Meredith \& Ridout, 2014). Mirroring the format for occupancy modelling, capture event independence was set at 60 minutes, meaning that videos were marked as independent of one another if taken at least an hour apart. Enforcing a one hour duration for capture event independence protects against inaccurate activity densities from forming due to repeat videos of the same individual to a camera station during the same visit. The entire camera-trap dataset was divided into on and off-trail subsamples with each species' activity times represented separately. Overlap in activity time kernel densities $(\Delta)$ was determined using nonparametric estimators introduced by Schmid \& Schmidt (2006) between sites on and off trail. 
This coefficient of overlap was compared on a range from 0 (no overlap) to 1 (complete overlap) to gauge the extent that temporal species behaviour differed by camera placement strategy. As recommended by Ridout \& LInkie (2009), species with capture events $<75$ used the $\Delta_{1}$ estimator and species $>75$ used the $\Delta_{4}$ estimator for determining the coefficient of overlapping. Using 5000 smoothed bootstrap samples for each species, 95\% confidence intervals for overlap coefficients were also calculated (Meredith \& Ridout, 2014). The Watson's two-sample test of homogeneity was then employed for determining differences in mean angle or angular variance of circular data. This was used to test for significant differences between the on and off trail density functions. Time of video capture data was converted to circular distributions in radians and run through the Watson's two-sample test using the "circular" package in R (Lund et al., 2017). This test creates a critical value based on the desire significance value ( 0.05 for this analysis) from which to compare against the analysis output $\left(U^{2}\right) . A U^{2}$ of a greater value than the critical value suggests a $p$-value lower than 0.05 , the null hypothesis is rejected, and the two kernel densities are considered significantly different.

\subsection{Results}

Camera trap data was collected across 114 camera trap sites (57 paired locations), with a total of 9,928 camera trap nights (average of 174 nights with a range between 28 and 706 combined trap nights per pair location) recorded between August of 2017 and April of 2020. Total trap nights varied between stations due to theft or malfunctions in hardware or positioning, and activity times of camera pairs were trimmed accordingly to only reflect their new overlapping activity. The minimum camera activity of 28 combined trap nights occurred only for one pair and was seen as an acceptable length to allow potential detections for all species in the area. Average distance between on and off trail cameras was 49.6 meters apart with a range between 25 and 75 meters. This range in distance between paired cameras was also viewed as an acceptable distance for maintaining spatial dependence. 


\section{Species richness}

Across all camera sites, 37 terrestrial animal species were recorded with an additional 8 where captures could not be identified to a species level. Cameras placed on trail across the entire field site captured 33 unique species compared to the 36 species found off trail. One species, Horsfield's tarsier (Cephalopachus bancanuswere), was only found by cameras placed on trails. Four species, the otter civet (Cynogale bennettii), the plantain squirrel (Callosciurus notatus), the large ground treeshrew (Tupaia tana), and the Bornean bay cat (Pardofelis badia) were only found by cameras placed off trails. Between on and off trail camera sites, the Wilcoxon signed-rank test showed no significant differences for species richness means (5.66 vs. $5.2, p$-value $=0.73$ ). Shannonwiener diversity index values were slightly higher on trail $(H=2.81)$ compared to off trail $(H=2.68)$, with J' evenness index values proving the inverse: 0.76 for on trail cameras and 0.80 for off trail cameras. Due to overlapping confidence intervals, the accumulation of new species was at no point significantly different between placement strategies during the study period (Figure 3.1).

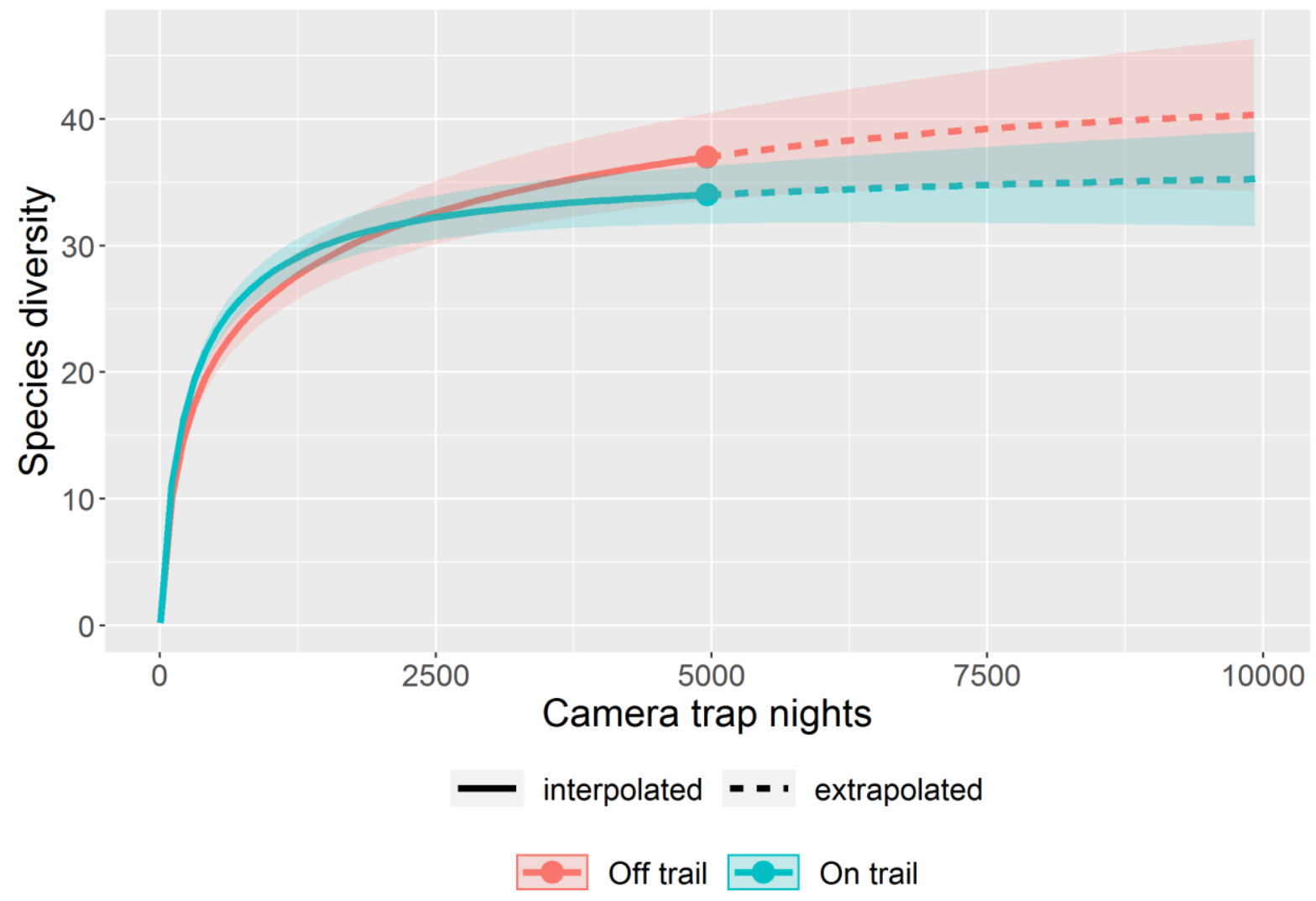

Figure 3.1: Species richness accumulation curve for cameras placed selectively on trails (blue elements) and randomly off trail (red elements). Shaded bands represent 95\% confidence intervals with dots representing the total sample effort per placement strategy (4,964 camera trap nights). Interpolated (solid) and extrapolated (dashed) lines were calculated from the real sample effort using 500 bootstrap iterations with replacement. 


\section{Relative abundance indices}

Total on trail independent captures were $9 \%$ greater than off trail, with no significant difference in mean RAls between camera placement strategies on a community level. For all speciesspecific records, 19 had higher mean RAls on trail-based cameras, 14 had higher mean RAls on offtrail cameras, and 4 had equal RAls between the two placement strategies (Table 3.2). Six species exhibited a significant difference in mean RAls according to the Wilcoxon rank-sign test. Five of the six species had significantly greater mean RAls on trails: T. kanchil, V. tangalunga, H. brachyuran, $N$. diardi, and M. flavigula. Only $T$. dorsalis had a significantly lower mean RAl on trails. Although not an individual species, records for Muridae spp. also had significantly lower mean RAls on trail systems. 
Table 3.2: Mean relative abundance indices (RAls), RAl standard deviations in parentheses, and independent captures for all terrestrial species captured within the study site. Wilcoxon rank-sign tests were run for mean RAls between on and off-trail cameras. Species with a significant difference in mean RAls ( $p$-value $<0.05)$ are marked in bold.

\begin{tabular}{|c|c|c|c|c|c|c|c|c|c|}
\hline \multirow{2}{*}{$\begin{array}{l}\text { Sp. } \\
\text { code }\end{array}$} & \multirow{2}{*}{ Scientific name } & \multirow[t]{2}{*}{ Family } & \multirow[t]{2}{*}{ Common name } & \multicolumn{2}{|c|}{ On trail cameras } & \multicolumn{2}{|c|}{ Off trail cameras } & \multirow[t]{2}{*}{ p-value } & \multirow{2}{*}{$\begin{array}{l}\text { Total } \\
\text { capture }\end{array}$} \\
\hline & & & & Mean RAI & $\begin{array}{l}\text { Ind. } \\
\text { captures }\end{array}$ & Mean RAl & $\begin{array}{l}\text { Ind. } \\
\text { captures }\end{array}$ & & \\
\hline ALL & - & - & All species & 24.09 (32.24) & 1196 & $21.98(31.82)$ & 1091 & $>0.10$ & 2287 \\
\hline $\mathrm{BP}$ & Sus barbatus & Suidae & Bearded pig & $4.51(9.20)$ & 224 & $4.81(13.32)$ & 239 & $>0.05$ & 463 \\
\hline $\mathrm{KCL}$ & Tragulus kanchil & Tragulidae & Lesser mouse deer & $4.69(7.82)$ & 233 & $2.16(4.37)$ & 107 & $<0.05$ & 340 \\
\hline TKM & Muridae spp. & Muridae & Mouse or rat sp. & $1.75(5.00)$ & 87 & $4.83(9.44)$ & 240 & $<0.05$ & 327 \\
\hline TA & Viverra tangalunga & Viverridae & Malay civet & $2.16(5.35)$ & 107 & $0.81(3.59)$ & 40 & $<0.05$ & 147 \\
\hline $\mathrm{LI}$ & Trichys fasciculata & Hystricidae & Long-tailed porcupine & $0.89(3.32)$ & 44 & $0.97(3.84)$ & 48 & $>0.10$ & 92 \\
\hline BDM & Muntiacus atherodes & Cervidae & Bornean yellow muntjac & $0.83(2.16)$ & 41 & $1.01(2.47)$ & 50 & $>0.10$ & 91 \\
\hline AHB & Lophura ignita & Phasianidae & Crested fireback & $1.05(3.30)$ & 52 & $0.60(2.80)$ & 30 & $>0.05$ & 82 \\
\hline $\mathrm{BD}$ & Muntiacus muntjak & Cervidae & Southern red muntjac & $0.66(2.11)$ & 33 & $0.73(2.02)$ & 36 & $>0.10$ & 69 \\
\hline WP & Rollulus rouloul & Phasianidae & Green wood partridge & $0.60(2.44)$ & 30 & $0.73(2.81)$ & 36 & $>0.10$ & 66 \\
\hline SQT & Lariscus insignis & Sciuridae & $\begin{array}{l}\text { Three-striped ground } \\
\text { squirrel }\end{array}$ & $0.44(1.44)$ & 22 & $0.83(5.26)$ & 41 & $>0.05$ & 63 \\
\hline LA & Hystrix brachyura & Hystricidae & Malayan porcupine & $0.93(3.52)$ & 46 & $0.32(2.91)$ & 16 & $<0.05$ & 62 \\
\hline KAB & Tragulus napu & Tragulidae & Greater mouse deer & $0.58(3.74)$ & 29 & $0.54(2.71)$ & 27 & $>0.10$ & 56 \\
\hline RW & Argusuanus argus & Phasianidae & Argus pheasant & $0.56(1.87)$ & 28 & $0.52(1.84)$ & 26 & $>0.10$ & 54 \\
\hline LSM & Hemigalus derbyanus & Viverridae & Banded palm civet & $0.52(3.83)$ & 26 & $0.42(1.26)$ & 21 & $>0.10$ & 47 \\
\hline YT & Martes flavigula & Mustelidae & Yellow-throated marten & $0.64(3.14)$ & 32 & $0.10(0.85)$ & 5 & $<0.05$ & 37 \\
\hline ER & Echinosorex gymnura & Erinaceidae & Moonrat & $0.32(1.59)$ & 16 & $0.32(1.13)$ & 16 & $>0.10$ & 32 \\
\hline MD & Neofelis diardi & Felidae & Clouded leopard & 0.54 (3.59) & 27 & $0.06(0.31)$ & 3 & $<0.05$ & 30 \\
\hline $\mathrm{MN}$ & Herpestes brachyurus & Herpestidae & Short-tailed mongoose & $0.26(2.50)$ & 13 & $0.34(1.90)$ & 17 & $>0.10$ & 30 \\
\hline TPL & Tupaia longipes & Tupaiidae & Plain treeshrew & $0.22(0.72)$ & 11 & $0.18(1.52)$ & 9 & $>0.10$ & 20 \\
\hline TPH & Tupaia dorsalis & Tupaiidae & Striped treeshrew & 0.06 & 3 & 0.30 & 15 & $<0.05$ & 18 \\
\hline
\end{tabular}




\begin{tabular}{|c|c|c|c|c|c|c|c|c|c|}
\hline \multirow{2}{*}{$\begin{array}{l}\text { Sp. } \\
\text { code }\end{array}$} & \multirow{2}{*}{ Scientific name } & \multirow{2}{*}{ Family } & \multirow[t]{2}{*}{ Common name } & \multicolumn{2}{|c|}{ On trail cameras } & \multicolumn{2}{|c|}{ Off trail cameras } & \multirow[t]{2}{*}{ p-value } & \multirow{2}{*}{$\begin{array}{l}\text { Total } \\
\text { captures }\end{array}$} \\
\hline & & & & Mean RAI & $\begin{array}{l}\text { Ind. } \\
\text { captures }\end{array}$ & Mean RAI & $\begin{array}{l}\text { Ind. } \\
\text { captures }\end{array}$ & & \\
\hline AHM & $\begin{array}{l}\text { Lophura } \\
\text { erythrophthalma }\end{array}$ & Phasianidae & Crestless fireback & 0.20 & 10 & 0.16 & 8 & $>0.10$ & 18 \\
\hline BGC & Carpococcyx radiatus & Cuculidae & Bornean ground-cuckoo & 0.20 & 10 & 0.10 & 5 & $>0.10$ & 15 \\
\hline$P C$ & $\begin{array}{l}\text { Paradoxurus } \\
\text { hermaphroditus }\end{array}$ & Viverridae & Common palm civet & 0.20 & 10 & 0.08 & 4 & $>0.10$ & 14 \\
\hline TG & $\begin{array}{l}\text { Rheithrosciurus } \\
\text { macrotis }\end{array}$ & Sciuridae & Tufted ground squirrel & 0.16 & 8 & 0.06 & 3 & $>0.10$ & 11 \\
\hline $\mathrm{BA}$ & Varanus salvator & Varanidae & Asian water monitor & 0.10 & 5 & 0.10 & 5 & $>0.10$ & 10 \\
\hline SB & Helarctos malayanus & Ursidae & Sun bear & 0.06 & 3 & 0.10 & 5 & $>0.10$ & 8 \\
\hline TPP & Tupaia spp. & Tupaiidae & Unknown treeshrew & 0.06 & 3 & 0.10 & 5 & $>0.10$ & 8 \\
\hline BDX & Muntiacus spp. & Cervidae & Unknown barking deer & 0.08 & 4 & 0.08 & 4 & $>0.10$ & 8 \\
\hline KBL & Felis bengalensis & Felidae & Leopard cat & 0.12 & 6 & 0.04 & 2 & $>0.10$ & 8 \\
\hline $\mathrm{CIX}$ & Viverridae spp. & Viverridae & Unknown civet & 0.12 & 6 & 0.02 & 1 & $>0.10$ & 7 \\
\hline MLK & Paguma larvata & Viverridae & Masked palm civet & 0.06 & 3 & 0.08 & 4 & $>0.10$ & 7 \\
\hline TL & Manis javanica & Manidae & Sunda pangolin & 0.08 & 4 & 0.04 & 2 & $>0.10$ & 6 \\
\hline $\mathrm{BI}$ & Arctictis binturong & Viverridae & Binturong & 0.10 & 5 & 0.02 & 1 & $>0.10$ & 6 \\
\hline LS & Prionodon linsang & Viverridae & Banded linsang & 0.04 & 2 & 0.02 & 1 & $>0.10$ & 3 \\
\hline MBB & Cynogale bennettii & Viverridae & Otter civet & 0.00 & 0 & 0.06 & 3 & $>0.10$ & 3 \\
\hline KAX & Tragulus spp. & Tragulidae & Unknown mouse deer & 0.02 & 1 & 0.04 & 2 & $>0.10$ & 3 \\
\hline HD & Pardofelis marmorata & Felidae & Marbled cat & 0.02 & 1 & 0.02 & 1 & $>0.10$ & 2 \\
\hline $\mathrm{AHX}$ & Lophura spp. & Phasianidae & Unknown forest chicken & 0.02 & 1 & 0.02 & 1 & $>0.10$ & 2 \\
\hline TPT & Tupaia tana & Tupaiidae & Large ground treeshrew & 0.00 & 0 & 0.02 & 1 & $>0.10$ & 1 \\
\hline KBT & Pardofelis badia & Felidae & Bornean bay cat & 0.00 & 0 & 0.02 & 1 & $>0.10$ & 1 \\
\hline SQX & Sciuridae spp. & Sciuridae & Unknown squirrel & 0.02 & 1 & 0.00 & 0 & $>0.10$ & 1 \\
\hline
\end{tabular}




\begin{tabular}{|c|c|c|c|c|c|c|c|c|c|}
\hline \multirow{2}{*}{$\begin{array}{l}\text { Sp. } \\
\text { code }\end{array}$} & \multirow{2}{*}{ Scientific name } & \multirow{2}{*}{ Family } & \multirow[t]{2}{*}{ Common name } & \multicolumn{2}{|c|}{ On trail cameras } & \multicolumn{2}{|c|}{ Off trail cameras } & \multirow[t]{2}{*}{ p-value } & \multirow{2}{*}{$\begin{array}{l}\text { Total } \\
\text { captures }\end{array}$} \\
\hline & & & & Mean RAI & $\begin{array}{l}\text { Ind. } \\
\text { captures }\end{array}$ & Mean RAI & $\begin{array}{l}\text { Ind. } \\
\text { captures }\end{array}$ & & \\
\hline TS & $\begin{array}{l}\text { Cephalopachus } \\
\text { bancanuswere }\end{array}$ & Tarsiidae & Horsfield's tarsier & 0.02 & 1 & 0.00 & 0 & $>0.10$ & 1 \\
\hline LSH & Mustela spp. & Mustelidae & Unknown mustelid & 0.00 & 0 & 0.02 & 1 & $>0.10$ & 1 \\
\hline $\mathrm{CN}$ & Callosciurus notatus & Sciuridae & Plantain squirrel & 0.00 & 0 & 0.02 & 1 & $>0.10$ & 1 \\
\hline
\end{tabular}




\section{Occupancy model effects and estimates}

Of the 45 terrestrial species records, including records where species could not be identified to a species level, $18 \mathrm{had}$ an acceptable sample size that were used in occupancy models. A cut-off of 30 capture events was determined as the appropriate number for modelling detection probability as capture events for the entire community exhibited a natural fall-off at 30 captures, and an acceptable goodness of fit ( $\hat{c}$ of less than 2 ) was not possible for species with lower than 30 independent camera records (Fig. 3.2) (MacKenzie \& Bailey, 2004). Additional primate species (Pongo pygmaeus and Macaca nemestrina) also possessed more than 30 independent capture events each, although they were excluded from this study due to their primarily arboreal behaviour.

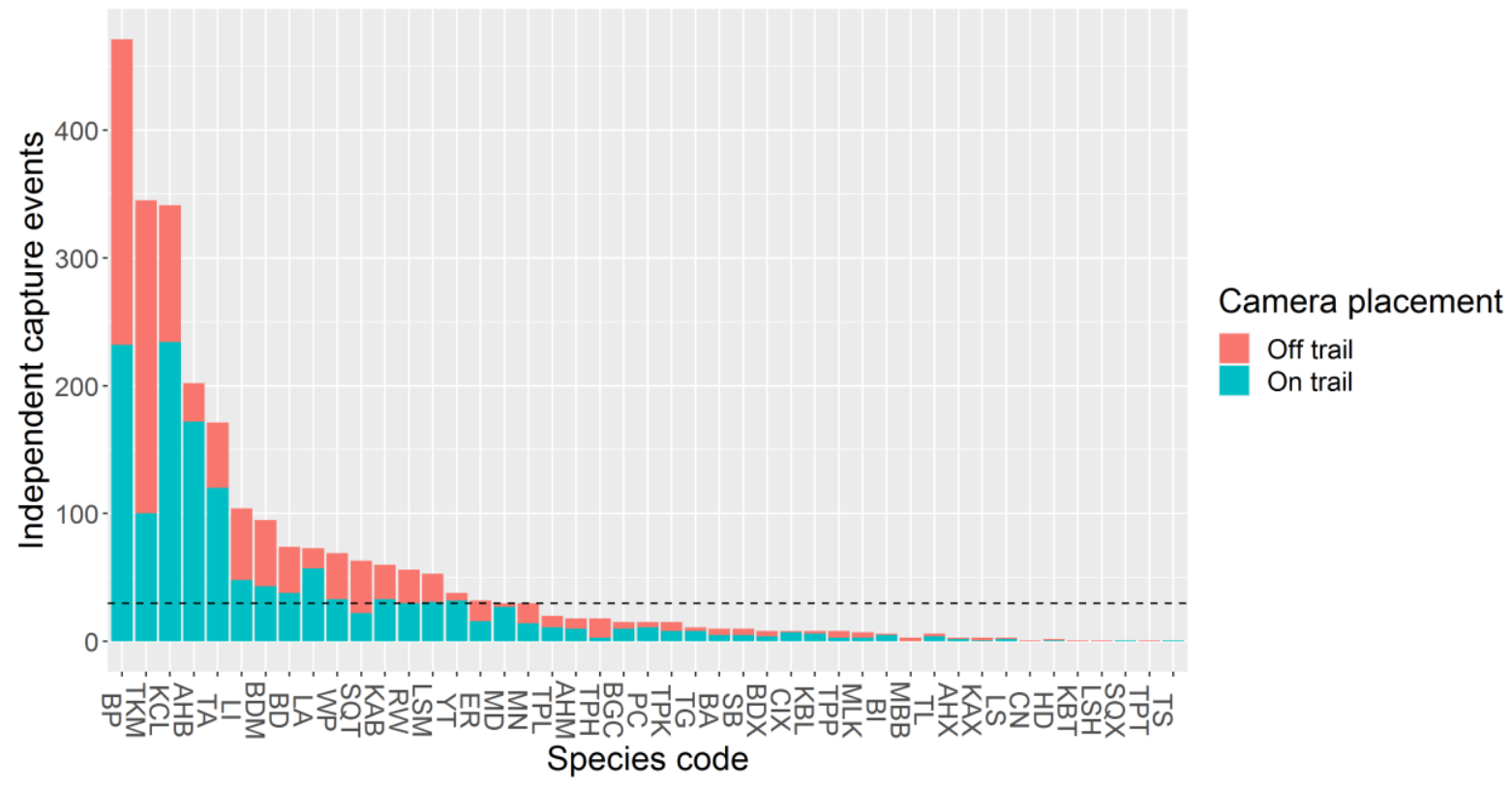

Figure 3.2: Species capture events with a 60 minute independence buffer. Note that vertical axis is on a logarithmic scale. Blue shaded area is for capture events on trail, and red shaded area denotes off trail capture events. The horizontally dashed line indicates 30 independent capture events: the cut-off for inclusion in the model framework.

Of the 18 species modelled, 9 showed camera placement as a strong explanatory variable for detection (Table 3.3). Of the 9 species whose detection was described by camera placement, 6 showed a positive relationship with on-trail camera placement: T. kanchil, L. ignata, V. tangalunga, H. brachyura, M. flavigula, and N. diardi. Muridae spp., L. insignis, and S. barbutus showed negative relationships with on-trail camera placement and $p$. The species deemed to have a strong influence 
on detection probability by their AICc weights also have strong overlap with those found to be significant by their mean RAls in Table 3.2, with exception of L. insignis, L. ignata, and S. barbutus; which did not have low enough $p$-values for their RAls to be deemed significantly different.

Alternative covariates also applied a strong influence on $p$ with select species (Table 3.3). Muridae spp., H. brachyura, L. insignis, S. barbutus, and H. derbyanus all had higher detection probabilities during the wet season, while $A$. argus and E. gymnura displayed higher detection probabilities in the dry season. Nine of the eighteen species modelled showed search effort to have an influence on detection probability, and all species detection probability displayed a positive response to increased search effort. Habitat type was the most impactful covariate of those modelled for $p$, with twelve out of the eighteen species' detection probabilities showing an AIC weight $>=0.70$. N. diardi, M. flavigula, M. atherodes, and M. muntjak displayed higher detection probability in upland habitat, while T. kanchil, S. barbutus, L. ignata, A. argus, R. rouloul, T. fasciculata, T. napu, and E. gymnura had higher estimates of $p$ in lowland habitats. Only five species included human presence as a function of local occupancy in their top models, and of these five, $R$. rouloul (0.77) and T. napu (0.81) displayed high AIC weights. Both of these species' beta values signified lower detection probability with increased human presence. 
Table 3.3: All modelled species, their associated top models with all covariates for $p$ (global), the number of parameters for each model (K), the $\triangle A I C c$ for top models including and excluding camera placement as a function for $p$, and AICc weights for each $p$ covariate. (+) and (-) indicates the direction of the effect on detection probability. Camera placement covariates were modelled with the on trail cameras as the reference value. Season and habitat covariates were modelled with the wet season and upland habitat as the reference values respectively. AlCc weights equalling or above 0.70 are bolded.

\begin{tabular}{|c|c|c|c|c|c|c|c|}
\hline Species & Top model & K & $\triangle \mathrm{AICC}$ & $\begin{array}{l}\text { Placement } \\
\text { AIC wgt }\end{array}$ & $\begin{array}{l}\text { Search effort } \\
\text { AIC wgt }\end{array}$ & $\begin{array}{l}\text { Seasons } \\
\text { AIC wgt }\end{array}$ & $\begin{array}{l}\text { Habitat AIC } \\
\text { wgt }\end{array}$ \\
\hline Muridae spp. & $\Psi(.) \Theta($ human presence)p(global) & 8 & 21.88 & $1.00(-)$ & $0.99(+)$ & $0.70(+)$ & $0.39(+)$ \\
\hline Tragulus kanchil & $\Psi(.) \Theta() p.($ global) & 7 & 16.74 & $1.00(+)$ & $0.98(+)$ & $0.34(-)$ & $0.99(-)$ \\
\hline Neofelis diardi & $\Psi$ (habitat) $\Theta() p.($ global) & 8 & 15.65 & $1.00(+)$ & $0.27(+)$ & $0.27(-)$ & $0.83(+)$ \\
\hline Hystrix brachyura & $\Psi(.) \Theta() p.($ global) & 7 & 12.81 & $1.00(+)$ & $0.80(+)$ & $0.74(+)$ & $0.44(-)$ \\
\hline Martes flavigula & $\Psi$ (habitat) $\Theta() p.($ global) & 8 & 13.06 & $1.00(+)$ & $0.31(+)$ & $0.30(-)$ & $0.97(+)$ \\
\hline Viverra tangalunga & $\Psi(.) \Theta() p.($ global) & 7 & 8.88 & $0.99(+)$ & $0.58(+)$ & $0.27(+)$ & $0.47(+)$ \\
\hline Lariscus insignis & $\Psi$ (habitat) $\Theta() p.($ global $)$ & 8 & 4.02 & $0.88(-)$ & $0.44(+)$ & $0.35(+)$ & $0.31(-)$ \\
\hline Sus barbatus & $\Psi(.) \Theta() p.($ global) & 7 & 2.9 & $0.81(-)$ & $0.63(+)$ & $0.80(+)$ & $0.97(-)$ \\
\hline Lophura ignita & $\Psi(.) \Theta() p.($ global) & 7 & 2.58 & $0.78(+)$ & $0.97(+)$ & $0.95(+)$ & $0.99(-)$ \\
\hline Muntiacus atherodes & $\Psi(.) \Theta() p.($ global) & 7 & 1.86 & $0.38(+)$ & $0.95(+)$ & $0.61(+)$ & $0.83(+)$ \\
\hline Hemigalus derbyanus & $\Psi$ (habitat) $\Theta() p.($ global $)$ & 8 & 1.13 & $0.36(+)$ & $0.67(+)$ & $0.74(+)$ & $0.57(-)$ \\
\hline Argusuanus argus & $\Psi$ (habitat) $\Theta() p.($ global $)$ & 8 & 1.99 & $0.27(+)$ & $0.93(+)$ & $0.77(-)$ & $0.75(-)$ \\
\hline Rollulus rouloul & $\Psi(.) \Theta($ human presence)p(global) & 8 & 1.48 & $0.33(-)$ & $0.91(+)$ & $0.58(+)$ & $0.99(-)$ \\
\hline Herpestes brachyurus & $\Psi(.) \Theta() p.($ global) & 7 & 1.61 & $0.31(-)$ & $0.28(+)$ & $0.69(-)$ & $0.27(-)$ \\
\hline Trichys fasciculata & $\Psi(.) \Theta() p.($ global) & 7 & 1.91 & $0.28(-)$ & $0.99(+)$ & $0.31(+)$ & $0.93(-)$ \\
\hline Muntiacus muntjak & $\Psi(.) \Theta($ human presence)p(global) & 8 & 1.97 & $0.27(+)$ & $0.87(+)$ & $0.27(-)$ & $0.95(+)$ \\
\hline Tragulus napu & $\Psi(.) \Theta($ human presence)p(global) & 8 & 2 & $0.27(-)$ & $0.51(+)$ & $0.27(+)$ & $0.95(-)$ \\
\hline Echinosorex gymnura & $\Psi$ (habitat) $\Theta($ human presence)p(global) & 9 & 2 & $0.27(-)$ & $0.42(+)$ & $0.98(-)$ & $0.95(-)$ \\
\hline
\end{tabular}




\section{Detection percent changes and detectability curves}

The percent change in estimated detection probability between on and off trail camera positions was also measured for each species where camera placement was deemed important by AIC weight (Table 3.4). Although all species in Table 3.4 exhibited a strong influence in terms of their AICc weight, large standard errors caused overlap in the calculated percent changes in $p$ between camera for the H. brachyura, L. ignata, and S. barbutus. Muridae spp. displayed the smallest 'significant' percent change $(-47.88 \%)$ in detection probability when comparing detection probability for off trail cameras to on trail cameras. The most sizeable difference was found with N. diardi, where on trail detection probability experienced a more than $900 \%$ increase compared to off trail cameras.

Table 3.4: Percent change (+ or -) in detection probability for on vs off trail cameras by species. Estimates for $p$ were calculated using the species-specific top model used in determining camera placement AIC weights. Only species are shown where camera placement was deemed significant. The median value for search effort during the wet season was used to predict $p$ for on vs. off trail camera placements. SE = standard error for estimates of $p .{ }^{*}$ signifies species with overlapping detection probability $S E$.

\begin{tabular}{|c|c|c|c|}
\hline \multirow[t]{2}{*}{ Species } & \multicolumn{2}{|c|}{ Top model estimates of $p$} & \multirow{2}{*}{$\begin{array}{l}\% \text { Change in detection } \\
\text { probability }\end{array}$} \\
\hline & On-trail cameras & Off-trail cameras & \\
\hline Muridae spp. & $0.118(0.020)$ & $0.227(0.033)$ & -47.88 \\
\hline Tragulus kanchil & $0.378(0.052)$ & $0.230(0.036)$ & 64.59 \\
\hline Viverra tangalunga & $0.124(0.017)$ & $0.070(0.012)$ & 77.33 \\
\hline Lophura ignita * & $0.369(0.093)$ & $0.238(0.066)$ & 55.06 \\
\hline Hystrix brachyura * & $0.153(0.100)$ & $0.051(0.035)$ & 199.22 \\
\hline Neofelis diardi & $0.087(0.045)$ & $0.009(0.007)$ & 904.60 \\
\hline Martes flavigula & $0.287(0.059)$ & $0.062(0.028)$ & 361.58 \\
\hline Lariscus insignis & $0.121(0.030)$ & $0.235(0.043)$ & -48.64 \\
\hline Sus barbatus * & $0.174(0.034)$ & $0.227(0.043)$ & -23.38 \\
\hline
\end{tabular}

The minimum survey effort necessary to detect a species at least once within the research site with 95\% confidence was calculated using Eq. 1 and the estimated detection probability from their respective top models listed in Table 3.4. For species whose AICc weights were found to be important for camera placement strategies in Table 3.4, large divergences in required survey effort became apparent (Fig. 3.3). Disparities in survey effort between placement type followed the same pattern as the percent changes for each species, with differences in survey effort increasing 
proportional to percent change. For some species, such as S. barbutus, only a difference of 20 camera trap nights existed between placement strategies. For $N$. diardi, detecting an individual off trail with $95 \%$ confidence would take almost an order of magnitude longer (on trail = 173 trap nights, off trail $=1721$ trap nights). Although all species included in Figure 3.3 were deemed important in accordance with their AIC weights, L. ignita, H. brachyura, and S. barbutus detection probabilities had overlapping confidence intervals that invalidated the interpretation of differences in search effort. 

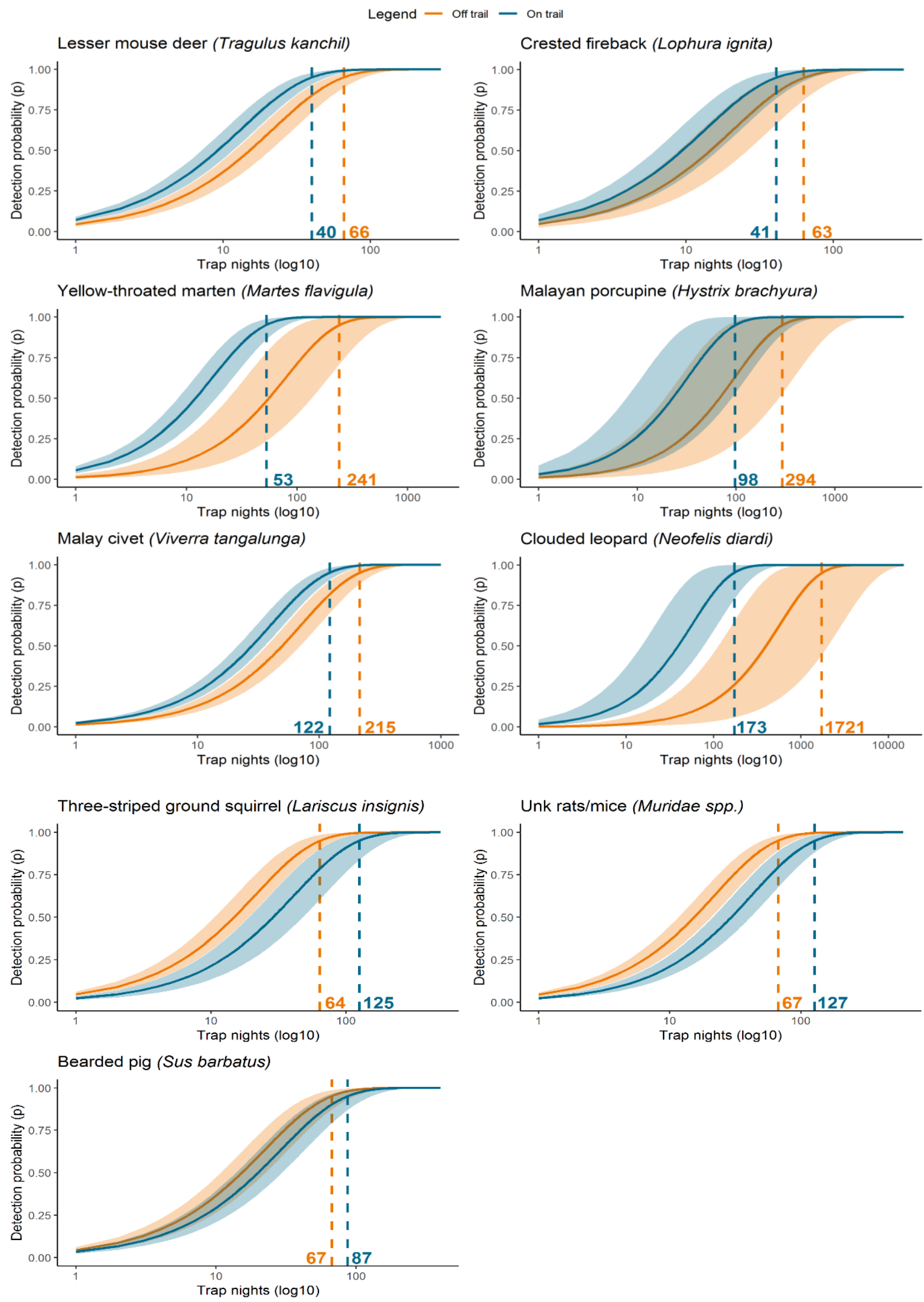

Figure 3.3: Species detection probability curves based on top model detection probability estimates and minimum necessary trap nights for $95 \%$ detection (dotted lines and annotations along the $x$ axis). Note that the $x$-axis is in log scale and is not the same across plots. 


\section{Taxonomic and dietary trends}

Camera placement beta estimates were ordered by taxonomic group and by diet to highlight potential ecological justifications for detection probability trends. Ordering species by diet and by taxa was decided a priori, before it was discovered that limited sample sizes would lead to the omission of many terrestrial species from these models. Apart from the felid taxonomic group, whose sole member is $N$. diardi, no taxonomic group expressed a substantial influence for camera placement on $p$ amongst all of their members (Fig. 3.4). However, every taxonomic group exhibited at least one member species with a notably high camera placement weight. Similarly, no dietary category exhibited exclusively strong AIC weights for camera placement in either direction. For the terrestrial community as a whole, on trail camera placement had a more extreme influence on detection probability in terms of the number of species and effect size. See Appendix 1 for a table of each group by species and their associate camera placement coefficient estimates.
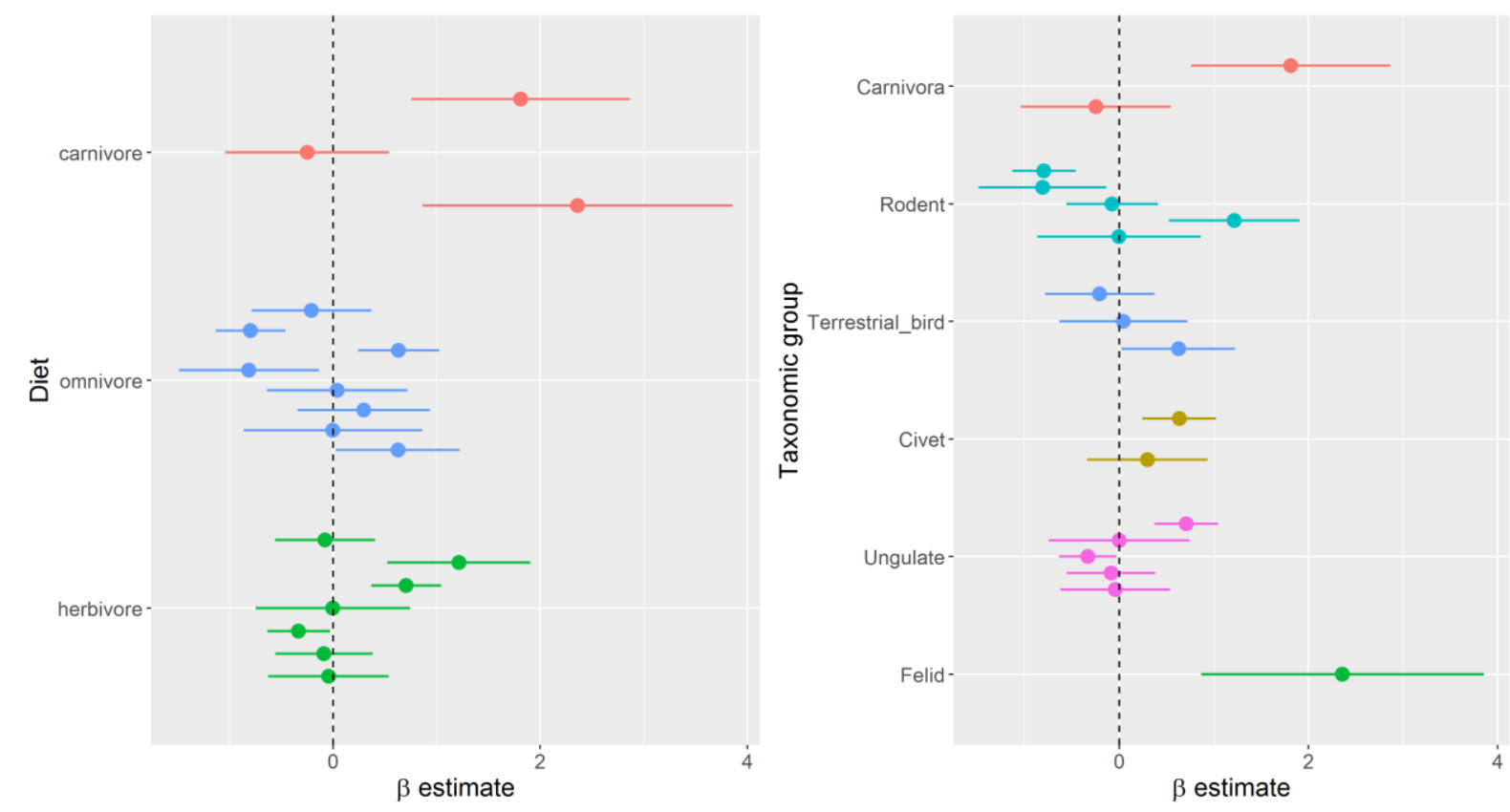

Figure 3.4: On-trail beta estimates for detection probability grouped and colour coordinated by diet (left) and taxonomic group (right). The camera placement covariate was programmed with on trail cameras as the reference value: positive estimates suggest higher on trail detection and negative suggests higher off trail detection. Error bars indicate confidence intervals (0.95). Dashed line indicates where $b$ estimates $=0$. 


\section{Body weight and trail detectability}

The vast majority of the terrestrial community were below $20 \mathrm{kgs}$ in mean body weight, and the outlier S. barbutus data point greatly unbalanced the range of average body size in the subsequent correlation plots. As a community, there was no significant relationship between body size and camera placement detection probability $\beta$ values $(R=0.37, p$-value $=0.13)$ (Fig. 3.5). Of the three diet classes, the omnivore group showed a positive significant correlation between camera placement detection probability $\beta$ values and body weight $(R=0.9, p$-value $=0.0011)$ (Fig. 3.6). The herbivore group showed a moderately negative, but insignificant correlation $(R=-0.64, p$-value $=$ 0.14). The carnivore group consisted of only 3 species, and consequently had a sample size inappropriate for this analysis. Because of the limited selection in modellable species, the felid, civet, carnivora, terrestrial bird, and treeshrew groups only contained 1-3 species each and were excluded from the correlation tests. For the included rodent and ungulate taxonomic groups, neither exhibited a significant negative or positive relationship with body size (Fig. 3.6). See Appendix 1 for average weights.

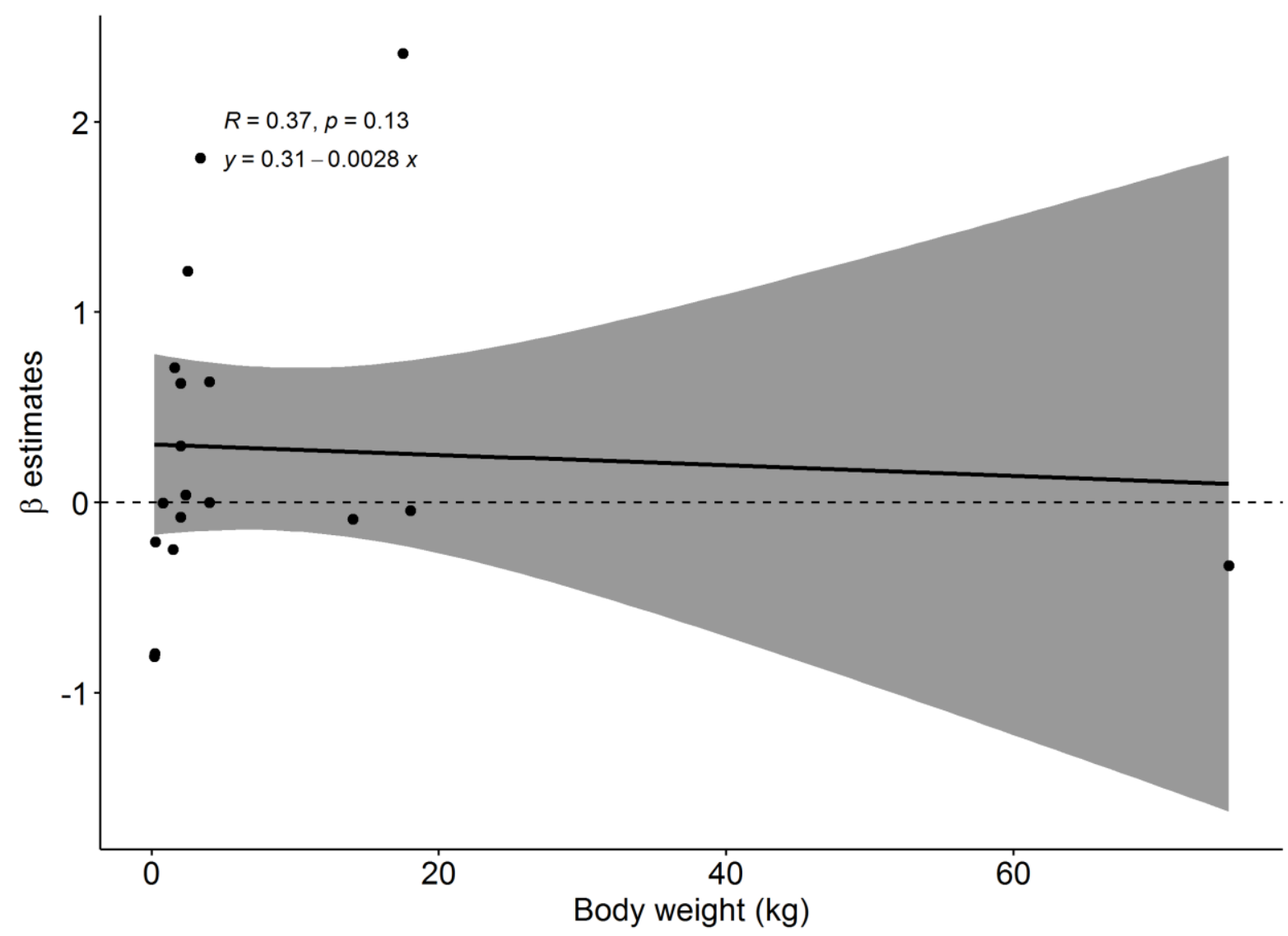

Figure 3.5: Body weight vs. camera placement detection probability 6 estimates for the entire modelled community. Features the associated Spearman's correlation coefficient, $p$-values, and regression line equation. Shaded area represents $95 \%$ confidence interval for the regression line. Dashed line indicates where $B$ estimates $=0$. 


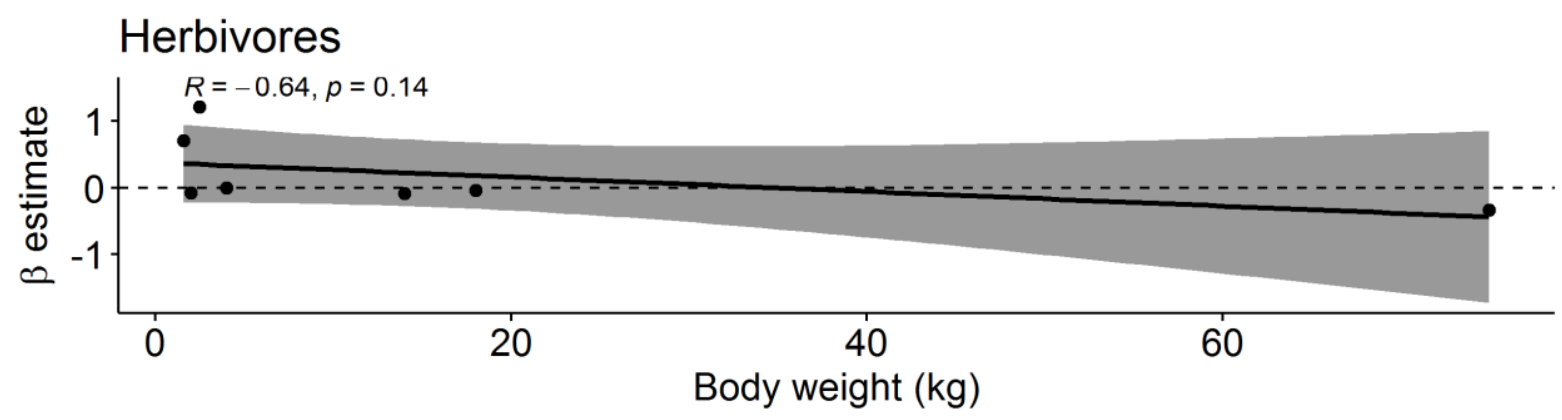

\section{Omnivores}

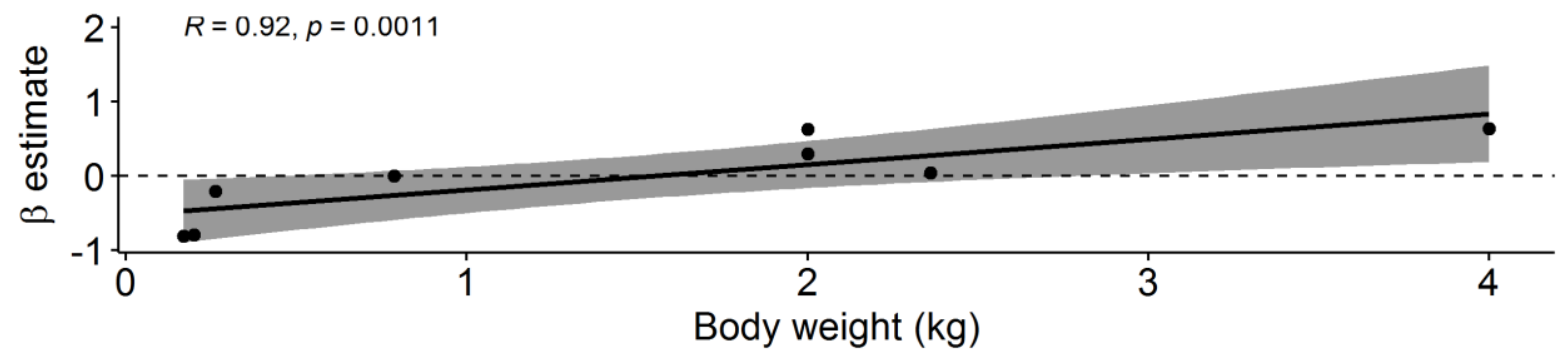

\section{Rodents}

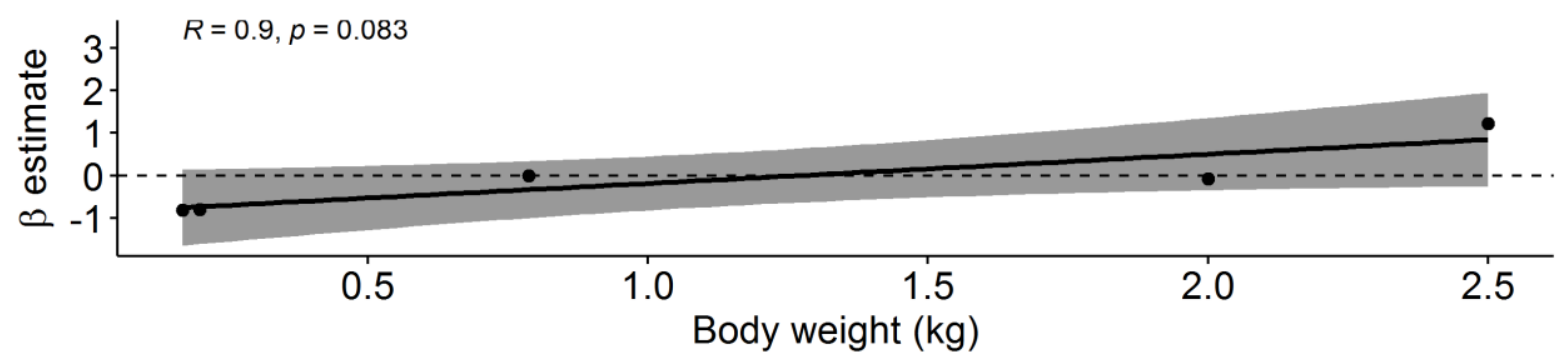

\section{Ungulates}

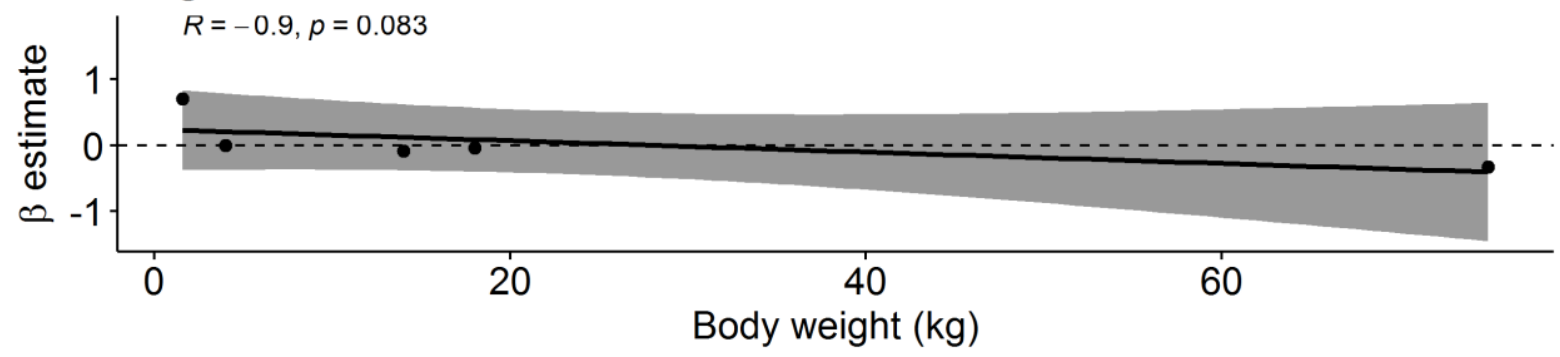

Figure 3.6: Body weight vs. camera placement detection probability 6 estimates by diet (top 2 plots) and by taxa (bottom 2 plots) with associated Spearman's correlation coefficients and p-values. Note that $x$ and $y$ axes are not constant across plots. Shaded area represents $95 \%$ confidence interval for the regression line. Dashed line indicates where $B$ estimates $=0$. 


\section{Temporal variation by camera placement}

Three of the eighteen species presented statistically significant differences between activity patterns on and off trail. These species included; S. barbutus $\left(\Delta_{1}=0.82, U^{2}=0.3549, p<0.01\right), T$. kanchil $\left(\Delta_{1}=0.84, U^{2}=0.1933, p<0.05\right)$, and $M$. atherodes $\left(\Delta_{4}=0.72, U^{2}=0.2265, p<0.05\right)$ (Table 3.5). All of these species belong to the ungulate taxonomic group described previously. All three of these species experienced shifts in peak activity, but largely retained the shape of their activity curves. T. kanchil exhibited crepuscular activity with bimodal peaks around dawn and dusk, however its nocturnal activity on trail was dramatically higher. Similarly, S. barbutus had slightly higher, more consistent on trail activity during the night. S. barbutus peak activity also shifted from dusk on trails to dawn off trails. Interestingly, M. atherodes had more distinct diurnal activity on trail, with higher nocturnal activity during the night. All of these differences in activity are visualized in Figure 3.7. See Appendix 2 for the full table of overlap coefficients and Watson test statistics across the community.

Table 3.5: Camera placement sample sizes, overlap coefficient for activity on and off trail ( $\Delta)$, lower and upper 95\% confidence intervals (CI) and Watson's two-sample test $p$-values and respective test statistic $\left(U^{2}\right)$. Watson's test statistic critical value $=0.187$ for $>95 \%$ confidence.

\begin{tabular}{|llllllll|}
\hline Species & $\begin{array}{l}\text { On-trail } \\
\text { sample } \\
\text { size }\end{array}$ & $\begin{array}{l}\text { Off-trail } \\
\text { sample } \\
\text { size }\end{array}$ & $\begin{array}{l}\text { Coefficient of } \\
\text { overlap }(\Delta)\end{array}$ & $\begin{array}{l}\text { Lower } \\
\mathrm{Cl}\end{array}$ & $\begin{array}{l}\text { Upper } \\
\mathrm{Cl}\end{array}$ & p-value & $\begin{array}{l}\text { Test } \\
\text { statistic } \\
\left(\mathrm{U}^{2}\right)\end{array}$ \\
\hline Tragulus kanchil & 233 & 107 & 0.84 & 0.77 & 0.92 & $<0.05$ & 0.1933 \\
\hline Sus barbatus & 224 & 239 & 0.82 & 0.75 & 0.89 & $<0.01$ & 0.3549 \\
\hline $\begin{array}{l}\text { Muntiacus } \\
\text { atherodes }\end{array}$ & 41 & 50 & 0.72 & 0.59 & 0.85 & $<0.05$ & 0.2265 \\
\hline
\end{tabular}



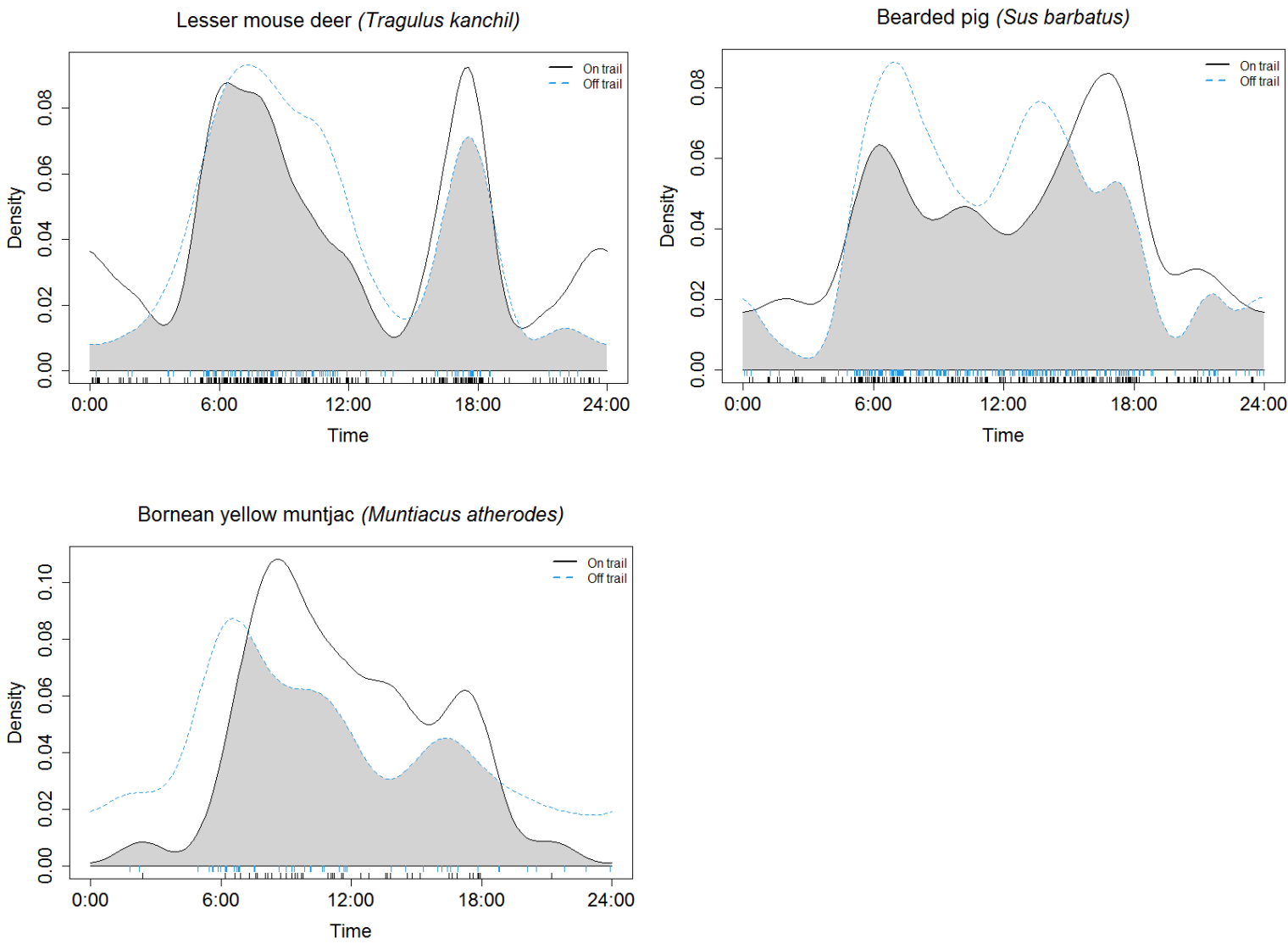

Figure 3.7: Activity patterns over a 24 hour cycle for all species with temporal behaviour deemed significantly different by the Watson's two-sample test. Species activity patterns are compared between on trial (black solid line) and off trail (blue dashed line) with overlap denoted by the grey shaded area.

\subsection{Discussion}

\section{Species richness}

Across a 3 year study period, species richness and composition was only marginally different between camera placements. Species richness declined by $10 \%$ when capturing species on trail (34 unique species) versus off trail ( 37 unique species). Of the 38 unique species recorded in the paired camera design, off trail cameras collected all but C. bancanus, which was recorded only once in 2017 on trail. The species recorded entirely by off trail cameras were also exclusively rare individuals, including the $C$. bennettii, $C$. notatus, $T$. tana, and the famously-reclusive $P$. badia. Based on additional cameras within the CPRS site that were not part of this paired design, only $P$. planiceps was not recorded as a part of this study. As a primarily riparian species (Muul \& Lim, 1970; Wilting et 
al., 2010), it is not surprising that this species escaped detection, as only a small fraction of on or off trail cameras placed in GPNP were in the vicinity of waterways. Similar to overall species richness, mean species richness by camera site was also slightly higher off trail than on, although not significantly according to a Wilcoxon signed-rank test. Although just a small difference in overall species richness between camera placement types was found, even minimal sightings of rare species can have real influences on estimates of species diversity, community composition, abundance, and range extents (Peet, 1974). Amongst other studies comparing species richness across camera placement types, this is the first system where the treatment cameras (on trail in this case) presented lower species richness than the control (off trail) (Cusack et al., 2015; Kolowski \& Forrester, 2017). The higher slope at the beginning of the study period for the on trail camera accumulation curve is indicative of a higher Simpson's diversity index, which is often seen in sample patches that display moderate microhabitat variability as seen in locations where cameras are selectively placed (Lande et al., 2000). Whereas previous studies found accumulation rates to be significantly different between camera trap placement strategies while survey effort was low (Cusack et al., 2015; Kolowski \& Forrester, 2017), at no time during this survey (either in its early or late stages) was this accurate. This suggests that, although total species richness did vary slightly, camera placement does not influence the rate at which new species are recorded within the site. This is likely a result of both camera placements having similar total species richness and overall capture events, both of which influence the shape of accumulation curves (Lande et al., 2000). Although there were no major differences found with species richness apart from minor dissimilarities in species composition, this analysis is one of just a handful looking at species richness between microhabitat camera placement strategies on a community-level (Cusack et al., 2015; Martin et al., 2018).

\section{Relative abundance}

As a community, the difference in relative abundance indices (capture rate $\times 100$ trap nights) between camera placements was small, with a $9 \%$ increase in RAls for cameras placed on trails. Despite the small overall difference in RAls, 6 species as well as the combined mouse and rat group were found to have a significant difference in relative abundances between placement strategies. $N$. diardi and $M$. flavigula displayed the largest divergence, with 9 and 6.4 times the number of on trail relative abundance estimates than those off trail respectively. More modest, but still statistically significant, differences between placement strategies were also found in species with large sample sizes. For some of the most commonly-recorded species, such as T. kanchil, V. tangalunga, and 
Muridae spp.; on versus off-trail RAls ranged between less than half to more than double. Of the significant 7 records, 5 showed higher RAls with on-trail camera placement. Some of the rarest species, despite having noticeable differences in RAls between camera placements, were not deemed significant by the Wilcoxon signed-rank test due to their small sample sizes. Indeed, the species present only on or off trail systems were those with independent capture events $<5$ in total, making it uncertain whether differences in species richness were derived from real differences in detection between camera placements or just random chance encounters of rare species. Although many studies use trail systems to obtain higher detections with felids (Karanth \& Nichols, 1998; Trolle \& Kéry, 2005), observations from this study of the Bornean bay cat are in line with those of Wearn et al. (2013), who suggest that $P$. badia population estimates may be underestimated due to on-trail camera placement preference. A limited knowledge of habitat preference for $P$. badia highlights the importance of using an unbiased camera trap study design to allow for a more diverse selection of microhabitats to be sampled. The fact that relative abundance indices do not account for imperfect detection is already a strong reason to take their estimates guardedly, and the presence of significantly different RAl estimates occurring for common and rare species alike only emphasizes the point. These results suggest that common and rare species alike are sensitive to changes in their relative abundance estimates induced by camera placement

\section{Detection probability from occupancy models}

Based on results from my occupancy models, detection probability was substantially impacted by camera placement strategies for a considerable portion of the community. Similar to the species richness analysis, few studies have explored detection probability across an entire community using a multi-method occupancy model framework (Kolowski \& Forrester, 2017). Of the eighteen species (including Muridae spp.) modelled, nine exhibited a strong response in detection probability between camera placement strategies. Six of these nine species, or a third of the modelled population, demonstrated higher detection probability on trail systems. The magnitude of this effect was made apparent through my detectability curves, in which the differences in survey effort needed to detect a species with $95 \%$ confidence was quantified. It was found that the differences that camera placement creates in necessary survey effort could be overcome relatively quickly for most species. Although all species' detection probabilities that were found to be influenced by camera placement displayed non-trivial percent changes between on and off trail placements, just one month of normal camera operation at this site given its current sampling intensity would be sufficient to eliminate this disparity. For rarer individuals, much larger percent 
changes between on and off camera placement (905\% and 362\% for N. diardi and M. flavigula respectively) translated to a very real inequality in the required survey effort needed to ensure detection.

Alternative explanatory variables of varying influence on detection probability were also tested. As expected, detection probability had a positive relationship with search effort for all modelled species, indicating that the more time a camera was active during a 5-day survey period, the higher the probability of detecting a species. Seasonality also had a similar influence on species detection to on-trail camera placement, as one-third of the modelled population displayed higher detection probability during the 'wet' season. Habitat type had a meaningful impact on species detection for almost three fourths of the species modelled, with the majority of those tested displaying higher detection in lowland habitats. Interestingly, upland habitat displayed higher detectability for N. diardi, M. flavigula, and the two muntjac species; both of which are known prey of the former two predators (anecdotal accounts exists of martens taking down juvenile deer) (Phillipps \& Phillipps, 2016). Habitat type clearly had a strong effect on $p$, and future analyses in this study site would undoubtedly benefit from additional description of camera sites. Covariates that quantify particular habitat characteristics, such as stem density, canopy coverage, basal area coverage, slope, distance of maximum visibility, and trail width or quality would likely aid in refining the effects of camera placement on detection probability even more. Although not modelled for detection probability, increased human presence led to lower local occupancy for greater mouse deer and green wood pheasant. The average distance of 50 meters between paired on and off trail cameras may have allowed human presence at either camera position affect the other for especially sensitive species. From an analytical standpoint, using the total numbers of human captures per camera as a representation of human activity per camera site may not provide the temporal resolution necessary to gauge how human presence affects local species occupancy. The time elapsed since last human detection may provide an alternative means of measuring human influence on species local occupancy for on and off-trail cameras.

Although no taxonomic or dietary group exhibited completely important detection differences by camera placement, two of the three species with a primarily carnivorous diet displayed distinctly higher detection probability on trail than randomly off trail. These findings are supported by other studies that point toward higher detection probability for carnivorous species on trails and roads (Sollmann et al., 2012; Wysong et al., 2020). The ungulate group had detection probabilities that were generally unaffected by camera placement, with the exception of S. barbutus off trail and $T$. kanchil on trail. Other studies have identified trends in lower prey detections on trail with ungulates (Kays et al., 2009) and beavers (Severud et al., 2011) possibly in response to 
increased predator detections on trails. This may be a potential explanation for lower S. barbutus detections on trails, as they are a known prey species of $N$. diardi. Further, more detailed cooccurrence models would be required to support this possible interaction. Despite no wholesale group impacts in detection probability by camera placement, every taxonomic and dietary group included in this study contained a member that experienced an influence. This emphasizes that the effects of camera placement methodology on detectability is widespread throughout the terrestrial community of GPNP.

\section{Body weight and detection probability}

Of the dietary and taxonomic groups included in the occupancy modelling portion of this paper, only the omnivore group displayed a significant relationship between camera placement beta values for detection probability and body size. This was a positive relationship, suggesting that as body size increased, the probability of detection on trail rather than off trail also increased. As a result, the omnivore guild is the only group that supports my hypothesis that species of increasing body size will have higher detectability on trail. The lack of a significant correlation found in other groups and as a single terrestrial community have a number of potential reasons. For some groups, differences in detectability may not stem from variation in body size, but rather from predator-prey dynamics that are not properly accounted for within this study. As seen with carnivores here and herbivores in other studies (Blake \& Mosquera, 2014; Rovero et al., 2014), predator-prey interactions may influence detectability to an extent that confounds the effects of body size. The omnivore group found in GPNP is composed of less typical prey species for both $N$. diardi and $M$. flavigula, and so may display less predator avoidance with trails than herbivores, as also seen with the omnivore guild in the camera trap study by Mann et al., (2015). Another reason may also lie within the study sampling limitations. Creating an analysis for measuring correlations between body weight and camera placement beta estimates was challenged by a small sample size and an uneven distribution of average weights amongst the tested species. Low capture rates for some of the more reclusive species, even when the cut-off was $>30$ independent captures, resulted in the exclusion of more than half of the species recorded in the study site. Outlier body weights, such as S. barbutus, may also have disproportionately affected correlation calculations compared to species of much more common lower body weights. 


\section{Activity times}

Through this analysis, it was shown that for three species, detectability also varied temporally by camera placement. Of the three species exhibiting a significant difference in activity patterns on and off trail, all were in the ungulate taxonomic group. Between on and off trail activity for all species, the general activity intervals were constant, with the exception of $T$. kanchil and $S$. barbutus, which showed a noticeable increase in nocturnal activity on trail. Another study in California noted a positive relationship in night-time activity in bobcats and mule deer in response to lower human activity, and it is tempting to note that the same trend may be observed with T. kanchil and S. barbutus. None of the species with significantly different activity curve overlaps by camera placement were impacted by human presence in the previous occupancy models however, weakening human activity as a viable explanation. Activity curve peaks were also mostly consistent on and off trail, although S. barbutus activity flipped from off trail peaks around dawn to on trail peaks at roughly dusk. The fact that there are significant differences in activity curve overlaps suggests that trail microhabitat may enable some form of temporal niche partitioning within species. As activity curves were constructed from data pooled across a 3 year span, the observed differences in activity shape and peaks may be a result of interannual (Morán et al., 2018) or even seasonal patterns (Porfirio et al., 2016). Although limited conclusions can be made in regards to the ecological justifications of these observed differences in intraspecific activity, their existence highlights the fact that camera placement not only affects species state parameters and indices, but has a noticeable impact on behavioural observations and needs to be accounted for as well. 


\section{Chapter 4 General Conclusion}

In this thesis, I demonstrated that the effects of camera placement on species state parameters and behaviour is pervasive in the terrestrial community of GPNP. There were no definitive results suggesting that camera placement on or off trail effected detection probability or relative abundance indices for the community as a whole, yet substantial differences were found for a non-trivial number of species and a single functional group. Much higher detection probabilities and RAI estimates of two out of the three carnivore species from trail cameras has been corroborated by other studies (Mann et al., 2015; Trolle \& Kéry, 2005). These findings provide evidence that, at least for the carnivore guild, study designs within GPNP featuring disproportionate survey effort on trail systems should not be trusted to give unbiased estimates of occupancy or abundance.

Accumulation curves suggested that the detection of new species records was not hugely affected by camera placement strategies in this study site, although the case can be made here that some rare or specialist species risk non-detection if an exclusively-selective trail placement study design is applied. For future studies that focus on the detectability of one or a small number of species, this thesis provides further proof that camera trap study design can have real impacts on a number of state parameters. With this in mind, the validity of using selective camera placement hinges much on the scope and research questions of a study. Single-species studies may be justified in tailoring placement designs to focus on specific habitat features (e.g. roads, trails, watering holes etc.) in order to maximize capture rates, providing that the ecology of the target species is fully understood or at least very well researched. Even still, this may limit the discovery of novel behaviour or microhabitat use (Carbone et al., 2001; Karanth, 1999). Such a case was even observed within GPNP with interspecific differences in habitat use for $N$. diardi. Capture-recapture data collected by Allen et al (2016) using cameras based on trails in GPNP, collected N. diardi capture records that were dominated by male individuals. In the study, the majority of observations of female and male $N$. diardi were spatially distinct, with males appearing more commonly on trail systems and females visible mostly off-track. Additionally, while most males were found at sampling sites where other males were also present, typically only a single female was recorded at each location (Allen et al., 2016). Based on these observations, sampling exclusively on or off trails may lead to an underestimation of the overall abundance of $N$. diardi or inaccurate conclusions on habitat use and behaviour based on a male-biased sample population. In this way, camera placement has already been observed to affect intraspecific data interpretation for at least one 
species within GPNP and provides supplemental evidence for unbiased study designs. Any future study would invariably benefit from including any spatial selectivity that they have into their analysis and/or controlling for them within the study design itself.

Indeed, as the number of species of interest grows for any given study, so does the potential for selective camera placement to have effects on species detectability that are either unforeseen or not sufficiently accounted for. This supports the case for the use of randomly-distributed cameras in the many situations where the relationship between camera placement and species detectability is unknown (Wearn et al., 2013). As stated in the intro of Chapter 3, however, random camera placement runs the risk of significantly lower detectability for some species. In GPNP, detectability curves suggest that, for the majority of species displaying a bias towards on or off trail detectability, differences in survey effort could be overcome with a relatively modest increase in overall cameras or camera activity. The results from this thesis largely suggest that, for camera trap studies focusing on multiple terrestrial species, random camera placement would reduce detection bias with minimal necessary increases in survey effort. This is a novel observation for this part of the world, as the majority of literature covering the influence of placement strategies on detection have taken place in neotropical ecosystems. Of the neotropical studies, some compare different selective placement strategies exclusively, such as roads vs logging trails (Negrões et al., 2010); without including a control group off trail. The research conducted in this thesis is one example of just a few measuring the effects of camera placement on species state parameters and behaviour in the old world tropics (Wearn et al., 2013). Because it was also based in an ecosystem representative of an undisturbed wildlife community, these findings may very well be applied in other protected areas in Borneo or Southeast Asia sharing similar species and habitat assemblages. Efforts to better understand the effects of camera placement on species detectability are a crucial step towards larger regional or even international study designs such as the Tropical Ecology Assessment and Monitoring (TEAM) network mentioned in section 1.1 of this thesis (Rovero \& Ahumada, 2017). No matter the scale, combined datasets all hinge upon standardized study designs whose methods are well understood and accounted for within their respective target communities.

Of course, the results from Chapter 3 would certainly be most applicable for future terrestrial species research within GPNP, such as a study of plant productivity and faunal response proposed in my literature review. As my prospective analyses dealt with the effect of fluctuations of fruit availability on species abundance and distribution, accurately detecting species across the entire terrestrial community is critical. Capture data from randomly-placed cameras off-trail along with covariates of monthly plant productivity data from CPRS' phenology plots (measured as stem densities of trees bearing ripe fruit), could be readily input into occupancy models and model 
extensions (Royle, 2004) to generate estimates of occupancy and abundance without introduced spatial bias from selective camera placement. Doing so would ensure that any observed changes in occupancy or abundance through time could be accurately compared against plant productivity without the confounding factor of camera placement. This is just one example of many where primarily methodological conclusions can pave the way towards answering ecology-driven questions with greater confidence.

Another important impression from my research is that, while accounting for camera placement strategies through a single explanatory variable can provide considerable insight as to how it affects detectability, additional data on microhabitat characteristics could only allow for a more detailed understanding of the methodological and ecological processes that shape this influence. Including measures of understory density or trail width for instance, may enable a better understanding of variability in species detection. These potential covariates can also be utilized to describe local occupancy and expand our knowledge of species habitat preference and niche partitioning on finer spatial scales. Camera placement strategies are just one methodological component of many for study sampling designs that need to be taken into consideration by researchers. Other variables, such as camera trigger settings, camera type, and focal point distance, optimal survey lengths have been shown to have a considerable impact on species detection probability; and require careful tailoring depending on the characteristics of the site, species, and research questions (Hamel et al., 2013; Swann et al., 2011). Camera positioning even within microhabitats (Apps \& McNutt, 2018; Tourani et al., 2020) as well as the number of cameras placed at one station play a significant role in detection probability, and has been found to vary by species (Evans et al., 2019).

The influence of body size on species detectability has been mentioned widely in other papers exploring camera placement methodologies (Anile \& Devillard, 2016; Kays et al., 2010), yet none have incorporated the potential interaction of on and off trail camera placement into their analysis. My analysis suggests a potential interaction between camera placement and body size for a small to medium-sized assemblage of omnivores. These results are unique in testing this relationship between placement strategy detectability and body size across a whole terrestrial community, as well as for species ranging from small to large builds. Previous research has only focused on variations in detectability for organisms of exclusively large size (Palmer et al., 2018) or within just one taxonomic family (Anile \& Devillard, 2016). As Anile \& Devillard (2016) had explored with cameras including and excluding bait lures, camera placement can be subject to other interacting factors that may change the extent to which species detectability is affected. Although differences in detectability between predator and prey species alludes to an interaction, it is still yet uncertain how 
the existence of trails play into predator prey-dynamics or micro-niche partitioning. In the future, separate cooccurrence models for each camera placement type may help tease out the prospective roles that microhabitat features play in various species' occupancy. In addition, differences in intraspecific activity for three ungulate species in this study site provides further evidence that accounting for selective camera placement is not just applicable for accurate estimates of systems states, but for behavioural studies as well. In future studies, the effect of microhabitat presence on species activity could be extended to interspecific interactions, by which predator-prey or competitor temporal overlaps are compared between camera placement strategies. Alternative intraspecific analyses could be performed in this study, where specific actions (feeding, traveling, resting, etc.) observed in species for each video capture could be compared by camera placement strategies to delineate other behavioural differences in microhabitat use. Indeed, the more researchers understand how selective placement and other interacting factors affect detectability, the more effective camera traps can be in the fields of ecology, animal behaviour, and conservation management. 


\section{References:}

Allen, M. L., Wittmer, H. U., Setiawan, E., Jaffe, S., \& Marshall, A. J. (2016). Scent marking in Sunda clouded leopards (Neofelis diardi): novel observations close a key gap in understanding felid communication behaviours. Scientific Reports, 6, 354. doi:10.1038/srep35433

Allen, R. B., \& Platt, K. (1990). Annual seedfall variation in Nothofagus solandri (Fagaceae), Canterbury, New Zealand. Oikos, 57(2), 199-206. doi:10.2307/3565940

Anile, S., \& Devillard, S. (2016). Study design and body mass influence RAls from camera trap studies: evidence from the Felidae. Animal Conservation, 19(1), 35-45.

Apps, P. J., \& McNutt, J. W. (2018). How camera traps work and how to work them. African Journal of Ecology, 56(4), 702-709. doi:https://doi.org/10.1111/aje.12563

Ashton, P. S. (1988). Dipterocarp biology as a window to the understanding of tropical forest structure. Annual Review of Ecology and Systematics, 19(1), 347-370.

Ashton, P. S., Givnish, T. J., \& Appanah, S. (1988). Staggered Flowering in the Dipterocarpaceae: New Insights Into Floral Induction and the Evolution of Mast Fruiting in the Aseasonal Tropics. The American Naturalist, 132(1), 44-66. doi:10.1086/284837

Barrueto, M., Ford, A. T., \& Clevenger, A. P. (2014). Anthropogenic effects on activity patterns of wildlife at crossing structures. Ecosphere, 5(3), 27. doi:10.1890/es13-00382.1

Birds of the World. (2020). Retrieved from https://birdsoftheworld.org/bow/home

Blake, J. G., \& Mosquera, D. (2014). Camera trapping on and off trails in lowland forest of eastern Ecuador: does location matter? Mastozoología neotropical, 21(1), 17-26.

Bolger, D., Morrison, T., Vance, B., Lee, D., \& Farid, H. (2012). A computer-assisted system for photographic mark-recapture analysis. Methods in Ecology and Evolution, 3, 813-822. doi:10.1111/j.2041-210X.2012.00212.x

Borries, C., Primeau, Z. M., Ossi-Lupo, K., Dtubpraserit, S., \& Koenig, A. (2014). Possible predation attempt by a marbled cat on a juvenile Phayre's leaf monkey. Raffles Bulletin of Zoology, 62.

Brodie, J., Giordano, A., Zipkin, E., Bernard, H., Mohd-Azlan, J., \& Ambu, L. (2014). Correlation and Persistence of Hunting and Logging on Tropical Rainforest Mammals. Conservation Biology, 29, 110-121. doi:10.1111/cobi.12389

Brooks, D. M., \& Cheyne, S. M. (2018). A camera-trap survey of avifauna in a Bornean peat-swamp forest. The Wilson Journal of Ornithology, 130(4), 969-980.

Bukombe, J., Senzota, R. B., Fryxell, J. M., Kittle, A., Kija, H., Hopcraft, J. G. C., . . Sinclair, A. R. E. (2016). Do animal size, seasons and vegetation type influence detection probability and 
density estimates of Serengeti ungulates? African Journal of Ecology, 54(1), 29-38. doi:https://doi.org/10.1111/aje.12255

Burnham, K. P., \& Anderson, D. R. (2002). A practical information-theoretic approach. Model selection and multimodel inference, 2nd ed. Springer, New York, 2.

Burrows, L. E., \& Allen, R. B. (1991). Silver beech (Nothofagus menziesii (Hook. f.) Oerst.) seedfall patterns in the Takitimu Range, South Island, New Zealand. New Zealand Journal of Botany, 29(4), 361-365. doi:10.1080/0028825X.1991.10415489

Burton, A. C., Neilson, E., Moreira, D., Ladle, A., Steenweg, R., Fisher, J. T., . . Boutin, S. (2015). Wildlife camera trapping: a review and recommendations for linking surveys to ecological processes. Journal of applied ecology, 52(3), 675-685.

Cannon, C. H., Curran, L. M., Marshall, A. J., \& Leighton, M. J. E. L. (2007). Long-term reproductive behaviour of woody plants across seven Bornean forest types in the Gunung Palung National Park (Indonesia): suprannual synchrony, temporal productivity and fruiting diversity. 10(10), 956-969.

Caravaggi, A., Banks, P. B., Burton, A. C., Finlay, C. M. V., Haswell, P. M., Hayward, M. W., . . Wood, M. D. (2017). A review of camera trapping for conservation behaviour research. Remote Sensing in Ecology and Conservation, 3(3), 109-122. doi:https://doi.org/10.1002/rse2.48

Carbone, C., Christie, S., Conforti, K., Coulson, T., Franklin, N., Ginsberg, J. R., . . Wan Shahruddin, W. N. (2001). The use of photographic rates to estimate densities of tigers and other cryptic mammals. Animal Conservation, 4(1), 75-79. doi:10.1017/s1367943001001081

Carlo, T. A., Collazo, J. A., \& Groom, M. J. (2004). Influences of Fruit Diversity and Abundance on Bird Use of Two Shaded Coffee Plantations. Biotropica, 36(4), 602-614. doi:10.1111/j.17447429.2004.tb00354.x

Carlos M. Herrera, Pedro Jordano, Javier Guitián, \& Anna Traveset. (1998). Annual Variability in Seed Production by Woody Plants and the Masting Concept: Reassessment of Principles and Relationship to Pollination and Seed Dispersal. The American Naturalist, 152(4), 576-594. doi:10.1086/286191

Chapman, S., Syktus, J., Trancoso, R., Salazar, A., Thatcher, M., Watson, J. E., . . McAlpine, C. A. (2020). Compounding impact of deforestation on Borneo's climate during El Niño events. Environmental Research Letters, 15(8), 084006.

Christenhusz, M. J. M., \& Byng, J. W. (2016). The number of known plants species in the world and its annual increase. 2016, 261(3), 17. doi:10.11646/phytotaxa.261.3.1 
Clark, J. S., Nuñez, C. L., \& Tomasek, B. (2019). Foodwebs based on unreliable foundations: spatiotemporal masting merged with consumer movement, storage, and diet. Ecological Monographs, 89(4), e01381. doi:10.1002/ecm.1381

Clua, E., Chauvet, C., Read, T., Werry, J. M., \& Lee, S. Y. (2013). Behavioural patterns of a tiger shark (Galeocerdo cuvier) feeding aggregation at a blue whale carcass in Prony Bay, New Caledonia. Marine and freshwater behaviour and physiology, 46(1), 1-20.

Colón, C. P. (2002). Ranging behaviour and activity of the Malay civet (Viverra tangalunga) in a logged and an unlogged forest in Danum Valley, East Malaysia. Journal of Zoology, 257(4), 473-485. doi:10.1017/S0952836902001073

Colwell, R. K., Mao, C. X., \& Chang, J. (2004). Interpolating, extrapolating, and comparing incidencebased species accumulation curves. Ecology, 85(10), 2717-2727.

Colyn, R., Radloff, F. G. T., \& O'Riain, M. (2018). Camera trapping mammals in the scrubland's of the Cape Floristic Kingdom - the importance of effort, spacing and trap placement. Biodiversity and Conservation, 27(2), 503-520.

Cooch, E., \& White, E. (2005). Program MARK: a gentle introduction. 313 p. In.

Corlett, R. T., \& Lafrankie, J. V. (1998). Potential Impacts of Climate Change on Tropical Asian Forests Through an Influence on Phenology. Climatic Change, 39(2), 439-453. doi:10.1023/A:1005328124567

Crawley, M. J., \& Long, C. R. (1995). Alternate Bearing, Predator Satiation and Seedling Recruitment in Quercus Robur L. Journal of Ecology, 83(4), 683-696. doi:10.2307/2261636

Curran, L. M., Caniago, I., Paoli, G. D., Astianti, D., Kusneti, M., Leighton, M., . . Haeruman, H. (1999). Impact of El Niño and Logging on Canopy Tree Recruitment in Borneo. Science, 286(5447), 2184. doi:10.1126/science.286.5447.2184

Curran, L. M., \& Leighton, M. (2000). Vertebrate Responses To Spatiotemporal Variation In Seed Production Of Mast-Fruiting Dipterocarpaceae. Ecological Monographs, 70(1), 101-128. doi:10.1890/0012-9615(2000)070[0101:Vrtsvi]2.0.Co;2

Cusack, J. J., Dickman, A. J., Rowcliffe, J. M., Carbone, C., Macdonald, D. W., \& Coulson, T. (2015). Random versus Game Trail-Based Camera Trap Placement Strategy for Monitoring Terrestrial Mammal Communities. PloS one, 10(5), e0126373. doi:10.1371/journal.pone.0126373

Cutler, T. L., \& Swann, D. E. (1999). Using Remote Photography in Wildlife Ecology: A Review. Wildlife Society Bulletin (1973-2006), 27(3), 571-581. Retrieved from http://www.jstor.org/stable/3784076 
Darnell, R. M. (1961). Trophic Spectrum of an Estuarine Community, Based on Studies of Lake Pontchartrain, Louisiana. Ecology, 42(3), 553-568. doi:10.2307/1932242

Di Bitetti, M. S., Paviolo, A. J., \& de Angelo, C. D. (2014). Camera trap photographic rates on roads vs. off roads: location does matter. Mastozoología neotropical, 1(03/2014), 37-46.

Dillis, C., Beaudrot, L., Feilen, K. L., Clink, D. J., Wittmer, H. U., \& Marshall, A. J. (2015). Modeling the ecological and phenological predictors of fruit consumption by gibbons (Hylobates albibarbis). Biotropica, 47(1), 85-93.

Dillis, C., Marshall, A., Webb, C., \& Grote, M. (2018). Prolific fruit output by the invasive tree Bellucia pentamera Naudin (Melastomataceae) is enhanced by selective logging disturbance. Biotropica, 50, 598-605. doi:10.1111/btp.12545

Dillis, C., Marshall, A. J., \& Rejmánek, M. (2017). Change in disturbance regime facilitates invasion by Bellucia pentamera Naudin (Melastomataceae) at Gunung Palung National Park, Indonesia. Biological Invasions, 19(4), 1329-1337. doi:10.1007/s10530-016-1345-5

Dudley, S. F., Anderson-Reade, M. D., Thompson, G. S., \& McMullen, P. B. (2000). Concurrent scavenging off a whale carcass by great white sharks, Carcharodon carcharias, and tiger sharks, Galeocerdo cuvier. Fishery Bulletin, 98(3), 646-649.

Edwards, S. A., \& Heiduk, F. (2015). Hazy days: Forest fires and the politics of environmental security in Indonesia. Journal of Current Southeast Asian Affairs, 34(3), 65-94.

Evans, B. E., Mosby, C. E., \& Mortelliti, A. (2019). Assessing arrays of multiple trail cameras to detect North American mammals. PloS one, 14(6), e0217543. doi:10.1371/journal.pone.0217543

Fernández-Martínez, M., Belmonte, J., \& Espelta, J. M. (2012). Masting in oaks: disentangling the effect of flowering phenology, airborne pollen load and drought. Acta Oecologica, 43, 51-59.

Fredriksson, G., Danielsen, L., \& Swenson, J. (2007). Impacts of El Nino related drought and forest fires on sun bear fruit resources in lowland dipterocarp forest of East Borneo. Biodiversity and Conservation, 16(6), 1823-1838.

Fuller, A. K., Linden, D. W., \& Royle, J. A. (2016). Management decision making for fisher populations informed by occupancy modeling. The Journal of Wildlife Management, 80(5), 794-802.

Ganesh, T., \& Davidar, P. (1999). Fruit biomass and relative abundance of frugivores in a rain forest of southern Western Ghats, India. Journal of Tropical Ecology, 15(4), 399-413. doi:10.1017/S0266467499000917

Gaveau, D. L. A., Kshatriya, M., Sheil, D., Sloan, S., Molidena, E., Wijaya, A., . . Meijaard, E. (2013). Reconciling Forest Conservation and Logging in Indonesian Borneo. PloS one, 8(8), e69887. doi:10.1371/journal.pone.0069887 
Gaveau, D. L. A., Sloan, S., Molidena, E., Yaen, H., Sheil, D., Abram, N. K., . . Meijaard, E. (2014). Four Decades of Forest Persistence, Clearance and Logging on Borneo. PloS one, 9(7), e101654. doi:10.1371/journal.pone.0101654

Gerber, B. D., Karpanty, S. M., \& Kelly, M. J. (2012). Evaluating the potential biases in carnivore capture-recapture studies associated with the use of lure and varying density estimation techniques using photographic-sampling data of the Malagasy civet. Population Ecology, 54(1), 43-54. doi:10.1007/s10144-011-0276-3

Gergis, J. L., \& Fowler, A. M. (2009). A history of ENSO events since A.D. 1525: implications for future climate change. Climatic Change, 92(3), 343-387. doi:10.1007/s10584-008-9476-z

Geyle, H. M., Stevens, M., Duffy, R., Greenwood, L., Nimmo, D. G., Sandow, D., . . Ritchie, E. G. (2020). Evaluation of camera placement for detection of free-ranging carnivores; implications for assessing population changes. Ecological Solutions and Evidence, 1(1), e12018. doi:https://doi.org/10.1002/2688-8319.12018

Gibbons, J. D., \& Chakraborti, S. (2014). Nonparametric Statistical Inference: Revised and Expanded: CRC press.

Givnish, T. J. (1980). Ecological Constraints on the Evolution of Breeding Systems in Seed Plants: Dioecy and Dispersal in Gymnosperms. Evolution, 34(5), 959-972. doi:10.2307/2408001 Gleditsch, J. M., \& Carlo, T. A. (2011). Fruit quantity of invasive shrubs predicts the abundance of common native avian frugivores in central Pennsylvania. Diversity and Distributions, 17(2), 244-253. doi:10.1111/j.1472-4642.2010.00733.x

Gotelli, N. J., \& Colwell, R. K. (2011). Estimating species richness. Biological diversity: frontiers in measurement and assessment, 12, 39-54.

Greenville, A. C., Wardle, G. M., Tamayo, B., \& Dickman, C. R. (2014). Bottom-up and top-down processes interact to modify intraguild interactions in resource-pulse environments. Oecologia, 175(4), 1349-1358. doi:10.1007/s00442-014-2977-8

Hamel, S., Killengreen, S. T., Henden, J.-A., Eide, N. E., Roed-Eriksen, L., Ims, R. A., \& Yoccoz, N. G. (2013). Towards good practice guidance in using camera-traps in ecology: influence of sampling design on validity of ecological inferences. Methods in Ecology and Evolution, 4(2), 105-113. doi:10.1111/j.2041-210x.2012.00262.x

Hancock, P. A., Milner-Gulland, E. J., \& Keeling, M. J. (2005). An individual based model of bearded pig abundance. Ecological Modelling, 181(2-3), 123-137.

doi:10.1016/j.ecolmodel.2004.06.026 
Harmsen, B. J., Foster, R. J., Silver, S., Ostro, L., \& Doncaster, C. P. (2010). Differential Use of Trails by Forest Mammals and the Implications for Camera-Trap Studies: A Case Study from Belize. Biotropica, 42(1), 126-133. doi:https://doi.org/10.1111/i.1744-7429.2009.00544.x

Harrison, R. D. (2001). Drought and the consequences of El Niño in Borneo: a case study of figs. Population Ecology, 43(1), 63-75. doi:10.1007/pl00012017

Hernández, L., Laundré, J. W., Grajales, K. M., Portales, G. L., López-Portillo, J., González-Romero, A., ... Martínez, J. M. (2011). Plant productivity, predation, and the abundance of black-tailed jackrabbits in the Chihuahuan Desert of Mexico. Journal of Arid Environments, 75(11), 10431049. doi:https://doi.org/10.1016/i.jaridenv.2010.12.021

Herrera, C. M., Jordano, P., Guiti, xe, n, J., \& Traveset, A. (1998). Annual Variability in Seed Production by Woody Plants and the Masting Concept: Reassessment of Principles and Relationship to Pollination and Seed Dispersal. The American Naturalist, 152(4), 576-594. doi:10.1086/286191

Hiller, M. A., Jarvis, B. C., Lisa, H., Paulson, L. J., Pollard, E. H., \& Stanley, S. A. (2004). Recent trends in illegal logging and a brief discussion of their causes: a case study from Gunung Palung National Park, Indonesia. Journal of Sustainable Forestry, 19(1-3), 181-212.

Hobbs, N. T., \& Hanley, T. A. (1990). Habitat evaluation: do use/availability data reflect carrying capacity? The Journal of Wildlife Management, 515-522.

Hopcraft, J. G. C., Olff, H., \& Sinclair, A. R. E. (2010). Herbivores, resources and risks: alternating regulation along primary environmental gradients in savannas. Trends in Ecology \& Evolution, 25(2), 119-128. doi:https://doi.org/10.1016/i.tree.2009.08.001

Houlihan, P. R., Stone, M., Clem, S. E., Owen, M., \& Emmel, T. C. (2019). Pollination ecology of the ghost orchid (Dendrophylax lindenii): A first description with new hypotheses for Darwin's orchids. Scientific Reports, 9(1), 12850. doi:10.1038/s41598-019-49387-4

Hsieh, T. C., Ma, K. H., \& Chao, A. (2016). iNEXT: an R package for rarefaction and extrapolation of species diversity (Hill numbers). Methods in Ecology and Evolution, 7(12), 1451-1456. doi:https://doi.org/10.1111/2041-210X.12613

Hunter, M. D., \& Price, P. W. (1992). Playing Chutes and Ladders: Heterogeneity and the Relative Roles of Bottom-Up and Top-Down Forces in Natural Communities. 73(3), 724-732. doi:10.2307/1940152

IUCN. (2020). The IUCN red list of threatened species. Version 2020-1. In: IUCN Gland, CH, and Cambridge, UK.

Janzen, D. H. (1971). Seed predation by animals. Annual Review of Ecology and Systematics, 2(1), 465-492. 
Jenks, K. E., Chanteap, P., Kanda, D., Peter, C., Cutter, P., Redford, T., .. Leimgruber, P. (2011). Using relative abundance indices from camera-trapping to test wildlife conservation hypothesesan example from Khao Yai National Park, Thailand. Tropical Conservation Science, 4(2), 113131.

Johnson, A. E., Knott, C. D., Pamungkas, B., Pasaribu, M., \& Marshall, A. J. (2005). A survey of the orangutan (Pongo pygmaeus wurmbii) population in and around Gunung Palung National Park, West Kalimantan, Indonesia based on nest counts. Biological Conservation, 121(4), 495-507.

Jones, C. G., Ostfeld, R. S., Richard, M. P., Schauber, E. M., \& Wolff, J. O. (1998). Chain reactions linking acorns to gypsy moth outbreaks and Lyme disease risk. Science, 279(5353), 10231026.

Karanth, K. U. (1995). Estimating tiger Panthera tigris populations from camera-trap data using capture-recapture models. Biological Conservation, 71(3), 333-338. doi:https://doi.org/10.1016/0006-3207(94)00057-W

Karanth, K. U. (1999). Riding the Tiger: Tiger Conservation in Human-dominated Landscapes. Cambridge, UK: Cambridge University Press.

Karanth, K. U., \& Nichols, J. D. (1998). Estimation of tiger densities in India using photographic captures and recaptures. Ecology, 79(8), 2852-2862.

Kays, R., Kranstauber, B., Jansen, P., Carbone, C., Rowcliffe, M., Fountain, T., \& Tilak, S. (2009). Camera traps as sensor networks for monitoring animal communities. Paper presented at the 2009 IEEE 34th Conference on Local Computer Networks.

Kays, R., Tilak, S., Kranstauber, B., Jansen, P. A., Carbone, C., Rowcliffe, M. J., . . He, Z. (2010). Monitoring wild animal communities with arrays of motion sensitive camera traps. arXiv preprint arXiv:1009.5718.

Kelly, D., Geldenhuis, A., James, A., Penelope Holland, E., Plank, M. J., Brockie, R. E., . . Byrom, A. E. (2013). Of mast and mean: differential-temperature cue makes mast seeding insensitive to climate change. Ecology Letters, 16(1), 90-98. doi:10.1111/ele.12020

Kelly, D., McKone, M. J., Batchelor, K. J., \& Spence, J. R. (1992). Mast seeding of Chionochloa (Poaceae) and pre-dispersal seed predation by a specialist fly (Diplotoxa, Diptera: Chloropidae). New Zealand Journal of Botany, 30(2), 125-133. doi:10.1080/0028825X.1992.10412893

Kelly, D., \& Sullivan, J. J. (1997). Quantifying the Benefits of Mast Seeding on Predator Satiation and Wind Pollination in Chionochloa pallens (Poaceae). Oikos, 78(1), 143-150. doi:10.2307/3545810 
Kery, M., \& Royle, J. A. (2020). Applied Hierarchical Modeling in Ecology: Analysis of Distribution, Abundance and Species Richness in R and BUGS (Vol. 2). London, UK: Academic Press.

Kier, G., Mutke, J., Dinerstein, E., Ricketts, T. H., Küper, W., Kreft, H., \& Barthlott, W. (2005). Global patterns of plant diversity and floristic knowledge. Journal of Biogeography, 32(7), 11071116. doi:https://doi.org/10.1111/j.1365-2699.2005.01272.x

Koenig, W. D., Knops, J. M. H., Carmen, W. J., \& Pearse, I. S. (2015). What drives masting? The phenological synchrony hypothesis. Ecology, 96(1), 184-192. doi:10.1890/14-0819.1

Kolowski, J. M., \& Forrester, T. D. (2017). Camera trap placement and the potential for bias due to trails and other features. PloS one, 12(10), e0186679. doi:10.1371/journal.pone.0186679

LaFrankie, J. V., \& Chan, H. T. (1991). Confirmation of Sequential Flowering in Shorea (Dipterocarpaceae). Biotropica, 23(2), 200-203. doi:10.2307/2388308

Lambert, F. R., \& Marshall, A. G. (1991). Keystone Characteristics of Bird-Dispersed Ficus in a Malaysian Lowland Rain Forest. Journal of Ecology, 79(3), 793-809. doi:10.2307/2260668

Lande, R., DeVries, P. J., \& Walla, T. R. (2000). When species accumulation curves intersect: implications for ranking diversity using small samples. Oikos, 89(3), 601-605. doi:https://doi.org/10.1034/j.1600-0706.2000.890320.x

Liu, Y., Goodrick, S., \& Heilman, W. (2014). Wildland fire emissions, carbon, and climate: Wildfireclimate interactions. Forest Ecology and Management, 317, 80-96. doi:https://doi.org/10.1016/i.foreco.2013.02.020

LoGiudice, K., Ostfeld, R. S., Schmidt, K. A., \& Keesing, F. (2003). The ecology of infectious disease: effects of host diversity and community composition on Lyme disease risk. Proceedings of the National Academy of Sciences, 100(2), 567-571.

Luken, J. O., \& Thieret, J. W. (1996). Amur honeysuckle, its fall from grace. BioScience, 46(1), 18-24.

Lund, U., Agostinelli, C., \& Agostinelli, M. C. (2017). Package 'circular'. Repository CRAN.

MacKenzie, D. I., \& Bailey, L. a. L. (2004). Assessing the fit of site-occupancy models. Journal of Agricultural, Biological, and Environmental Statistics, 9(3), 300-318.

MacKenzie, D. I., \& Kendall, W. L. (2002). How should detection probability be incorporated into estimates of relative abundance? Ecology, 83(9), 2387-2393. doi:https://doi.org/10.1890/0012-9658(2002)083[2387:HSDPBI]2.0.CO;2

MacKenzie, D. I., Nichols, J. D., Royle, J. A., Pollock, K. H., Bailey, L., \& Hines, J. E. (2017). Occupancy Estimation and Modeling: Inferring Patterns and Dynamics of Species Occurrence: Elsevier Science.

Mackinnon, K., Hatta, G., Halim, H., \& Mangalik, A. (1996). The Ecology of Kalimantan, Indonesian Borneo (1997/09/01 ed. Vol. 3): Cambridge University Press. 
Mann, G. K. H., O'Riain, M. J., \& Parker, D. M. (2015). The road less travelled: assessing variation in mammal detection probabilities with camera traps in a semi-arid biodiversity hotspot. Biodiversity and Conservation, 24(3), 531-545. doi:10.1007/s10531-014-0834-z

Marshall, A. J. (2004). Population ecology of gibbons and leaf monkeys across a gradient of Bornean forest types. (PhD). Harvard University, Cambridge, MA.

Marshall, A. J. (2009). Are montane forests demographic sinks for Bornean white-bearded gibbons Hylobates albibarbis? Biotropica, 41(2), 257-267.

Marshall, A. J., Beaudrot, L., \& Wittmer, H. U. (2014). Responses of primates and other frugivorous vertebrates to plant resource variability over space and time at Gunung Palung National Park. International Journal of Primatology, 35(6), 1178-1201.

Marshall, A. J., Cannon, C. H., \& Leighton, M. (2009). Competition and niche overlap between gibbons (Hylobates albibarbis) and other frugivorous vertebrates in Gunung Palung National Park, West Kalimantan, Indonesia. In The Gibbons (pp. 161-188): Springer.

Martin, S. A., Rautsaw, R. M., Bolt, M. R., Parkinson, C. L., \& Seigel, R. A. (2018). Estimating the response of wildlife communities to coastal dune construction. Ocean \& Coastal Management, 161, 31-36. doi:https://doi.org/10.1016/j.ocecoaman.2018.04.021

Maury-Lechon, G., \& Curtet, L. (1998). A Review of Dipterocarps: Taxonomy, Ecology and Silviculture. Center for International Forestry Research, Indonesia. Bogor, Indonesia: Center for International Forestry Research.

Maycock, C. R., Thewlis, R. N., Ghazoul, J., Nilus, R., \& Burslem, D. F. R. P. (2005). Reproduction of dipterocarps during low intensity masting events in a Bornean rain forest. Journal of Vegetation Science, 16(6), 635-646. doi:https://doi.org/10.1111/i.1654-1103.2005.tb02406.x

Mazerolle, M. J., \& Mazerolle, M. M. J. (2017). Package 'AICcmodavg'. R package.

McAlpine, C. A., Johnson, A., Salazar, A., Syktus, J., Wilson, K., Meijaard, E., . . Sheil, D. (2018). Forest loss and Borneo's climate. Environmental Research Letters, 13(4), 044009. doi:10.1088/1748-9326/aaa4ff

Mccoy, J. C., Ditchkoff, S. S., \& Steury, T. D. (2011). Bias associated with baited camera sites for assessing population characteristics of deer. The Journal of Wildlife Management, 75(2), 472-477. doi:https://doi.org/10.1002/jwmg.54

McShea, W., Forrester, T., Costello, R., He, Z., \& Kays, R. (2016). Volunteer-run cameras as distributed sensors for macrosystem mammal research. Landscape Ecology, 31(1), 55-66. doi:10.1007/s10980-015-0262-9 
Meek, P., Ballard, G., Fleming, P., \& Falzon, G. (2016). Are we getting the full picture? Animal responses to camera traps and implications for predator studies. Ecology and Evolution, 6(10), 3216-3225. doi:https://doi.org/10.1002/ece3.2111

Meek, P. D., Fleming, P., Ballard, G., Banks, P., Claridge, A. W., Sanderson, J., \& Swann, D. (2014). Camera trapping: wildlife management and research (Vol. 2). Melbourne, Australia: Csiro Publishing

Meredith, M., \& Ridout, M. (2014). Overview of the overlap package. R. Proj, 1-9.

Miettinen, J., Shi, C., \& Liew, S. C. (2017). Fire distribution in Peninsular Malaysia, Sumatra and Borneo in 2015 with special emphasis on peatland fires. Environmental management, 60(4), 747-757.

Mola, J. M., \& Williams, N. M. (2018). Fire-induced change in floral abundance, density, and phenology benefits bumble bee foragers. Ecosphere, 9(1), e02056. doi:10.1002/ecs2.2056

Morán, L., García, L., Ferrebuz, J. D., Sánchez, R., Sánchez-Mercado, A., Porta, A., \& Ferrer-Paris, J. R. (2018). Interannual and daily activity patterns of mid-sized mammals in Maracaibo Lake Basin, Venezuela. Therya, 9(3), 227-236.

Muul, I., \& Lim, B.-L. (1970). Ecological and Morphological Observations of Felis planiceps. Journal of Mammalogy, 51(4), 806-808. doi:10.2307/1378310

Netto, S. A., \& Meneghel, A. (2014). Pulse of marine subsidies: the role of surf diatom Asterionellopsis glacialis accumulations in structuring the meiofauna of sandy beaches. Marine Biodiversity, 44(3), 445-457. doi:10.1007/s12526-014-0253-0

Newey, S., Davidson, P., Nazir, S., Fairhurst, G., Verdicchio, F., Irvine, R. J., \& van der Wal, R. (2015). Limitations of recreational camera traps for wildlife management and conservation research: A practitioner's perspective. Ambio, 44(4), 624-635.

Niedballa, J., Sollmann, R., Courtiol, A., \& Wilting, A. (2016). camtrapR: an R package for efficient camera trap data management. Methods in Ecology and Evolution, 7(12), 1457-1462.

Norton, D. A., \& Kelly, D. (1988). Mast Seeding Over 33 Years by Dacrydium cupressinum Lamb. (rimu) (Podocarpaceae) in New Zealand: The Importance of Economies of Scale. Functional Ecology, 2(3), 399-408. doi:10.2307/2389413

Nowak, K., le Roux, A., Richards, S. A., Scheijen, C. P., \& Hill, R. A. (2014). Human observers impact habituated samango monkeys' perceived landscape of fear. Behavioral Ecology, 25(5), 11991204.

O'Brien, T. G., Kinnaird, M. F., \& Wibisono, H. T. (2003). Crouching tigers, hidden prey: Sumatran tiger and prey populations in a tropical forest landscape. Animal Conservation, 6(2), 131-139. 
O'Connell, A. F., Nichols, J. D., \& Karanth, K. U. (2010). Camera Traps in Animal Ecology: Methods and Analyses. Japan: Springer Science \& Business Media

O'Connell, A. F., Nichols, J. D., \& Karanth, K. U. (2010). Camera traps in animal ecology: methods and analyses: Springer Science \& Business Media.

O'Donnell, C. F. J., \& Phillipson, S. M. (1996). Predicting the incidence of mohua predation from the seedfall, mouse, and predator fluctuations in beech forests. New Zealand Journal of Zoology, 23(3), 287-293. doi:10.1080/03014223.1996.9518087

O'Brien, T. G., \& Kinnaird, M. F. (2011). Estimation of species richness of large vertebrates using camera traps: an example from an Indonesian rainforest. In Camera Traps in Animal Ecology (pp. 233-252): Springer.

Oberosler, V., Groff, C., lemma, A., Pedrini, P., \& Rovero, F. (2017). The influence of human disturbance on occupancy and activity patterns of mammals in the Italian Alps from systematic camera trapping. Mammalian Biology, 87, 50-61.

doi:10.1016/j.mambio.2017.05.005

Ostertag, R., Scatena, F. N., \& Silver, W. L. (2003). Forest Floor Decomposition Following Hurricane Litter Inputs in Several Puerto Rican Forests. Ecosystems, 6(3), 261-273. Retrieved from www.jstor.org/stable/3658892

Palmer, M. S., Swanson, A., Kosmala, M., Arnold, T., \& Packer, C. (2018). Evaluating relative abundance indices for terrestrial herbivores from large-scale camera trap surveys. African Journal of Ecology, 56(4), 791-803. doi:https://doi.org/10.1111/aje.12566

Paoli, G. D., Curran, L. M., \& Zak, D. R. (2006). Soil nutrients and beta diversity in the Bornean Dipterocarpaceae: evidence for niche partitioning by tropical rain forest trees. Journal of Ecology, 94(1), 157-170.

Pearce, J., \& Ferrier, S. (2001). The practical value of modelling relative abundance of species for regional conservation planning: a case study. Biological Conservation, 98(1), 33-43. doi:https://doi.org/10.1016/S0006-3207(00)00139-7

Pearse, I. S., Koenig, W. D., \& Kelly, D. (2016). Mechanisms of mast seeding: resources, weather, cues, and selection. New Phytologist, 212(3), 546-562. doi:10.1111/nph.14114

Pearse, I. S., Koenig, W. D., \& Knops, J. M. H. (2014). Cues versus proximate drivers: testing the mechanism behind masting behavior. Oikos, 123(2), 179-184. doi:10.1111/j.16000706.2013.00608.x

Pereira, H. M., Ferrier, S., Walters, M., Geller, G. N., Jongman, R. H. G., Scholes, R. J., . . Wegmann, M. (2013). Essential Biodiversity Variables. 339(6117), 277-278. doi:10.1126/science.1229931 \%J Science 
Peres, C. A., \& Palacios, E. (2007). Basin-wide effects of game harvest on vertebrate population densities in Amazonian forests: Implications for animal-mediated seed dispersal. Biotropica, 39(3), 304-315.

Phillipps, Q., \& Phillipps, K. (2016). Phillipps' Field Guide to the Mammals of Borneo and Their Ecology: Sabah, Sarawak, Brunei, and Kalimantan. Princeton, NJ: Princeton University Press.

Polis, G. A., \& Strong, D. R. (1996). Food web complexity and community dynamics. The American Naturalist, 147(5), 813-846.

Porfirio, G., Foster, V. C., Fonseca, C., \& Sarmento, P. (2016). Activity patterns of ocelots and their potential prey in the Brazilian Pantanal. Mammalian Biology, 81(5), 511-517.

Power, M. E. (1992). Top-Down and Bottom-Up Forces in Food Webs: Do Plants Have Primacy. 73(3), 733-746. doi:10.2307/1940153

Rabinowitz, A., Andau, P., \& Chai, P. P. (1987). The clouded leopard in Malaysian Borneo. Oryx, 21(2), 107-111.

Richardson, B. A., Richardson, M. J., González, G., Shiels, A. B., \& Srivastava, D. S. (2010). A Canopy Trimming Experiment in Puerto Rico: The Response of Litter Invertebrate Communities to Canopy Loss and Debris Deposition in a Tropical Forest Subject to Hurricanes. Ecosystems, 13(2), 286-301. doi:10.1007/s10021-010-9317-6

Ridout, M. S., \& Linkie, M. (2009). Estimating overlap of daily activity patterns from camera trap data. Journal of Agricultural, Biological, and Environmental Statistics, 14(3), 322-337. doi:10.1198/jabes.2009.08038

Rovero, F., \& Ahumada, J. (2017). The Tropical Ecology, Assessment and Monitoring (TEAM) Network: An early warning system for tropical rain forests. Science of the Total Environment, $574,914-923$.

Rovero, F., Martin, E., Rosa, M., Ahumada, J. A., \& Spitale, D. (2014). Estimating Species Richness and Modelling Habitat Preferences of Tropical Forest Mammals from Camera Trap Data. PloS one, 9(7), e103300. doi:10.1371/journal.pone.0103300

Rovero, F., Zimmermann, F., Berzi, D., \& Meek, P. (2013). "Which camera trap type and how many do I need?" A review of camera features and study designs for a range of wildlife research applications. Hystrix, 24(2).

Royle, J. A. (2004). N-Mixture Models for Estimating Population Size from Spatially Replicated Counts. Biometrics, 60(1), 108-115. doi:10.1111/j.0006-341X.2004.00142.x

Salafsky, N. (1994). Drought in the rain forest: effects of the $1991 \mathrm{El}$ Niño-Southern Oscillation event on a rural economy in West Kalimantan, Indonesia. Climatic Change, 27(4), 373-396. 
Schauber, E. M., Kelly, D., Turchin, P., Simon, C., Lee, W. G., Allen, R. B., . . Brockie, R. E. (2002). Masting by Eighteen New Zealand Plant Species: The Role of Temperature as a Synchronizing Cue. Ecology, 83(5), 1214-1225. doi:10.1890/0012-9658(2002)083[1214:Mbenzp]2.0.Co;2

Schmid, F., \& Schmidt, A. (2006). Nonparametric Estimation of the Coefficient of OverlappingTheory and Empirical Application. Computational Statistics \& Data Analysis, 50, 1583-1596. doi:10.1016/j.csda.2005.01.014

Schwinning, S., \& Sala, O. E. (2004). Hierarchy of responses to resource pulses in arid and semi-arid ecosystems. Oecologia, 141(2), 211-220. doi:10.1007/s00442-004-1520-8

Scotson, L., Fredriksson, G., Ngoprasert, D., Wong, W.-M., \& Fieberg, J. (2017). Projecting range-wide sun bear population trends using tree cover and camera-trap bycatch data. PloS one, 12(9), e0185336. doi:10.1371/journal.pone.0185336

Severud, W. J., Belant, J. L., Bruggink, J. G., \& Windels, S. K. (2011). Predator cues reduce American beaver use of foraging trails. Human-Wildlife Interactions, 5(2), 296-305.

Shanahan, M. J. (2000). Ficus seed dispersal guilds: ecology, evolution and conservation implications. (PhD). University of Leeds(Centre for Biodiversity and Conservation/School of Biology),

Sodhi, N. S., Koh, L. P., Brook, B. W., \& Ng, P. K. L. (2004). Southeast Asian biodiversity: an impending disaster. Trends in Ecology \& Evolution, 19(12), 654-660. doi:https://doi.org/10.1016/i.tree.2004.09.006

Soininen, E. M., Jensvoll, I., Killengreen, S. T., \& Ims, R. A. (2015). Under the snow: a new camera trap opens the white box of subnivean ecology. Remote Sensing in Ecology and Conservation, 1(1), 29-38. doi:https://doi.org/10.1002/rse2.2

Sollmann, R., Furtado, M. M., Hofer, H., Jácomo, A. T. A., Tôrres, N. M., \& Silveira, L. (2012). Using occupancy models to investigate space partitioning between two sympatric large predators, the jaguar and puma in central Brazil. Mammalian Biology, 77(1), 41-46. doi:10.1016/j.mambio.2011.06.011

Sollmann, R., Mohamed, A., Samejima, H., \& Wilting, A. (2013). Risky business or simple solution Relative abundance indices from camera-trapping. Biological Conservation, 159, 405-412. doi:https://doi.org/10.1016/j.biocon.2012.12.025

Srbek-Araujo, A. C., \& Chiarello, A. G. (2013). Influence of camera-trap sampling design on mammal species capture rates and community structures in southeastern Brazil. Biota Neotropica, 13(2), 51-62.

Steenweg, R., Hebblewhite, M., Kays, R., Ahumada, J., Fisher, J. T., Burton, C., . . Rich, L. N. (2017). Scaling-up camera traps: monitoring the planet's biodiversity with networks of remote sensors. 15(1), 26-34. doi:10.1002/fee.1448 
Stevenson, P. R. (2008). The relationship between fruit production and primate abundance in Neotropical communities. Biological Journal of the Linnean Society, 72(1), 161-178. doi:10.1111/j.1095-8312.2001.tb01307.x

Sutherland, W. J. (2006). Ecological census techniques: a handbook: Cambridge university press. Swann, D. E., Kawanishi, K., \& Palmer, J. (2011). Evaluating Types and Features of Camera Traps in Ecological Studies: A Guide for Researchers. In A. F. O'Connell, J. D. Nichols, \& K. U. Karanth (Eds.), Camera Traps in Animal Ecology: Methods and Analyses (pp. 27-43). Tokyo, Japan: Springer.

Team, R. C. (2020). R: a language and environment for statistical computing [Internet]. In.

Tobler, M. W., Carrillo-Percastegui, S. E., \& Powell, G. (2009). Habitat Use, Activity Patterns and Use of Mineral Licks by Five Species of Ungulate in South-Eastern Peru. Journal of Tropical Ecology, 25(3), 261-270. Retrieved from http://www.jstor.org/stable/25562616

Tobler, M. W., Carrillo-Percastegui, S. E., Pitman, R. L., Mares, R., \& Powell, G. (2008). An evaluation of camera traps for inventorying large-and medium-sized terrestrial rainforest mammals. Animal Conservation, 11(3), 169-178.

Tobler, M. W., Zúñiga Hartley, A., Carrillo-Percastegui, S. E., \& Powell, G. V. N. (2015). Spatiotemporal hierarchical modelling of species richness and occupancy using camera trap data. Journal of applied ecology, 52(2), 413-421. doi:10.1111/1365-2664.12399

Tourani, M., Brøste, E. N., Bakken, S., Odden, J., \& Bischof, R. (2020). Sooner, closer, or longer: detectability of mesocarnivores at camera traps. Journal of Zoology, 312(4), 259-270. doi:https://doi.org/10.1111/izo.12828

Trolle, M., \& Kéry, M. (2005). Camera-trap study of ocelot and other secretive mammals in the northern Pantanal. Mammalia, 69(3-4), 409-416.

Vander Wall, S. B. (2002). Masting in Animal-Dispersed Pines Facilitates Seed Dispersal. Ecology, 83(12), 3508-3516. doi:10.1890/0012-9658(2002)083[3508:Miadpf]2.0.Co;2

Vögeli, M., Serrano, D., Pacios, F., \& Tella, J. L. (2010). The relative importance of patch habitat quality and landscape attributes on a declining steppe-bird metapopulation. Biological Conservation, 143(5), 1057-1067. doi:https://doi.org/10.1016/j.biocon.2009.12.040

Wang, K., Franklin, S. E., Guo, X., \& Cattet, M. (2010). Remote sensing of ecology, biodiversity and conservation: a review from the perspective of remote sensing specialists. Sensors, 10(11), 9647-9667.

Wearn, O. R., Rowcliffe, J. M., Carbone, C., Bernard, H., \& Ewers, R. M. (2013). Assessing the status of wild felids in a highly-disturbed commercial forest reserve in Borneo and the implications for camera trap survey design. PloS one, 8(11), e77598. doi:10.1371/journal.pone.0077598 
Weckel, M., Giuliano, W., \& Silver, S. (2006). Jaguar (Panthera onca) feeding ecology: distribution of predator and prey through time and space. Journal of Zoology, 270(1), 25-30. doi:https://doi.org/10.1111/i.1469-7998.2006.00106.x

Wells, K., Corlett, R. T., Lakim, M. B., Kalko, E. K. V., \& Pfeiffer, M. (2009). Seed consumption by small mammals from Borneo. Journal of Tropical Ecology, 25(5), 555-558. doi:10.1017/S0266467409990058

White, G. C., \& Garrott, R. A. (2012). Analysis of wildlife radio-tracking data: Elsevier.

Wilcoxon, F., Katti, S., \& Wilcox, R. A. (1970). Critical values and probability levels for the Wilcoxon rank sum test and the Wilcoxon signed rank test (Vol. 1). Tallahassee, Florida.

Williamson, G. B., \& Ickes, K. (2002). Mast fruiting and ENSO cycles - does the cue betray a cause? Oikos, 97(3), 459-461. doi:10.1034/j.1600-0706.2002.970317.x

Wilting, A., Cord, A., Hearn, A. J., Hesse, D., Mohamed, A., Traeholdt, C., ... Hofer, H. (2010). Modelling the Species Distribution of Flat-Headed Cats (Prionailurus planiceps), an Endangered South-East Asian Small Felid. PloS one, 5(3), e9612. doi:10.1371/journal.pone.0009612

Wintle, B. A., Kavanagh, R. P., Mccarthy, M. A., \& Burgman, M. A. (2005). Estimating and dealing with detectability in occupancy surveys for forest owls and arboreal marsupials. The Journal of Wildlife Management, 69(3), 905-917. doi:10.2193/0022541x(2005)069[0905:Eadwdi]2.0.Co;2

Wolff, J. O. (1996). Population fluctuations of mast-eating rodents are correlated with production of acorns. Journal of Mammalogy, 77(3), 850-856.

Wysong, M. L., lacona, G. D., Valentine, L. E., Morris, K., \& Ritchie, E. G. (2020). On the right track: placement of camera traps on roads improves detection of predators and shows non-target impacts of feral cat baiting. Wildlife Research, 47(8), 557-569. doi:https://doi.org/10.1071/WR19175

Yang, L. H., Bastow, J. L., Spence, K. O., \& Wright, A. N. (2008). What Can We Learn From Resource Pulses. Ecology, 89(3), 621-634. doi:10.1890/07-0175.1 


\section{Appendices}

Appendix 1: Camera placement beta estimates (B), beta standard error (SE), average weight used in body weight vs. $B$ analysis, species taxonomic group, and species primary diet group.

\begin{tabular}{|l|l|l|l|l|l|}
\hline Scientific name & $\boldsymbol{\beta}$ & SE & $\begin{array}{l}\text { Average } \\
\text { weight } \\
\mathbf{( k g )}\end{array}$ & Taxonomy & Diet \\
\hline Muridae spp. & -0.795 & 0.168 & 0.20 & Rodent & Omnivore \\
\hline Tragulus kanchil & 0.708 & 0.169 & 1.60 & Ungulate & Herbivore \\
\hline Neofelis diardi & 2.359 & 0.748 & 17.50 & Felid & Carnivore \\
\hline Martes flavigula & 1.812 & 0.527 & 3.40 & Carnivora & Carnivore \\
\hline Hystrix brachyura & 1.216 & 0.345 & 2.50 & Rodent & Herbivore \\
\hline Viverra tangalunga & 0.634 & 0.196 & 4.00 & Civet & Omnivore \\
\hline Lariscus insignis & -0.811 & 0.338 & 0.17 & Rodent & Omnivore \\
\hline Sus barbatus & -0.332 & 0.151 & 75.00 & Ungulate & Herbivore \\
\hline Lophura ignita & 0.627 & 0.300 & 2.00 & Terrestrial bird & Omnivore \\
\hline Muntiacus muntjak & -0.043 & 0.291 & 18.00 & Ungulate & Herbivore \\
\hline Hemigalus derbyanus & 0.297 & 0.319 & 2.00 & Civet & Omnivore \\
\hline Rollulus rouloul & -0.207 & 0.289 & 0.26 & Terrestrial bird & Omnivore \\
\hline Herpestes brachyurus & -0.248 & 0.396 & 1.50 & Carnivora & Carnivore \\
\hline Muntiacus atherodes & -0.087 & 0.234 & 14.00 & Ungulate & Herbivore \\
\hline Trichys fasciculata & -0.076 & 0.242 & 2.00 & Rodent & Herbivore \\
\hline Argusuanus argus & 0.041 & 0.339 & 2.36 & Terrestrial bird & Omnivore \\
\hline Tragulus napu & -0.001 & 0.372 & 4.00 & Ungulate & Herbivore \\
\hline Echinosorex gymnura & -0.002 & 0.431 & 0.79 & Rodent & Omnivore \\
\hline & & & & & \\
\hline
\end{tabular}


Appendix 2: Camera placement sample sizes, overlap coefficient for activity on and off trail ( $\Delta_{1}$ for samples $<75$ and $\Delta_{4}$ for samples $\left.>75\right)$, and Watson's two-sample test $p$-values and respective test statistic $\left(U^{2}\right)$. Watson's test statistic critical value $=0.187$ for $>95 \%$ confidence. NA indicates species with records 1 or 0 , which could not be modelled.

\begin{tabular}{|c|c|c|c|c|c|c|c|}
\hline Species & $\begin{array}{l}\text { On-trail } \\
\text { sample } \\
\text { size }\end{array}$ & $\begin{array}{l}\text { Off-trail } \\
\text { sample } \\
\text { size }\end{array}$ & $\begin{array}{l}\text { Coefficient } \\
\text { of overlap } \\
(\Delta)\end{array}$ & $\begin{array}{l}\text { Lower } \\
\mathrm{Cl}\end{array}$ & $\begin{array}{l}\text { Upper } \\
\mathrm{Cl}\end{array}$ & p-value & $\begin{array}{l}\text { Test } \\
\text { statistic }\end{array}$ \\
\hline Muridae spp. & 87 & 240 & 0.93 & 0.87 & 0.99 & $>0.10$ & 0.0472 \\
\hline Rollulus rouloul & 30 & 36 & 0.89 & 0.75 & 0.99 & $>0.10$ & 0.0479 \\
\hline Hystrix brachyura & 46 & 16 & 0.88 & 0.70 & 1.00 & $>0.10$ & 0.0742 \\
\hline $\begin{array}{l}\text { Paradoxurus } \\
\text { hermaphroditus }\end{array}$ & 10 & 4 & 0.85 & 0.49 & 1.00 & $>0.10$ & 0.0556 \\
\hline Echinosorex gymnura & 16 & 16 & 0.84 & 0.50 & 0.90 & $>0.10$ & 0.0526 \\
\hline Tragulus kanchil & 233 & 107 & 0.84 & 0.77 & 0.92 & $<0.01$ & 0.1933 \\
\hline Hemigalus derbyanus & 26 & 21 & 0.84 & 0.60 & 0.97 & $>0.10$ & 0.085 \\
\hline Lariscus insignis & 22 & 41 & 0.84 & 0.69 & 0.97 & $>0.10$ & 0.0481 \\
\hline Sus barbatus & 224 & 239 & 0.82 & 0.75 & 0.89 & $<0.01$ & 0.3549 \\
\hline Lophura ignita & 52 & 30 & 0.81 & 0.70 & 0.96 & $>0.10$ & 0.0283 \\
\hline Viverra tangalunga & 107 & 40 & 0.81 & 0.71 & 0.92 & $>0.10$ & 0.1006 \\
\hline Tragulus napu & 29 & 27 & 0.79 & 0.63 & 0.96 & $>0.10$ & 0.0764 \\
\hline Muntiacus muntjak & 33 & 36 & 0.78 & 0.62 & 0.92 & $>0.10$ & 0.1032 \\
\hline Carpococcyx radiatus & 10 & 5 & 0.78 & 0.24 & 0.85 & $>0.10$ & 0.0542 \\
\hline Trichys fasciculata & 44 & 48 & 0.77 & 0.61 & 0.89 & $>0.10$ & 0.1235 \\
\hline Tupaia longipes & 11 & 9 & 0.76 & 0.34 & 0.87 & $>0.10$ & 0.1117 \\
\hline Varanus salvator & 5 & 5 & 0.75 & 0.18 & 0.90 & $>0.10$ & 0.049 \\
\hline Argusuanus argus & 28 & 26 & 0.74 & 0.56 & 0.91 & $>0.10$ & 0.1054 \\
\hline Manis javanica & 4 & 2 & 0.73 & 0.01 & 0.83 & $>0.10$ & 0.0556 \\
\hline Muntiacus atherodes & 41 & 50 & 0.72 & 0.59 & 0.85 & $<0.01$ & 0.2265 \\
\hline $\begin{array}{l}\text { Rheithrosciurus } \\
\text { macrotis }\end{array}$ & 8 & 3 & 0.72 & 0.07 & 0.83 & $>0.10$ & 0.0455 \\
\hline Tupaia gracilis & 8 & 8 & 0.7 & 0.35 & 0.97 & $>0.10$ & 0.1027 \\
\hline Martes flavigula & 32 & 5 & 0.69 & 0.39 & 0.98 & $>0.10$ & 0.0402 \\
\hline Herpestes brachyurus & 13 & 17 & 0.62 & 0.40 & 0.91 & $>0.05$ & 0.1747 \\
\hline Muntiacus spp. & 4 & 4 & 0.57 & 0.16 & 0.95 & $>0.10$ & 0.1172 \\
\hline $\begin{array}{l}\text { Lophura } \\
\text { erythrophthalma }\end{array}$ & 10 & 8 & 0.56 & 0.31 & 0.84 & $>0.10$ & 0.0803 \\
\hline Helarctos malayanus & 3 & 5 & 0.5 & 0.13 & 0.89 & $>0.10$ & 0.0771 \\
\hline Felis bengalensis & 6 & 2 & 0.48 & 0.15 & 0.94 & $>0.10$ & 0.1458 \\
\hline Neofelis diardi & 27 & 3 & 0.48 & 0.39 & 0.92 & $>0.10$ & 0.1461 \\
\hline Tupaia dorsalis & 3 & 15 & 0.38 & 0.12 & 0.66 & $>0.10$ & 0.0843 \\
\hline Paguma larvata & 3 & 4 & 0.24 & 0.05 & 0.65 & $>0.10$ & 0.0952 \\
\hline Tupaia spp. & 3 & 5 & 0.14 & 0.00 & 0.71 & $>0.10$ & 0.0771 \\
\hline Lophura spp. & 1 & 1 & NA & NA & NA & NA & NA \\
\hline
\end{tabular}




\begin{tabular}{|llllllll|}
\hline Arctictis binturong & 5 & 1 & NA & NA & NA & NA & NA \\
\hline Viverridae spp. & 6 & 1 & NA & NA & NA & NA & NA \\
\hline Callosciurus notatus & 0 & 1 & NA & NA & NA & NA & NA \\
\hline Pardofelis marmorata & 1 & 1 & NA & NA & NA & NA & NA \\
\hline Tragulus spp. & 1 & 2 & NA & NA & NA & NA & NA \\
\hline Pardofelis badia & 0 & 1 & NA & NA & NA & NA & NA \\
\hline Prionodon linsang & 2 & 1 & NA & NA & NA & NA & NA \\
\hline Mustela spp. & 0 & 1 & NA & NA & NA & NA & NA \\
\hline Cynogale bennettii & 0 & 3 & NA & NA & NA & NA & NA \\
\hline Sciuridae spp. & 1 & 0 & NA & NA & NA & NA & NA \\
\hline Tupaia tana & 0 & 1 & NA & NA & NA & NA & NA \\
\hline $\begin{array}{l}\text { Cephalopachus } \\
\text { bancanuswere }\end{array}$ & 1 & 0 & NA & NA & NA & NA & NA \\
\hline
\end{tabular}

